University of Rhode Island

DigitalCommons@URI

Open Access Dissertations

1999

\title{
A Structural Equation Modeling Approach to Understanding Psychological Empowerment in Community Prevention Coalitions
}

Bradley Farrell McMillan

University of Rhode Island

Follow this and additional works at: https://digitalcommons.uri.edu/oa_diss

\section{Recommended Citation}

McMillan, Bradley Farrell, "A Structural Equation Modeling Approach to Understanding Psychological Empowerment in Community Prevention Coalitions" (1999). Open Access Dissertations. Paper 922. https://digitalcommons.uri.edu/oa_diss/922

This Dissertation is brought to you for free and open access by DigitalCommons@URI. It has been accepted for inclusion in Open Access Dissertations by an authorized administrator of DigitalCommons@URI. For more information, please contact digitalcommons-group@uri.edu. 


\section{A STRUCTURAL EQUATION MODELING APPROACH \\ TO UNDERSTANDING PSYCHOLOGICAL EMPOWERMENT}

IN COMMUNITY PREVENTION COALITIONS

BY

BRADLEY FARRELL MCMILLAN

A DISSERTATION SUBMITTED IN PARTIAL FULFILLMENT OF THE REQUIREMENTS FOR THE DEGREE OF

DOCTOR OF PHILOSOPHY

IN

PSYCHOLOGY

\#45124574

UNIVERSITY OF RHODE ISLAND 


\begin{abstract}
The increased attention in the past decade to health promotion strategies has led to an increase in the study of empowerment processes. Despite this growing attention, however, there are only a limited number of studies that address empowerment in a systematic and empirical fashion. The present study utilizes data from 284 members of thirty-five community coalitions working to prevent alcohol and other drug (AOD) problems in the state of Rhode Island. Structural Equation Modeling of three competing models of empowerment effects were conducted to determine the best indicators of individual-level empowerment. An inclusive direct effects model, a model of participation effects, and a model utilizing variables indicated in an earlier study with this data set were examined (McMillan, Florin, Stevenson, Kerman, and Mitchell, 1995). While all three models (which examined the relationships of demographic variables, community variables, participation variables, and organizational climate variables to empowerment) showed some fit to the data set, only a revised version of the McMillan et al., 1995 model provided a truly adequate fit. Implications of this study and future directions for research are discussed.
\end{abstract}




\section{Acknowledgements}

This dissertation—-indeed my academic career-would be incomplete without a heartfelt thanks to my major professor, Paul Florin, for all his gracious help in every aspect of this lengthy, grand adventure (graduate school). While my path through Clinical Psychology has been a plodding, even sometimes distasteful journey at times, Paul's always been there giving me encouragement every step of the way. So, once again, thanks! I would also like to extend equal thanks to the other members of my thesis committee, John Stevenson and Phil Clark. Without their practical advice, words of wisdom, and silent support, I'm sure that this project would not have come along quite as easily as it did. I'd also like to thank Richard Purnell for chairing my dissertation defense and Lisa Harlow for agreeing to participate at the last moment. Lisa's revision suggestions and helpful advice made the final dissertation much better than it would have been without her input. Thanks, Lisa!

I'd also like to acknowledge all the friends and family who helped keep my head above water over the years. You all know who you are, and I owe you all a great deal of thanks! 


\section{Table of Contents}

List of Tables vi

List of Figures. vii

Introduction .1

Praxis-oriented Empowerment and Empowerment Theory .........................................

Limitations and Criticisms of Empowerment ........................................................12

A Model of Empowerment Theory in Practice .........................................................16

Independent Variables Influencing Individual-Level Empowerment....................22

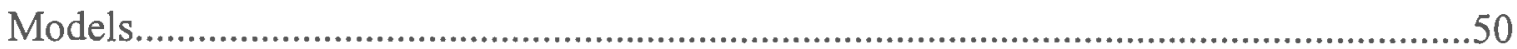

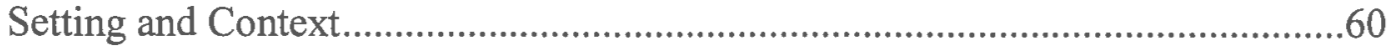

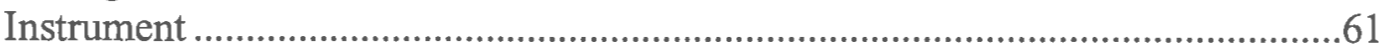

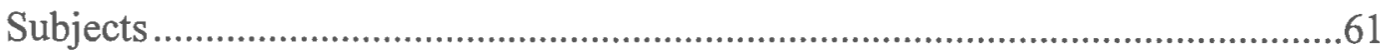

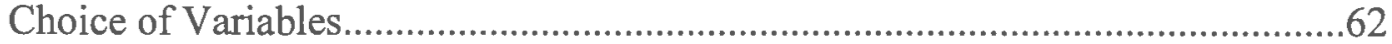

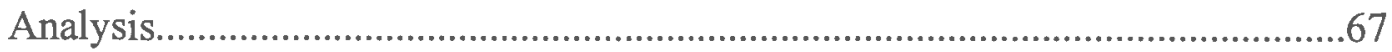

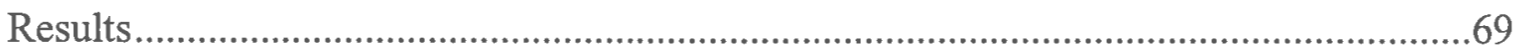

Inclusive Model of Direct Effects Analysis............................................................69

Zimmerman/Rappaport Model of Participation Effects...........................................76

McMillan et al., 1995 Model .............................................................................79

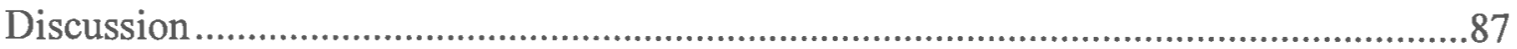

General Contributions and Implications ..........................................................8

Limitations and Directions for Future Research ..................................................95

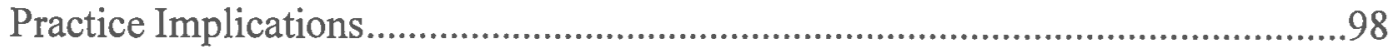

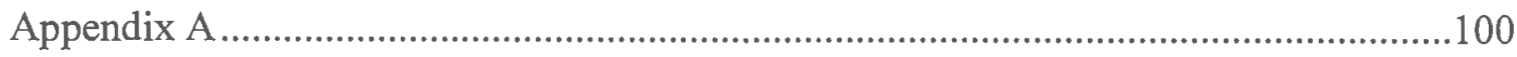

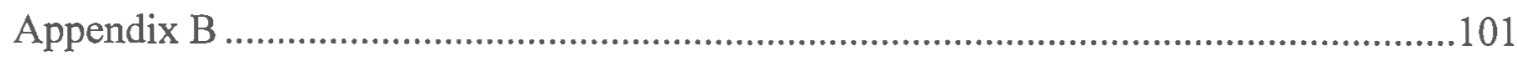

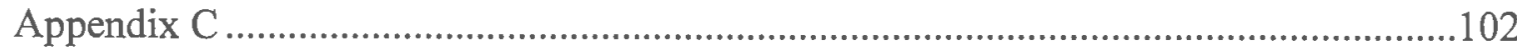

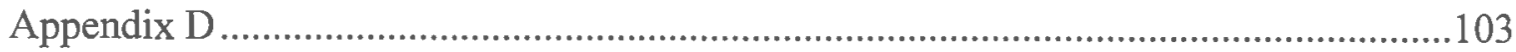


Appendix F.

Bibliography 


\section{List of Tables}

TABLE 1: $\quad$ Measurement Equations, Standard Errors, $Z$ statistics and Significance

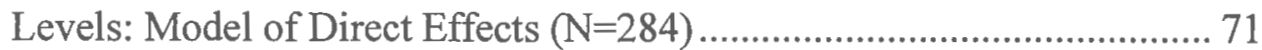

TABLE 2: $\quad$ Standardized Solution of the Model of Direct Effects ............................... 72

TABLE 3: $\quad$ Measurement Equations, Standard Errors, $Z$ statistics and Significance

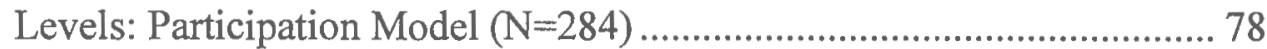

TABLE 4: $\quad$ Measurement Equations, Standard Errors, $Z$ statistics and Significance

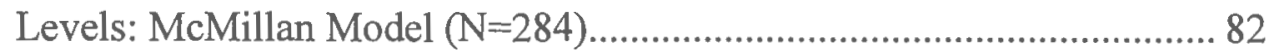

TABLE 5: $\quad$ McMillan et al., 1995 Standardized Solution ..........................................83 


\section{List of Figures}

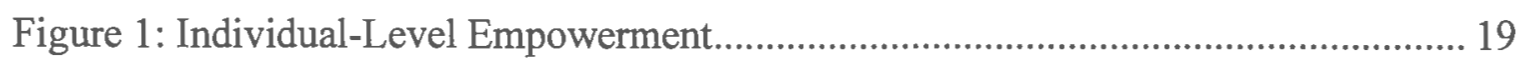

Figure 2: SEM Representation of Individual-Level Empowerment ............................... 22

Figure 3: Interaction of Independent Variables and Individual-level Empowerment....... 24

Figure 4: SEM Representation of Demographic Variables ............................................. 28

Figure5: SEM Representation of Community Variables ............................................... 34

Figure 6: SEM Representation of Participation Variables................................................. 42

Figure 7: SEM Representation of Organizational Variables ........................................... 49

Figure 8: Model \#1 Inclusive Model of Direct Effects....................................................5

Figure 9: Model \#2 Zimmerman/Rappaport Model of Participation Effects.................... 57

Figure 10: Model \#3 McMillan et al., 1995 Model ........................................................... 59

Figure 11: Standard Solution for Inclusive Model of Direct Effects Latent Constructs... 73

Figure 12: Inclusive Model of Direct Effects SEM ${ }^{\mathrm{a}}$........................................................ 75

Figure 13: Standard Solution for McMillan et al., 1995 Latent Constructs ...................... 84

Figure 14: McMillan et al., 1995 Final Structural Model................................................... 86 


\section{Introduction}

Empowerment, both as a theoretical framework and as a social intervention strategy, has garnered a lot of attention in recent years from many diverse fields (Bernstein. et al., 1994; Clark, 1989; Cowen, 1991; Florin \& Wandersman, 1990; Heller, 1989, 1990; Kieffer, 1984; Labonte, 1994; Levine, 1988; Rappaport, 1977, 1981, 1984, 1987, 1995; Robertson \& Minkler, 1994; Shinn, 1987; Swift and Levin, 1987;

Wallerstein, 1992; Wallerstein \& Bernstein, 1994; Yeich \& Levine, 1992; Zimmerman, 1990a, 1990b, 1995; Zimmerman \& Rappaport, 1988; Zimmerman \& Zahniser, 1991) . In community psychology alone, empowerment has gathered growing momentum and appeal in the current decade, although its history is actually rather extensive (Kieffer, 1984; Rappaport, 1977, 1984, 1987; Zimmerman, 1990a, 1995). Increased attention to health promotion, prevention ideologies and the desire to alleviate negative social effects has led to a growing body of literature focused on the health-enhancing properties of the empowerment process (Cowen, 1991; Fawcett, Seekins, Whang, Muiu \& Suarez de Balcazar, 1984; Swift \& Levin, 1987; Wallerstein, 1992; Zimmerman, 1990b). Julian Rappaport, as head of Division 27 (Community Psychology) of the American Psychological Association, even went so far as to call on researchers and practitioners to adopt empowerment as the rallying call of their division and to focus attention on the concept as a value orientation and a theoretical paradigm (Rappaport, 1987). But what exactly is this "ideal" construct—what exactly is empowerment?

Empowerment can generally be thought of as "...a social-action process that promotes participation of people, organizations, and communities towards the goals of 
increased individual and community control, political efficacy, improved quality of community life, and social justice" (Wallerstein, 1992, p.198). This is but one of several empowerment definitions, however, as the past decade has seen a proliferation in the study of empowerment in the research literature of diverse fields. Despite the growth in literature addressing the theoretical foundation of empowerment and its applicability in practice, there are still only a limited number of studies that address this concept empirically (Fawcett et al., 1984; Heller, 1988; Rappaport, 1981; Swift \& Levin, 1984; Wallerstein, 1992; Zimmerman, Israel, Schulz \& Checkoway, 1992; Zimmerman \& Rappaport, 1988). Part of the reason for the lack of empirical study of empowerment is that there are many different philosophical dimensions, levels of analysis and ways of operationalizing this elusive construct (Clark, 1989; Kieffer, 1984; Swift \& Levin, 1987; Wallerstein, 1992; Zimmerman, 1991; Zimmerman, 1995; Zimmerman \& Rappaport, 1988).

This present study makes an attempt to broaden our understanding of the empowerment process in voluntary community organizations. This study outlines an approach to looking at the empowerment construct at the individual level of analysis by examining the individual-level empowerment of members of thirty-five community prevention coalitions in the state of Rhode Island. It conceptualizes and empirically examines a model of the empowerment process in the context of member participation in the aforementioned community prevention coalitions which might be able to be generalized to similar contexts. The model of empowerment theory presented here draws its strength from its empirical relationship to other well-researched constructs such as: 
participation, sense of community and organizational/social climate, all of which have been indicated theoretically and empirically to be associated with empowerment (Chavis \& Wandersman, 1990; Florin \& Wandersman, 1990; Maton \& Rappaport, 1984; McMillan, Florin, Stevenson, Kerman, \& Mitchell, 1995; Wallerstein, 1992; Zimmerman, 1990b; Zimmerman et al., 1992; Zimmerman \& Rappaport, 1988).

Another important aim of this study is the proposal and empirical testing of the model of empowerment outlined above. Empirical analysis of this model is tested using a statistical procedure-structural equation modeling (SEM)--that combines the best features of factor analysis, path analysis, and multiple regression (Bentler, 1993; Byrne, 1994; Joreskog, 1993; Tanaka, 1993). Although the application of a statistical method of this level of sophistication has been recommended by a number of researchers in empowerment theory, utilization of SEM has not been widely used to examine empowerment (Florin \& Wandersman, 1990; Israel, Checkoway, Schulz, \& Zimmerman, 1994; McMillan, et al., 1995; Zimmerman, 1990b; Zimmerman, 1995; Zimmerman et al., 1992). Due to the cross-sectional nature of the data and other limitations, however, this study is not able to empirically confirm any particular model and is primarily exploratory in nature. Therefore, in order to more adequately test the proposed structural model of empowerment, this study examines this model in contrast with other, potentially competing structural models of empowerment.

\section{Praxis-oriented Empowerment and Empowerment Theory}

The concept of empowering individuals and communities first captured the imagination of social scientists in the 1930s, when Saul Alinsky first started to organize 
neighborhoods and to build community groups (Kieffer, 1984). Empowerment gained popularity and widespread support during the social movements of the sixties and seventies, as this concept became the rallying cry for the disenfranchised and disillusioned. This period in American history attracted the attention of researchers, and they finally began to give empowerment more careful scrutiny and study (Kieffer, 1984; Rappaport, 1977, 1984, 1987; Zimmerman, 1990a, 1995). It was the 1980's, however, that saw the greatest growth in the development of empowerment theory as psychologists, health officials and other professionals urged their respective fields to adopt empowerment as a guide to theory, practice and research (Bernstein. et al., 1994; Cowen, 1991; Labonte, 1994; Levine, 1988; Rappaport, 1981; Rappaport, 1987; Robertson \& Minkler, 1994; Schinn, 1987; Swift and Levin, 1987; Wallerstein, 1992). Rappaport (1987), in an invited address in the mid-eighties, urged community psychology to take up the concept of empowerment as a "phenomenon of interest,"and he recommended that the concept be the focus of theory development in the field (p.127). While he stressed that community psychology's "exemplar" should still be prevention (and that this should be the focus of concrete problem-solving in the field), he articulated that the "bottom line" of prevention efforts should be empowerment. In the 90 's, empowerment continues to be emphasized, and it continues to be touted as one of the best ways to increase a community's quality of life, to help ethnic and poor communities to develop an organized power base, to structure business organizations, to help rebuild American schools, and to give individuals feelings of mastery and perceived control (Cowen, 1991; Kieffer, 1984; 
Rappaport, 1981; Rosenfield, 1992; Schinn, 1987; Swift \& Levin, 1987; Wallerstein, 1992; Zimmerman, 1990a; Zimmerman, 1995; Zimmerman \& Rappaport, 1988).

One reason for empowerment's popularity is because-as Rappaport has indicated-empowerment is both a theoretical model and a means of attaining health and social goals. Empowerment in practice "...suggests goals, aims, and strategies for implementing change" (Zimmerman, 1995, p.582). Using empowerment in practice with an implicit underlying theory is a relatively innovative approach to combating stress and other health problems since, as Wallerstein and Bernstein (1994) indicated, "many health professionals and clinicians have defined the problems in medical or individual life-style models. Even in community settings, the language we use may reinforce a professionally driven solution to the problems." (p.141). Theorists and practitioners are starting to realize that individual life-style models offer only a limited field of vision when studying and affecting problems that occur at many different levels of society. Thus, there has been a movement towards studying health issues at more levels than just the individual (Perkins \& Zimmerman, 1995; Rappaport, 1984; Wallerstein \& Bernstein, 1994; Zimmerman, 1995). Confusion can arise when using this sort of approach, however, since each different setting and level of influence may require a radically different approach. Empowerment provides researchers and practitioners with a bridge across these various settings and levels of influence (Airhihenbuwa, 1994; Bernstein, et al., 1994; Butchart \& Seedat, 1990; Clark, 1989; Clark, 1994; Cowen, 1991; Eisen, 1994; Eng, Salmon, \& Mullan, 1992; Flick, Reese, Rogers, Fletcher, \& Sonn, 1994; Florin \& Wandersman, 
1990; Flynn, Ray, \& Rider, 1994; Israel, et al., 1994; Maton \& Rappaport, 1984;

McMillan et al., 1995; Purdey, Adhikari, Robinson, \& Cox, 1994; Zimmerman, 1995).

At all different levels of influence, an emerging body of literature has appeared outlining the positive effects of empowerment applications in a variety of different settings. Application of empowerment in community psychology and public health has primarily focused on its development in community initiatives (e.g., primarily non-profit organizations targeting high-risk populations, health promotion campaigns, coalitionbuilding, targeting disenfranchised populations). Also, community psychology and public health efforts have been mainly concerned with empowerment in terms of individual empowerment, participation, and sense of community (Bickman, Heflinger, Northrup, Sonnichsen, \& Schilling, 1998; Bolton \& Brookings, 1998; Butchart \& Seedat, 1990; Chinman \& Linney, 1998; Clarke \& Mass, 1998; Cummings, 1986; Eng, Salmon, \& Mullan, 1992; Fawcett et al., 1984; Mowbray, 1990; Neath and Shriner, 1998; Petoskey, Van Stelle, \& De Jong 1998; Purdey, Adhikari, Robinson, \& Cox, 1994; Rosenfield, 1992; Shinn, 1987; Unger \& Nelson, 1990; Wilson, 1997 Wallerstein \& Bernstein, 1994; Wickizer et al., 1993).

One example of implicit empowerment theory in community psychology can be found in an article by Chinman and Linney (1998) describing adolescent primary prevention programs. Chinman and Linney used the empowerment construct to examine popular adolescent interventions and activities used in prevention programming. In their study, they found that empowering components talked about in the adult literature (e.g., skill-building, critical awareness of problems, fostering peer involvement and cohesion) 
were effective strategies for working with this population (Chinman \& Linney, 1998).

Other empowerment approaches tapping into similar processes for students and families can be found in other places in the research literature (Bickman et al., 1998; Cummings, 1986; Unger \& Nelson, 1990)

Wilson (1997) found that the empowerment strategies described above were also helping in empowering people with disabilities in Ireland. Unlike Chinman \& Linney, however, Wilson spent part of her study teasing out the organizational characteristics and community politics that impacted upon empowerment (both positively and negatively). According to Wilson, positive organizational characteristics and community influences focus on creating a sense of "power with" rather than "power for" people with disabilities. Programs that ignore the goals of the political protests and social change generated by the disability movement work counter to empowering this minority groupprograms must focus on shared decision-making, working collaboratively with disabled leaders, and enhancing political efficacy. Similar sentiments are echoed in other articles focused on the issues of empowering individuals with disabilities (Bolton \& Brookings, 1998; Neath and Shriner, 1998).

Another primary prevention program with an empowerment focus can be found in an article by Petoskey, Van Stelle, and De Jong (1998) who examine a prevention demonstration grant in a Native American community. Unlike traditional high-risk youth grants, this program focused more on addressing the powerlessness of the Native American community at large rather than simply targeting interventions at the $4^{\text {th }}$ to $12^{\text {th }}$ grade youth who were also at risk. The authors examined the program in terms of a 
community empowerment approach and argued for using this focus with similar populations. Fawcett, Seekins, Whang, Muiu, and Suarez de Balcazar (1984) also recommended such a community empowerment approach, as they reported that it led to increased awareness of community problems, participation, skills, community leadership, and knowledge of community issues. Other researchers and practitioners echo this use of informal empowerment theory and the importance of community empowerment in the treatment of the mentally ill, primary and secondary prevention efforts, and health promotion efforts (Butchart \& Seedat, 1990; Clarke \& Mass, 1998; Eng, Salmon, \& Mullan, 1992; Mowbray, 1990; Purdey, Adhikari, Robinson, \& Cox, 1994; Rosenfield, 1992; Shinn, 1987; Wallerstein \& Bernstein, 1994; Wickizer et al., 1993).

In contrast to praxis-oriented empowerment as described above (based upon implicit empowerment theory), formal empowerment theory “...provides principles and a framework for organizing our knowledge. It suggests ways we can measure empowerment in different contexts, study empowering processes, and distinguish empowerment from other constructs such as self-esteem, self-efficacy, or locus of control" (Zimmerman, 1995, p.583). Establishing empowerment as a theoretical orientation has--to date-still not been well-researched and needs to be if we are to understand and utilize this concept effectively in practice (Kieffer, 1984; Rappaport, 1981; Wallerstein, 1992; Zimmerman, 1995; Zimmerman et al., 1992; Zimmerman \& Rappaport, 1988).

While "empowering" individuals and communities has been a slogan of community practice since Saul Alinsky's time, empowerment as a researched concept had 
not been examined or discussed in any systematic fashion until the late seventies and early eighties (Kieffer, 1984; Rappaport, 1977, 1981, 1984; Zimmerman, 1990a). As Kieffer (1984) noted, “Throughout the broad literatures of citizen participation and community organization, there is a striking absence of attention to issues of individual empowerment." (Kieffer, 1984, p.13). Kieffer was one of the first researchers who started to systematically examine the nature of individual empowerment. Kieffer saw empowerment as a developmental process - a transition from powerlessness to participatory competence. He broke the empowerment process down into four developmental stages with developmental tasks occuring at each level. Early stages were characterized by feelings of a sense of community and a growing awareness of community problems and injustices. As the individual gets involved with groups sharing similar world views and grows into that group, skill-building and organizational characteristics temper the individual. As the individual matures further, the individual becomes aware of organizational goals and objectives and also evaluates the potential barriers in the external environment. At this stage, the individual is more "self-confident, skilled, and fully participating." (Kieffer, 1984, p.21). In the final stage of individual empowerment, the individual is more able to adapt to the ever-changing environment and has more political efficacy. The individual is aware of their own empowerment and the successes of their organization. Kieffer wrapped up his discussion by summarizing what he considered to be the key components of the empowerment process: participation, sense of community, and experience (e.g., developing skills, political efficacy, organizational skills). 
Julian Rappaport catalyzed community psychology's interest in empowerment theory and his work helped put empowerment theory into a more empirical framework (Rappaport, 1977, 1981, 1984, 1987, 1995). By looking at empowerment as a variable to be studied rather than simply an ideological goal, Rappaport helped define empowerment further. As a first step towards operationalizing the concept, Rappaport defined empowerment as a "...construct that links individual strengths and competencies, natural helping systems, and proactive behaviors to social policy and social change" (Zimmerman \& Rappaport, 1987, p.726). Rappaport was one of the first theorists to suggest that empowerment definitions can vary depending on the various contexts in which it is being examined. In other words, what might be "empowering" in a grassroots ethnic neighborhood might be dramatically different than what is "empowering" in a middle-class religious community. In order to measure empowerment in different contexts, he suggested that researchers employ a wide range of different methodologies to examine the construct (Rappaport, 1995). Rappaport's initial writings about empowerment put forth the parameters of the concept as he understood them from prior writers and his own research (Rappaport, 1987). Those parameters included: the idea of empowerment as a multi-level construct with each level of influence impacting on the others; the idea of empowerment as an ecological construct (i.e., it can't be defined universally — it has to be examined in each unique context); cultural differences impact upon the process; the concept changes over time; and finally, the idea that participation is positively correlated with empowerment. 
Marc Zimmerman, a student of Rappaport's, helped elaborate on empowerment theory even further (Zimmerman, 1990a, 1990b, 1995; Zimmerman et al., 1992; Zimmerman \& Rappaport, 1988; Zimmerman \& Zahniser, 1991). Zimmerman proposed that empowerment is a multilevel construct in which each level of analysis is independent yet interdependent with the others. At each level of analysis, Zimmerman also suggests that empowerment takes different forms for different people, is contextually driven, and is a dynamic process that may fluctuate over time. Because of this, Zimmerman believes that "the development of a universal and global measure of empowerment is not an appropriate goal because it may not mean the same thing for every person, organization, or community everywhere" (Zimmerman, 1995, p.586). Despite Zimmerman's assertion that a global measure of empowerment was theoretically impossible, he did indicate that all measures of empowerment at the individual level should be measures that touch on an intrapersonal component (e.g., perceived competence), an interactional component (e.g., skill development), and a behavioral component (e.g., organizational participation). In examining this individual level of analysis, Zimmerman broke empowerment down into several components that integrated perceptions of personal control, a proactive approach to life, and a critical understanding of the sociopolitical environment. Like Rappaport, Zimmerman also felt that participation was positively correlated with empowerment, but — in addition—he also hypothesized that sense of community, a critical awareness of community problems and political barriers, and organizational characteristics had direct effects on empowerment outcomes (Zimmerman, 1990a). While many other researchers have provided alternative definitions in empowerment theory, the parameters outlined by 
Kieffer, Rappaport, and Zimmerman have remained large enough to encompass the majority of the empowerment theoretical research (Campbell \& Martinko, 1998; Cohen, 1998; Eisen, 1994; Eng \& Parker, 1994; Flick, Reese, Rogers, Fletcher, \& Sonn, 1994; Israel, Checkoway, Schulz, \& Zimmerman, 1994; Maxwell, 1997; McFarlane \& Fehir, 1994; Minkler, 1992; Pecukonis \& Wenocur, 1994; Plough \& Olafson, 1994; Rudd \& Comings, 1994; Schlaff, 1991; Speer \& Hughey, 1995; Wallerstein, 1992; Wang \& Burris, 1994).

\section{Limitations and Criticisms of Empowerment}

As empowerment theory started to grow, a smaller body of research began to appear on the shortcomings of the concept and its application (Bond \& Keys, 1993; Eisen, 1994; Gruber \& Trickett, 1987; Israel et al., 1994; Merideth, 1994; Kroeker, 1995; Perkins, 1995; Riger, 1993; Rissel, 1994; Serrano-Garcia, 1984). Perhaps the most famous of these studies is Gruber \& Trickett (1987). These researchers examined decision-making power and empowerment in relation to the governing of an alternative school. New board members were elected to the school board of this alternative school with the intention of "empowering" these new members (who were primarily parents of students, students, and other community representatives). Gruber \& Trickett reported that these new members - as a group-were considerably disempowered at the start of the study. They had few roles on the school board and in the community, few responsibilities, had a poor knowledge of the school and community environment, inadequate skills, and little control over policy. This, in and of itself, may not have been problematic if it were not for the organizational climate of the school administrators. While the goal was to 
empower new board members and to share decision-making power, the unspoken climate made it impossible for new members to participate. Longstanding board members and school officials were reluctant to share their power and undermined empowerment efforts. This study emphasized the importance of examining the organizational and community contexts that act on individuals and groups. Gruber \& Trickett's comments in their discussion are especially telling in their criticism of this particular aspect of the empowerment process:

"There is a fundamental paradox in the idea of people empowering others because the very institutional structure that puts one group in a position to empower also works to undermine the act of empowerment" (Gruber \& Trickett , 1987, p.353).

Another pertinent criticism of empowerment came from the work of Irma Serrano-Garcia (1984). Her work with low-income individuals working in grassroots organizations in Puerto Rico ran into other obstacles to empowerment. Participants in her study did not develop a sense of community, there was poor group cohesiveness, a lack of community support, and poor participation of group members overall. In examining the barriers that led to these negative outcomes, Serrano-Garcia found a number of external organizational and community processes that she feels impacted on the grassroots programs. Puerto Rican politics, weak grassroot organization leaders, and a lack of consciousness-raising among community members interfered with empowerment outcomes. Disempowerment of larger political groups above the grassroots organizations was also seen as problematic. Despite the problems, however, Serrano-Garcia did find some individual empowerment in that members reported a better awareness of community problems, they developed new skills, and gained feelings of competency. 
Stephanie Riger (1993) raised other criticisms of empowerment. Riger's review of the empowerment literature at the time of her study indicated that empowerment had two obvious deficits. Riger criticized the theory and practice of empowerment for its focus on "individualism" and "the masculine concepts of mastery, power, and control over the feminine concepts of communion and cooperation." (Riger, p.279). Although Riger raised good points about the lack of research addressing organizational and community empowerment, Riger's criticisms have been--in turn — criticized by others. Rappaport, in reporting on the state of theory and empirical inquiry in the research on empowerment, felt that Riger's criticism about involving more communion in the thinking of the field was justified, but that Riger's characterization of empowerment research "...as excessively individualistic may [have been] misread" (1995, p.798). Saegert and Winkel (1996) and Robertson and Minkler (1994) in their studies address Riger's criticism of empowerment's individualism by pointing out the fact that empowerment cannot occur for the individual unless he/she is embedded in an organizational or community context. Both studies emphasized the importance of building individual, group, and community capacity through networking, sharing resources, and other more traditionally feminine avenues of cooperation.

Other criticisms of empowerment can be found in Rissel (1994). In his review of theory and practice of empowerment in health promotion, Rissel pointed out several areas where he found the concept of empowerment inadequate. Rissel criticized the concept's lack of a clear theoretical underpinning, the lack of quantitative research in the empowerment literature, its inappropriate utilization in some areas of health promotion, 
and its lack of applicability in settings with zero-sum concepts of power. To combat these problems, Rissel emphasized the need for more of an empowerment foundation despite its contextual nature, more quantitative research on empowerment applications, the need for standardization of terminology, and more research addressing organizational impacts on empowerment outcomes. Other researchers have put forth similar suggestions in regard to expanding empowerment theory (Bond \& Keys, 1993; Eisen, 1994; Israel et al., 1994; Merideth, 1994; Kroeker, 1995; Perkins, 1995).

One final theoretical issue to emerge in the study of empowerment is in its applicability in relation to culture. As several researchers have noted, empowerment needs to be sensitive to culture, ethnicity, and how other non-Western, disenfranchised, and/or nontraditional groups view the concept (Airhihenbuwa, 1994; Braithwaite et al., 1994; Erzinger, 1994; Fawcett, et al., 1994; Trickett, 1994; Yuval-Davis, 1994). For example, Erzinger (1994) identified three themes in Spanish culture that direct the language of empowerment. Empowerment—in Spanish—can be viewed as: a participatory process rather than a desire for power; a concept that describes the individual embedded within the larger community; and a concept of collective selfesteem. These themes are also prevalent in empowerment strategies and theory regarding the gay and lesbian community; women's movements; and non-Western cultures (Airhihenbuwa, 1994; Braithwaite et al., 1994; Fawcett, et al., 1994; Trickett, 1994; Yuval-Davis, 1994; Stewart \& Weinstein, 1997). Empowerment needs to take a wide variety of different cultures and contexts into account if it is to be a viable tool for describing and structuring community initiatives. 
Despite some researchers' views that a global measure of empowerment at any level of analysis is impractical, several common themes do appear throughout the empowerment literature that are applicable in various settings and across different levels (see Appendix A). It is generally agreed that empowerment is a developmental process rather than just an outcome to be fostered. It is also a multi-level concept, affecting the individual, group, and community levels. It is a process of increasing people's control over different aspects of their lives, their feelings of purpose and belongingness, their access to previously restricted resources, and their awareness of their environment and their place in it. In addition - in order to alleviate the negative effects of powerlessness and to foster an empowering atmosphere-a number of barriers (such as lack of decisionmaking power, lack of resources, lack of knowledge, and lack of social supports) need to be identified and overcome. Finally, it is also generally assumed that individuals need to be involved in some way in alleviating their powerlessness rather than just having it removed by an outside agency if empowerment is to occur. It is an individual's participation, decision-making, resources/skills and purpose that are thought to lead to empowerment (Clark, 1989; Cowen, 1991; Fawcett et al., 1984; Heller, 1989; Kieffer, 1984; Swift \& Levin, 1987; Wallerstein, 1992; Zimmerman, 1990a). The next section details how these themes can be incorporated into an individual-level conceptualization of empowerment.

\section{A Model of Empowerment Theory in Practice}

In order to establish empowerment as a viable psychological tool, its theoretical underpinnings need to be more actively researched at all of its various levels of influence 
(i.e., individual, organizational, community) and in a number of different settings. This particular study focuses on the individual level of analysis and leaves other levels of empowerment effects to other researchers and future studies. The particular conceptualization of individual-level empowerment utilized in this study is derived from the theoretical and empirical contributions of many others in the literature (Clark, 1989; Florin \& Wandersman, 1990; Kieffer, 1984; McMillan et al., 1995; Prestby, Wandersman, Florin, Rich, \& Chavis, 1990; Rappaport, 1981; Swift \& Levin, 1987; Wallerstein, 1992; Yeich \& Levine, 1992; Yeich \& Levine, 1994; Zimmerman, 1990a; Zimmerman, 1995; Zimmerman \& Zahniser, 1991). As a first step in examining individual-level empowerment, a thorough review of the empowerment literature was conducted. In order to create an empowerment definition appropriate to the unique situations explored in this study, to keep it consistent with previous studies, and to make the definition appropriate for application in a wide variety of alternate settings, common empowerment themes were explored and incorporated into this work (see Appendix A). Although definitions of empowerment vary at more specific levels of measurement and theory, two dominant themes do prove to be fairly consistent across empowerment research studies at the individual level. It is upon these two themes that this study bases its approach to operationalization of empowerment. The first theme elaborated on in the literature is that empowerment is an ongoing social-action process that promotes-at a very broad level—efficacy and control (Foster-Fishman, Salem, Chibnell, Legler, \& Yapchai, 1998; Kieffer, 1984; Rappaport, 1981; Swift \& Levin, 1987; Wallerstein, 1992; Zimmerman, 1991; Zimmerman, 1995; Zimmerman \& Rappaport, 1988). The second 
theme mentioned is that individual-level empowerment is both a multi-level and contextspecific construct (Clark, 1989; Foster-Fishman et al., 1998; Kieffer, 1984; Zimmerman, 1991; Zimmerman, 1995; Zimmerman \& Rappaport, 1988). Both of these themes in the literature have suggested that empowerment may be viewed as a higher-order construct linking these two dimensions. The theme of empowerment as a process implies a linking of past, present, and future across a time dimension. And the theme of empowerment as being multi-level and context-specific links the individual with the collective (i.e., the individual links with the particular group or organization most appropriate for the specific context under study).

Figure 1 represents schematically how empowerment as conceptualized in this study links these two dimensions through five interrelated, nested constructs at the individual level. The five constructs conceptualized in this study as forming the basis for an individual-level framework are: perceived knowledge and skill development, perceived group/organizational accomplishments, perceived participatory competence, expectancies for future individual contributions, and expectancies for future group/organizational accomplishments. In a prior study using these constructs, factor analysis indicated that these five constructs formed one factor (McMillan et al., 1995). For the reasons stated below, this factor is conceptualized as individual-level empowerment. Each of these constructs is described briefly below: 


\section{Figure 1: Individual-Level Empowerment}

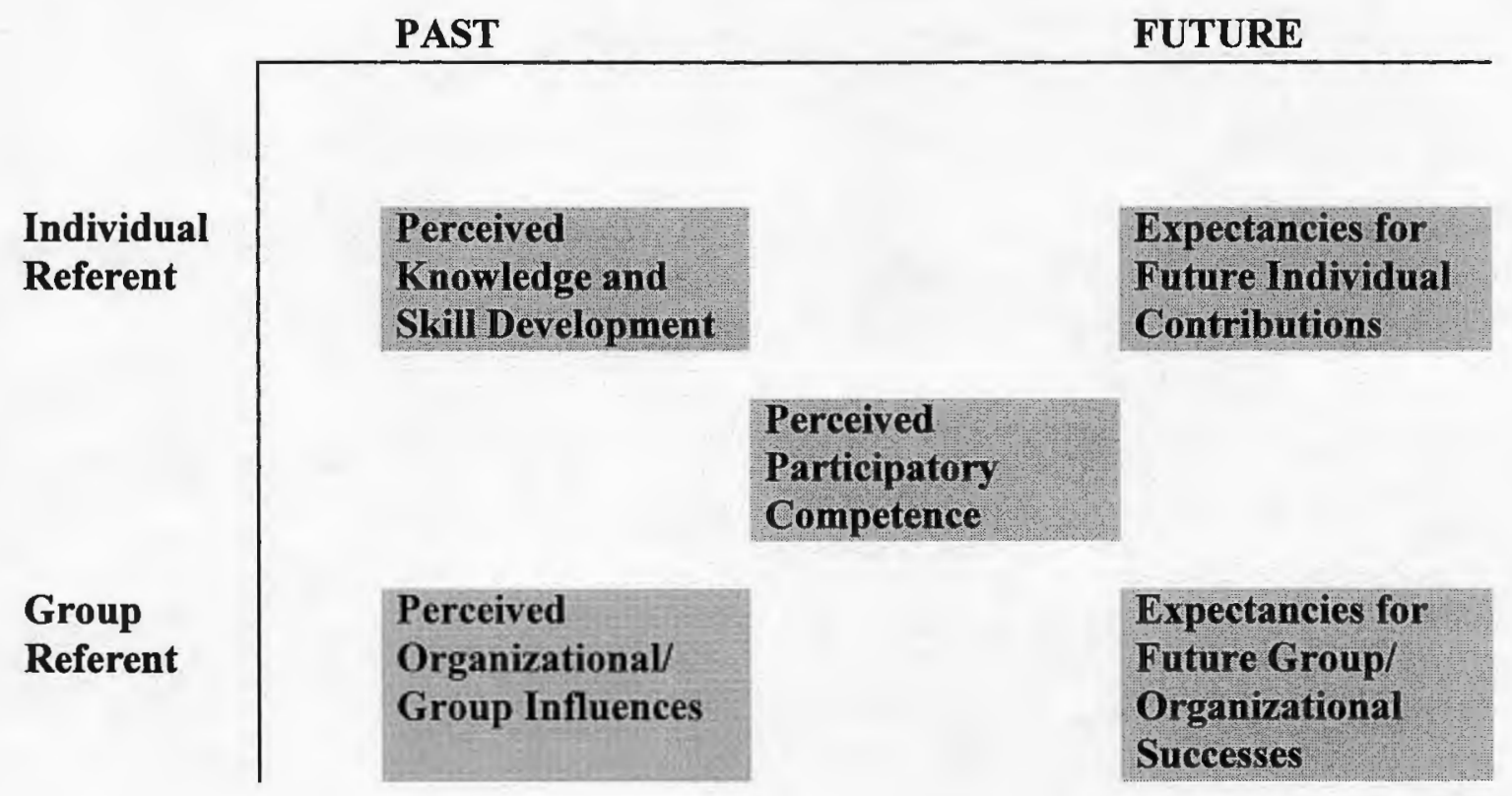

Perceived Knowledge And Skill Development is the degree to which an individual feels that participation in the group or organization has served to increase their own knowledge and skills. The construct is similar to the oft-mentioned self-efficacy component of empowerment (Rappaport, 1981; Wallerstein, 1992; Zimmerman, 1991; Zimmerman, 1995; Zimmerman \& Rappaport, 1988), but it differs in that it reports on perceived increases in self-efficacy that are directly attributed to the individual's participation in the group, thereby linking personal development with the collective experience of participation. This construct also taps into the extent to which the group has been "empowering" of the individual (Swift \& Levin, 1987).

Perceived Group/Organizational Accomplishments is the individual's perception of the extent to which the group in which they are participating has accomplished 
organizational goals and objectives. This construct is the equivalent of the individual's perception of the extent to which their group has been an "empowered" organization in the past (Swift \& Levin, 1987; Yeich \& Levine, 1994; Zimmerman \& Zahniser, 1991). That is, it addresses how successful their group or organization has been in coping with and impacting upon the social environment.

Perceived Participatory Competence is the individual's judgement of their ability to participate in and contribute to the operations of the group. This construct is the direct equivalent of perceived self-efficacy or the individual's self-judgement about their ability to organize and execute actions necessary to attain their goals (Bandura, 1982). The referent actions here involve what has been called participatory competence (Kieffer, 1984; Zimmerman \& Rappaport, 1988), and leadership competence (Kumpfer, Turner, Hopkins, \& Librett, 1993; Zimmerman \& Zahniser, 1991), behaviors which allow the individual to be involved with the organization and which build the group's efficacy.

Expectancies For Future Individual Contributions is the individual's expectation of continued involvement with and continued contribution to the group in the future. This construct is an aspect of empowerment, which channels other perceptions and judgements into more specific and direct intentions to act. It reflects the extent to which the individual has been personally engaged by their participation in the group or organization and has been "mobilized" sufficiently to project their continued participation in the future (Zimmerman, 1990b; Zimmerman, 1995; Zimmerman \& Rappaport, 1988).

Expectancies For Future Group/Organizational Accomplishments is the individual's judgement of the likelihood that the group or organization will achieve its 
objectives. This aspect of empowerment reflects outcome expectations (Mischel, 1973) for the collective effort of the group and a perceived control aspect of what has been referred to as the interpersonal component of psychological empowerment (Zimmerman, Israel, Schulz, \& Checkoway, 1992). Such expectations are built upon an individual's combined assessment of the collective capabilities of the group (or collective efficacy) and perceived responsiveness of the environment (Bandura, 1982).

While many possible patterns of relationships may exist between these variables, what is most salient here is simply that all five constructs are embedded within a higherorder construct which forms an individual-level empowerment framework. A structural equation modeling representation of how these variables may be organized as part of a higher-order construct is provided in Figure 2. 


\section{Figure 2: SEM Representation of Individual-Level Empowerment}

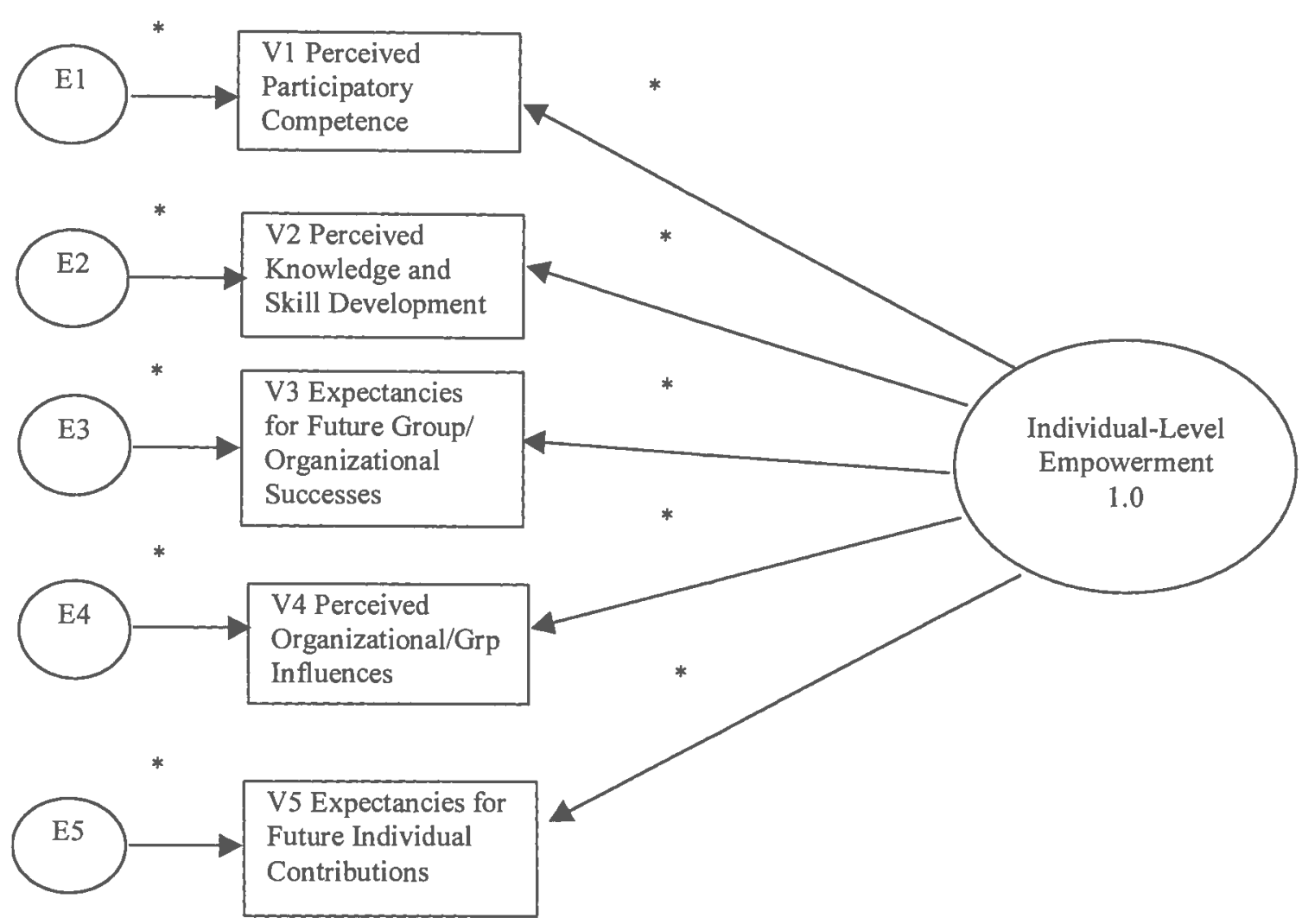

Independent Variables Influencing Individual-Level Empowerment

The model of empowerment proposed in this study consists of four major categories or "sets" of independent variables which work together to influence the individual-level framework of empowerment outlined above.

For the purposes of this study, it is assumed that when an individual comes to a group to participate, they arrive with at least two categories of pre-participation variables intact that influence the subsequent empowerment process. The first category of pre- 
participation variables includes demographic characteristics, and the second category of pre-participation variables includes feelings of a "sense of community." Demographic variables have been linked theoretically and empirically to community perceptions and attitudes as well as to participation in voluntary organizations (Chavis \& Wandersman, 1990; Florin \& Wandersman, 1984; Gruber \& Trickett, 1987; Serrano-Garcia, 1984; Zimmerman \& Rappaport, 1988; Zimmerman et al., 1992). Also, variables such as an individual's sense of community and perception of community problems have been theoretically and empirically linked to citizen participation (Chavis \& Wandersman, 1990; Wallerstein, 1992; Zimmerman, 1995). For example, Perkins, Florin, Rich, Wandersman, and Chavis (1990) have shown how "catalysts" in the physical environment (such as poorly maintained properties) and "enablers" in the social environment (such as neighboring behavior) can influence an individual's participation in a voluntary organization.

As the individual participates in a group, two other sets of variables shape the generation of empowerment at the individual level. These two sets of variables are participation and social climate/organizational characteristics. A developing empirical literature has associated participation with various aspects of empowerment (Florin \& Wandersman, 1990; Zimmerman \& Rappaport, 1988; Zimmerman et al., 1992). Participation has been found in previous studies to be associated with higher scores on measures of perceived political and personal efficacy (Zimmerman \& Rappaport, 1988), and individuals participating at higher levels in voluntary groups reported more confidence in their ability to solve community problems (Florin \& Wandersman, 1990). 
Organizational perceptions and attitudes have also been linked to participation and empowerment (Florin \& Wandersman, 1984; Kieffer, 1984; Gruber \& Trickett, 1987;

Riger, 1984; Serrano-Garcia, 1984; Swift \& Levin, 1987; Wallerstein, 1992; Zimmerman, 1990, 1995; Zimmerman et al., 1992). For example, feelings of satisfaction and commitment can lead to intentions for future participation or certain organizational climates can lead to development of participatory competence and more identification with the accomplishments of the collective. A general model of how all these variables interact to influence empowerment is offered in Figure 3.

\section{Figure 3: Interaction of Independent Variables and Individual-level Empowerment}

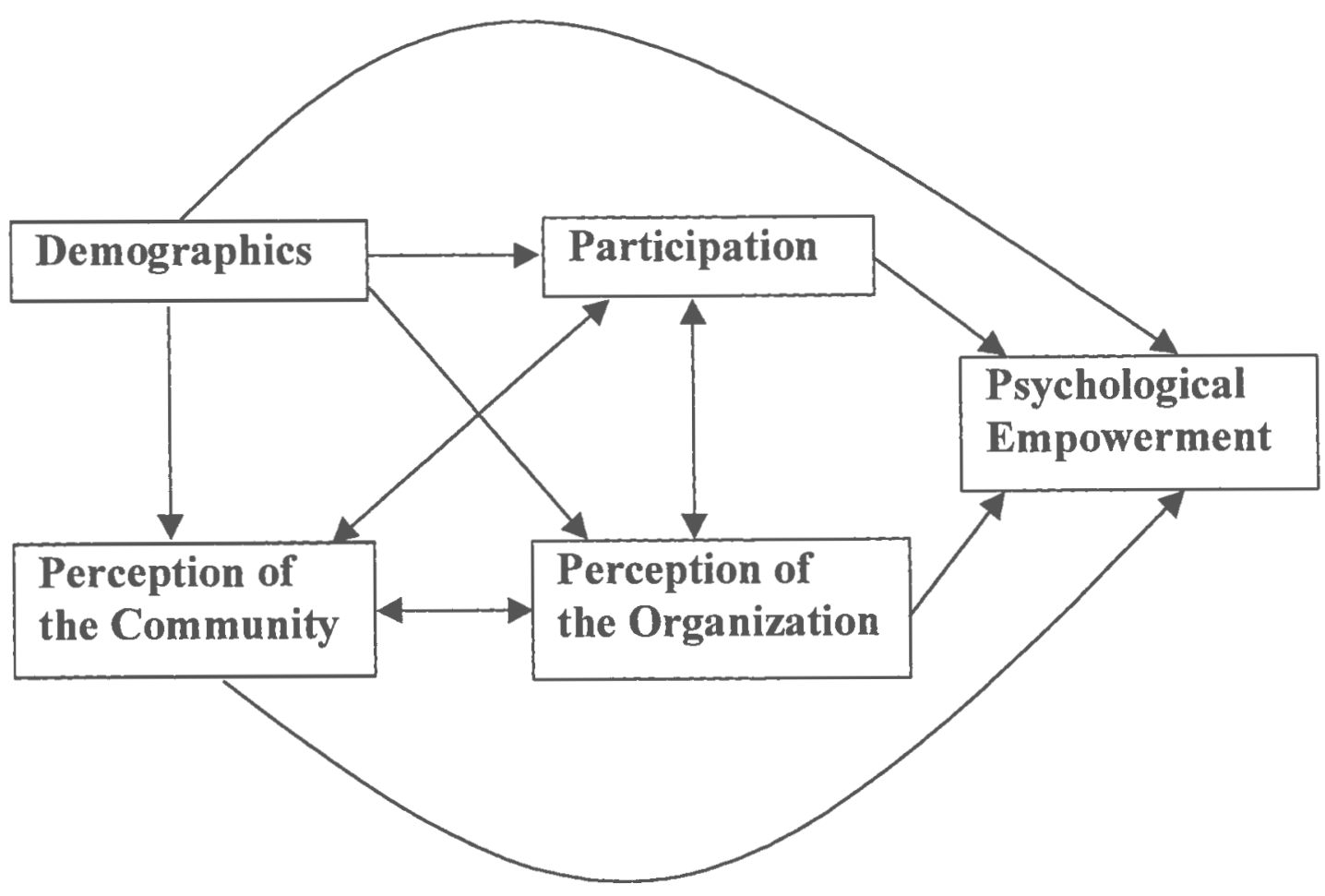


While the constructs described above are all related to empowerment-and many have been researched in studies as part of empowerment—-this study attempts to avoid conceptual and empirical overlap by not lumping all these constructs under the one general rubric of empowerment (Florin \& Wandersman, 1990). One reason for this is evident from research studies that show that a person can be participating in a group, perceive themselves to be in a favorable social climate, have access to resources, and yet still not feel empowered if other intrapsychic/interpersonal factors (such as decisionmaking authority and political efficacy) are absent (Gruber \& Trickett, 1987; Riger, 1984; Serrano-Garcia, 1984).

Other important reasons not to lump these constructs under the general empowerment umbrella are: 1) many of these constructs already have well-established research histories which would cause a great deal of redundancy and waste if they are simply researched under a new label; and 2) by including them in the empowerment definition, researchers run the risk of over-extending the construct and making it too broad to be of any practical value. Rather, it makes more sense theoretically to give empowerment a more specific focus and then to explore its relationship with these other constructs in terms of the already established research (Florin \& Wandersman, 1990). Each of these independent variables are examined below. 


\section{Demographic Variables and Empowerment}

Demographic variables describe individual characteristics such as age, education, gender, home ownership, and income among many others. Although several previous studies of demographic variables did not find evidence to support the notion that these variables significantly influence empowerment levels (McMillan et al., 1995; Zimmerman, 1990b; Zimmerman et al., 1992; Zimmerman \& Rappaport, 1998), these variables have been linked empirically to similar variables such as community perceptions and attitudes, and participation in voluntary organizations. In addition, demographics have certainly been linked theoretically to individual-level empowerment (Chavis \& Wandersman, 1990; Clark, 1989; Florin \& Wandersman, 1984; Gruber \& Trickett, 1987; Serrano-Garcia, 1984; Zimmerman, 1990b; Zimmerman et al., 1992; Zimmerman \& Rappaport, 1988).

In his 1995 article in a special empowerment issue of the American Journal of Community Psychology, Zimmerman describes how ethnicity, SES, age, gender, and other demographic factors can mask, mimic, or otherwise alter empowerment processes and outcomes. Zimmerman and other researchers have also tested demographic factors in relation to empowerment (Israel, et al., 1994; McMillan, et al., 1995; Spreitzer, 1995; Zimmerman, 1990b; Zimmerman et al., 1992; Zimmerman \& Rappaport, 1988; Zimmerman \& Zahniser, 1991). Results from these studies were mixed-Zimmerman \& Rappaport found that some empowerment outcomes were statistically significant when variance from demographic factors was partialled out, but other studies found no direct effects of demographic variables. Despite the mixed findings, it is salient to examine 
demographic factors when cultural influences are being evaluated (Airhihenbuwa, 1994; Braithwaite et al., 1994; Erzinger, 1994; Fawcett, et al., 1994; Petoskey, Van Stelle, \& De Jong, 1998; Serrano-Garcia, 1984; Trickett, 1994; Yuval-Davis, 1994). The demographic variables examined in this study have been shown to have the greatest relationship to variables such as participation and empowerment. Higher age groups, high socioeconomic status (a combination of education and income), and male gender have been found in some studies to impact upon participation and empowerment (Chavis \& Wandersman, 1990; Clark, 1989; Florin \& Wandersman, 1984; Gruber \& Trickett, 1987; Serrano-Garcia, 1984; Zimmerman et al., 1992; Zimmerman \& Rappaport, 1988). Structural equation modeling representations of the demographics examined in this study are provided in Figure 4. 
Figure 4: SEM Representation of Demographic Variables
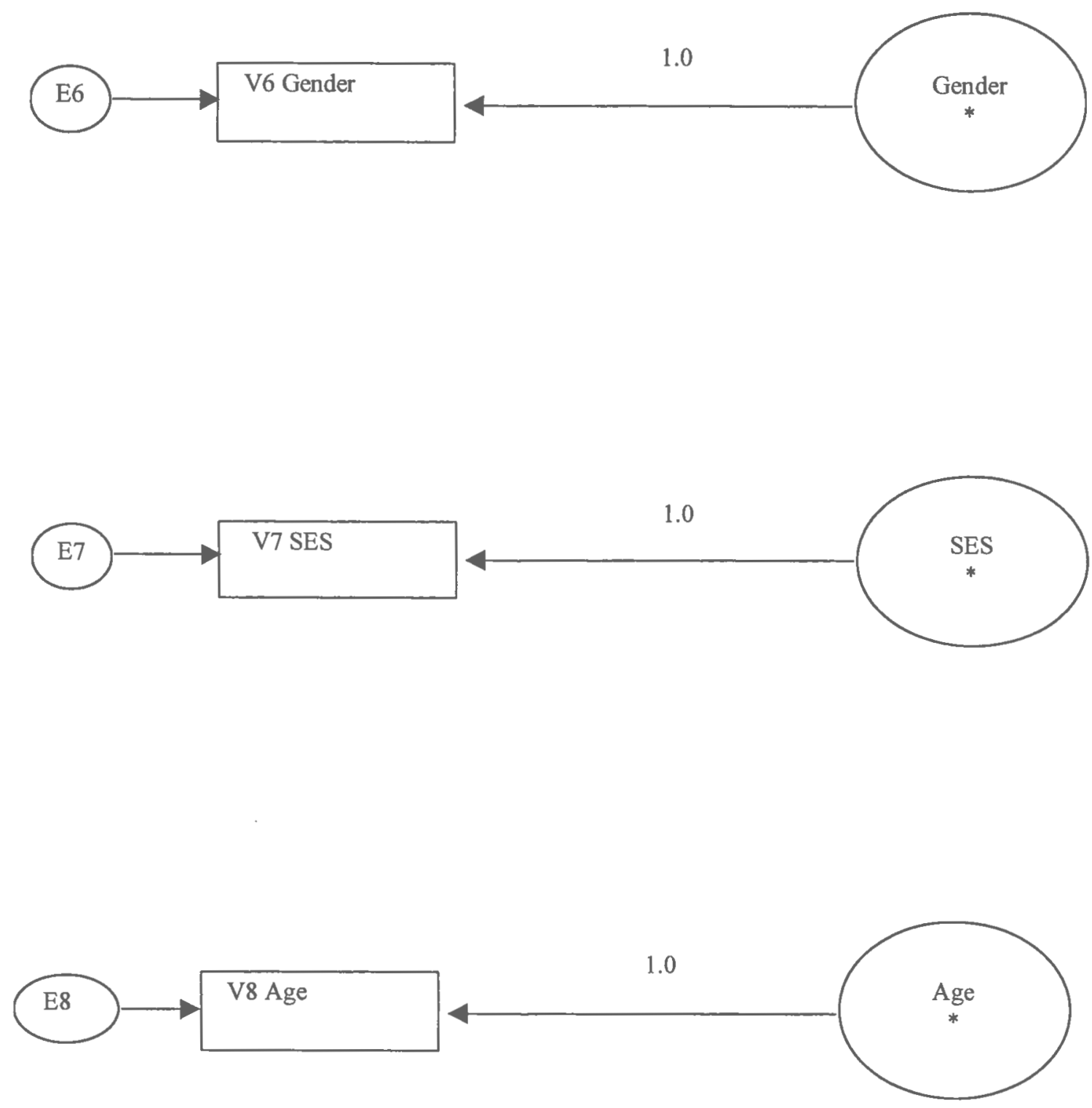


\section{Community Perceptions and Attitudes}

Community Perceptions and Attitudes (the other category of pre-participation variables) involve an individual's perceptions and feelings about their community. These variables have as their referent the physical and social context of the community, and they are seen to influence the level and intensity of individual participation and to color individual perceptions of the group in which people are participating. Variables such as an individual's sense of community and perceptions of community problems have been theoretically and empirically related to citizen participation (Chavis \& Wandersman, 1990; Fawcett et al., 1995; Flynn, Ray, \& Rider, 1994; Heller, 1989; Robinson \& Wilkinson, 1995; Wallerstein, 1992; Zimmerman, 1991; Zimmerman, 1995). A number of researchers have theorized a direct or indirect (through the mediation of participation variables) relationship between sense of community and empowerment (Chavis \& Wandersman, 1990; Cowen, 1991; Florin \& Wandersman, 1990; Heller, 1990; Maton \& Rappaport, 1984; Merideth, 1994; Saegert \& Winkel, 1996; Sagy, Stern, \& Krakover, 1996; Wallerstein, 1992; Zimmerman, 1990a; Zimmerman, 1995).

According to one definition, a community is "...a territory or geographical area (a neighborhood, town or city). A community is defined by the qualities of human interaction and social ties that draw people together. It emphasizes networks of individuals who interact within formal organizations and institutions and as members of informal groups" (Heller, 1990, p.3). In his 1990 article, "A Return to Community," Heller describes a sense of community as the force that binds people together in communities as he defined them above. In examining sense of community, he found 
strong correlations between sense of community and participation, found that awareness of community barriers and problems was essential in order for sense of community to build impetus for effective community action, and that a number of other factors (such as organizational characteristics, leadership, interpersonal resources, etc.) impacted upon sense of community. In his review of the literature, he also found that certain demographic factors (low SES, age, not being a homeowner, etc.) negatively impacted upon sense of community. In another article by Heller (1989), he looked at sense of community and participation in relationship to empowerment. He hypothesized that sense of community may be linked to empowering outcomes through participatory processes. As he stated, "increasing opportunities for positive contact fosters a sense of community, and at the same time, increases political influence through collective political power" (p.8). Heller's comments on the sense of community literature provide some directions for research, but-as he indicated in both articles-there is still much to be done to determine the direct and indirect effects of this construct on empowerment (Heller, 1989; Heller, 1990).

Currently, there are more studies that look at sense of community's relationship to empowerment as a more indirect relationship, operating through variables such as participation (Chavis \& Wandersman, 1990; Fawcett et al., 1995; Flynn, Ray, \& Rider, 1994; Merideth, 1994; Robinson \& Wilkinson, 1995; Sagy, Stern, \& Krakover, 1996; Stewart \& Weinstein, 1997). Stewart \& Weinstein found in their evaluation of volunteer group participants in three community AIDS prevention agencies that sense of community was positively correlated to some aspects of individual-level empowerment 
(high self-esteem, increased skills, increased knowledge and awareness, behavioral intentions to participate), but that it was correlated most strongly with individual participation. They also found that individuals who had a realistic assessment of community barriers participated more. Stewart \& Weinstein (1997)concluded that participation appeared to be a mediating variable between sense of community (and sense of community problems) and individual-level empowerment.

Other researchers have also noted this indirect relationship through participation effects. Chavis \& Wandersman (1990) examined 349 members of community grassroots agencies on their sense of community, participation, and empowerment. They found strong positive correlations between sense of community and participation, and strong positive correlations between participation and empowerment. Specifically, they found that expectancies of individual and collective control (two of Chavis \& Wandersman's sense of community variables) were two variables highly correlated with individual participation. In addition, awareness of community problems was found to be positively related to participation and behavioral intentions for future participation.

Other indirect relationships between sense of community, demographics, and empowerment can be found in Sagy, Stern, \& Krakover (1996). Studying neighborhoods in Israel, the researchers examined the development of sense of community in lowincome grassroots groups working to empower their neighborhoods. They found that some demographic factors impacted upon individual's perceptions of sense of community and ultimately level of perceived empowerment. Individuals who had lived in the community for several years, were in their thirties or older, lived in smaller apartment 
complexes (less crowded complexes), and viewed their physical environment as positive (noise level was acceptable, it was clean, etc.) were more likely to have a positive sense of community. In addition, satisfaction with the grassroots organization was also positively related to sense of community. Perceived empowerment was highest for individuals with a high sense of community score. Demographic factors, however, were pointed to as mediating factors in this study (Sagy, Stern \& Krakover, 1996).

Another study that indicated the importance of demographic factors in relation to sense of community and empowerment can be found in Robinson \& Wilkinson (1995). Robinson \& Wilkinson studied sense of community in relationship to empowerment in a Canadian mining village. They found that—as in the studies mentioned above—sense of community was related to higher levels of perceived empowerment. Like the previous study, though, demographic factors again played an important mediating function. Low education and income were negatively associated with sense of community, while owning a home, having children, and being married were positively related.

A final study looking at the effects other variables play in the relationship between sense of community and empowerment can be found in Merideth, 1994. In this study (a study of worker empowerment at the Casa en Casa Health Clinic in Oakland, $\mathrm{CA}$ ), organizational characteristics proved to be the strongest influence on sense of community. Having strong leadership and a favorable organizational climate (good group cohesion, satisfaction with the work environment, decision-making authority, etc.) led to higher levels of perceived empowerment and sense of community. In addition, awareness of community problems was found to be positively correlated with perceived 
empowerment and sense of community. This study supports the view that sense of community and empowerment are correlated, but-along with the studies mentioned earlier-it also makes the argument that community variables alone are not strong enough in and of themselves to foster individual-level empowerment. Participation, organizational variables, and demographics appear to have a strong impact on the establishment of a sense of community and an awareness of community barriers. Thus, while community variables appear to have an important part to play in the empowerment puzzle, there is also strong evidence to indicate that other mediating variables need to be taken into consideration. The community variables examined in this study include Sense of Community and Sense of Community Problems. These two variables have the most support of the community variables (Chavis \& Wandersman, 1990; Cowen, 1991; Fawcett et al., 1995; Florin \& Wandersman, 1990; Flynn, Ray, \& Rider, 1994; Heller, 1989, 1990; Maton \& Rappaport, 1984; Merideth, 1994; Robinson \& Wilkinson, 1995; Saegert \& Winkel, 1996; Sagy, Stern, \& Krakover, 1996; Wallerstein, 1992, 1995; Zimmerman, 1990a, 1991, 1995). The two scales specifically are drawn from several sources (Chavis \& Wandersman, 1990; Florin \& Wandersman, 1990; Heller, 1989, 1990), were used as part of the Consortium for Community Initiatives project (CRST, 1992), and were tested statistically in a prior study (McMillan et al., 1995). Structural equation modeling representations of the community variables examined in this study are provided in Figure 5. 


\section{Figure5: SEM Representation of Community Variables}
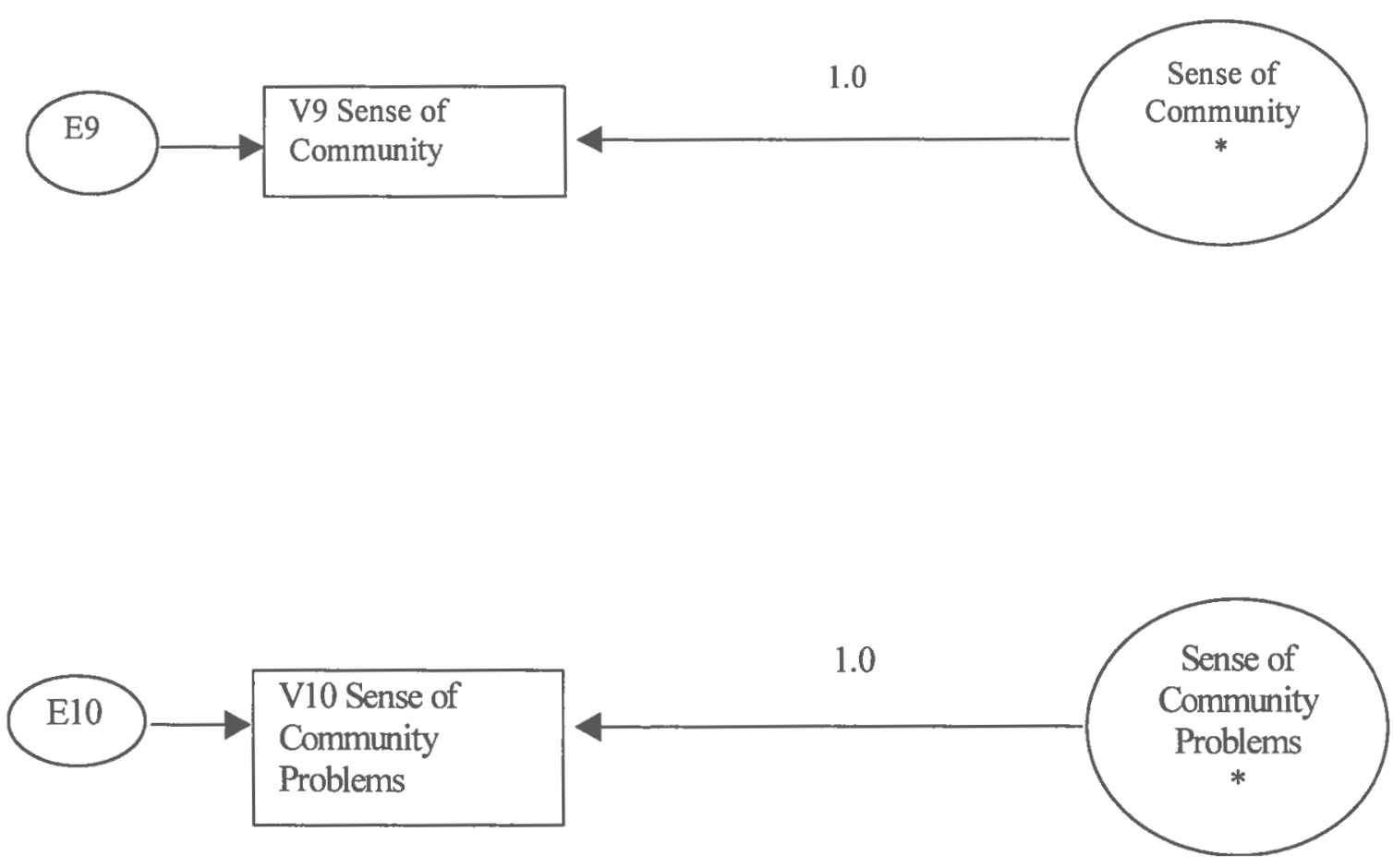

\section{Participation and Empowerment}

Participation involves the amount of time an individual devotes to the group, the different roles that an individual plays in an organization, and the costs and benefits of participation. The time and energy an individual devotes may provide opportunities for building participatory competence, developing or refining knowledge and skills, and contributing to collective accomplishments. As one definition states, "citizen participation is broadly defined as involvement in any organized activity in which the individual participates without pay in order to achieve a common goal" (Zimmerman \& Rappaport, 1988, p.726). There are a number of studies in the literature that report 
increased feelings of perceived control, development of a sense of community and increased self-esteem in relation to increased levels of citizen participation (Chavis \& Wandersman, 1990; Florin \& Wandersman, 1984; Florin \& Wandersman, 1990; O'Neill et al., 1988; Zimmerman, 1990a; Zimmerman, 1990b; Zimmerman et al., 1992; Zimmerman \& Rappaport, 1988). For example, Zimmerman and Rappaport (1988) found greater participation in community organizations to be related to higher scores on several measures reflecting the desire for and actual experience of personal and political efficacy. In McMillan et al. (1995), level of participation within community alcohol and drug prevention task forces and perceived benefits of participating within such groups were found to be linked with empowerment outcomes.

To date, participation's relationship to empowerment has the most extensive research base of the independent variables examined in this study. Several different studies utilizing a wide array of research methods have examined participation as a catalyst for empowering outcomes (Altman et al., 1998; Crabtree, 1998; Florin \& Wandersman, 1990; Israel et al., 1994; Lord \& Hutchinson, 1993; Lord, Ochocka, Czarny, \& MacGillivary, 1998; Prestby et al., 1990; Shefner-Rogers, Rao, Rogers, \& Wayangankar, 1998; Rich, Edelstein, Hallman, \& Wandersman, 1995; Yeich \& Levine, 1992; Zimmerman, 1990b; Zimmerman et. al., 1992; Zimmerman \& Rappaport, 1988). In order to understand this relationship, one must first examine exactly what constitutes participation. Florin \& Wandersman (1990) describe participation as "a process in which individuals take part in the institutions, programs and environments that affect them" (Wandersman, 1990, p.43). They address the fact that participation can take many 
different forms in many different settings. They point to citizen participation in social movements as one of the prime ways in which individuals have influenced social policy. In addition, they state that participation appears to have a wide variety of benefits at the national, community, interpersonal, and individual levels. One of these benefits is empowerment at multiple levels (individual, organizational, and community). As they state:

"There is some supportive evidence that voluntary community organizations can be empowering because participation in them has been related to higher competencies, confidence, sense of citizen duty and lower feelings of helplessness. Voluntary community organizations can also be empowered and some have influenced the distribution of power and decision-making within a community and neighborhood improvement" (Florin \& Wandersman, 1990, p.45).

Florin \& Wandersman articulate the view that there are three central issues of citizen participation: 1) Why do some people participate while others do not?; 2) Why are some organizations successful while others are ineffective and die out?; and 3) What are the effects of citizen participation? This study looks at this third question, and the following articles illustrate that one effect of citizen participation is empowerment of individuals and groups.

Lord \& Hutchinson (1993) examined fifty-five men and women involved in the struggle to become empowered. The men and women that participated in the study were drawn from several different areas, including: the disability movement, the health promotion field, and human services. All of the participants were chosen for their experience in their respective fields and their leadership roles. Using qualitative interviews, participant observation, and key informant interviews of these people who 
had experienced significant levels of powerlessness in their lives, they found that high levels of participation led people to report higher levels of empowerment as evidenced by: increased skills, increased knowledge, knowledge about community resources, increased networking, and other individual-level empowerment effects. Social isolation, organizational inflexibility, poverty, and abuse were found in their study to be barriers to individual-level empowerment.

Other studies examining the relationship between participation and empowerment include: Altman et al., 1998; Crabtree, 1998; Lord, Ochocka, Czarny, \& MacGillivary, 1998; and Shefner-Rogers, Rao, Rogers, \& Wayangankar, 1998. While these studies involve diverse settings and individuals, they all illustrate a powerful relationship between participation and empowerment. For example, in their study of 2,609 $9^{\text {th }}$ graders in six inner city schools participating in heart disease prevention activities, Altman et al. (1998) found participation to be strongly correlated with empowerment. In addition, sense of community was positively correlated with participation, and participation was most strongly correlated with the empowerment variables of self-efficacy, outcome expectancies, and perceived decision-making. In their case study of the processes of change in a mental health organization, Lord et al. (1998) found that the most effective way to increase employee empowerment was by broadening ownership through stakeholder involvement, increasing employee and consumer participation, and making the benefits of participation outweigh the inherent costs. Shefner-Rogers et al. (1998) also found that increased benefits of participation versus costs led to higher levels of perceived empowerment. Their study of 184 female dairy farmers in rural India found 
further evidence to support the link between participation and empowerment. The highest correlations in their study were found between these two constructs (individuals who participated the most and had the highest perception of direct or indirect benefits had the highest levels of individual-level empowerment). Finally, Crabtree (1998) found in her study of two cross-cultural participatory development and service-learning projects conducted in El Salvador and Nicaragua that participation and communication skills were most strongly correlated with perceived empowerment.

In an examination of voluntary organization participation in New York, Prestby et al., 1990, added other components to the research on participation and empowerment. Costs and benefits of participation were examined as well as direct participation in relation to empowerment and other factors. Benefits of participation include: working towards the improvement of a neighborhood or community, desiring to make a contribution, friendship, socialization, enjoyment of leadership, organizing, and material benefits to a lesser degree. Costs of participation include such things as: material costs, time, effort, giving up personal/family matters, giving of skills and knowledge, finances, interpersonal conflict, lack of social support, lack of others' participation or interest in the organization, lack of organizational success, disagreement about organizational goals, scheduling, and communication failures. Examining three culturally and economically different neighborhoods in New York City, Prestby et al. (1990) used factor analysis to examine cost and benefit variables and ANOVA analyses to test their hypotheses. They found that higher levels of participation in block associations were significantly related to higher benefits and lower costs. They suggest in their discussion of the findings that costs 
and benefits of participation appear linked to participation in an organization, and so these variables should be considered in future examinations of participation and empowerment.

Yeich \& Levine (1992) also examined individuals involved in the struggle to become empowered as part of a grassroots homeless persons union. Utilizing a case study approach, Yeich \& Levine examined participation of the union members individually and as a group in relationship to the larger community context. They found that the individuals who participated more tended to have an increased critical awareness of the environment (sense of community problems), increased sense of community, increased skills and knowledge, increased behavioral intentions to participate, and other facets of individual-level empowerment. In addition, they found that as the group fostered more participation of its members, it also grew more empowered in the community at large-it gained more recognition, more political efficacy, and helped identify more potential sources of resources for homeless individuals. Rich, Edelstein, Hallman, \& Wandersman (1995) also found similar multi-level results in their study of neighborhoods in the vicinity of environmental hazards. They found positive correlations between individual participation and empowerment, and they also found higher levels of organizational empowerment with neighborhood coalitions with high participation levels.

Of all the studies of participation and empowerment, Zimmerman \& Rappaport (1988) provides some of the best quantitative evidence. Examining college students and community residents in three different studies, they explored the relationship between participation and a measure of psychological empowerment (an individual-level 
empowerment construct based upon earlier works by Rappaport and Kieffer) using a variety of statistical techniques (MANOVAs, ANOVAs, regression analyses, factor analysis, etc.). They found strong support for the relationship between participation and a set of the empowerment variables (measuring personality, cognitive, and motivational aspects) that they hypothesized formed a general measure of individual empowerment. The variables that loaded most highly on the empowerment factor and were significantly related to participation were: self and political efficacy; desire for control; civic duty; and perceived competence. Also of note in this study is the fact that demographic factors did not load on Zimmerman \& Rappaport's empowerment factor and that organizational characteristics played more of a role than was initially hypothesized (perceptions of poor organizational climate dropped MANOVA analyses of participation and empowerment below the threshold of significance on some factors).

Zimmerman (Israel et al., 1994; Zimmerman, 1990b; Zimmerman et. al., 1992) continued to examine participation and empowerment in other studies. In his study of learned hopefulness, Zimmerman examined empowerment in relation to learned helplessness and participation. Finding positive correlations between participation and empowerment in the study mentioned above, he examined the relationship again, but this time using structural equation modeling (Zimmerman, 1990b). In addition, Zimmerman hypothesized that both constructs would be negatively related to learned helplessness. He hypothesized this negative relationship because he speculated that participation and individual-level empowerment formed the basis for learned hopefulness. His results supported the positive relationship between participation and empowerment, and also that 
both constructs were negatively correlated with his measure of learned helplessness. While Zimmerman did not examine sense of community and organizational characteristics in this study, he did propose future study of these constructs in relationship to this learned hopefulness model.

Finally, Zimmerman et al. (1992) looked once again at the relationship between participation and individual-level empowerment. Looking at citizen participation and perceived control (using variables similar to the variables outlined in this study) on the participation end, he outlined a study using urban and suburban samples with MANOVA analyses. On the empowerment side, he used the intrapersonal, interactional, and behavioral aspects of individual-level empowerment outlined in his prior works (and also incorporated in this study). As per previous studies, analyses replicated prior findings on the relationship between participation and empowerment in both the urban and suburban samples. Again, Zimmerman addressed the issue of adding sense of community and organizational variables to the study of individual-level empowerment (Zimmerman et al., 1992). Organizational variables suggested by Zimmerman and others are examined in the next section. The participation variables examined in this study include Participation Level and Net Benefits of Participation. These two variables have good reliability and theoretical support in the participation literature (Altman et al., 1998; Chavis \& Wandersman, 1990; Crabtree, 1998; Florin \& Wandersman, 1984; Florin \& Wandersman, 1990; Israel et al., 1994; Lord et al., 1998; Lord \& Hutchinson, 1993; O'Neill et al., 1988; Shefner-Rogers et al., 1998; Yeich \& Levine, 1992; Zimmerman, 1990a, 1990b; Zimmerman et al., 1992; Zimmerman \& Rappaport, 1988). The two scales 
specifically are drawn from several sources (Chavis \& Wandersman, 1990; Florin \& Wandersman, 1984; Florin \& Wandersman, 1990; Zimmerman \& Rappaport, 1988), were used as part of the Consortium for Community Initiatives project (CRST, 1992), and were tested statistically in a prior study (McMillan et al., 1995). Structural equation modeling representations of the participation variables examined in this study are provided in Figure 6.

\section{Figure 6: SEM Representation of Participation Variables}

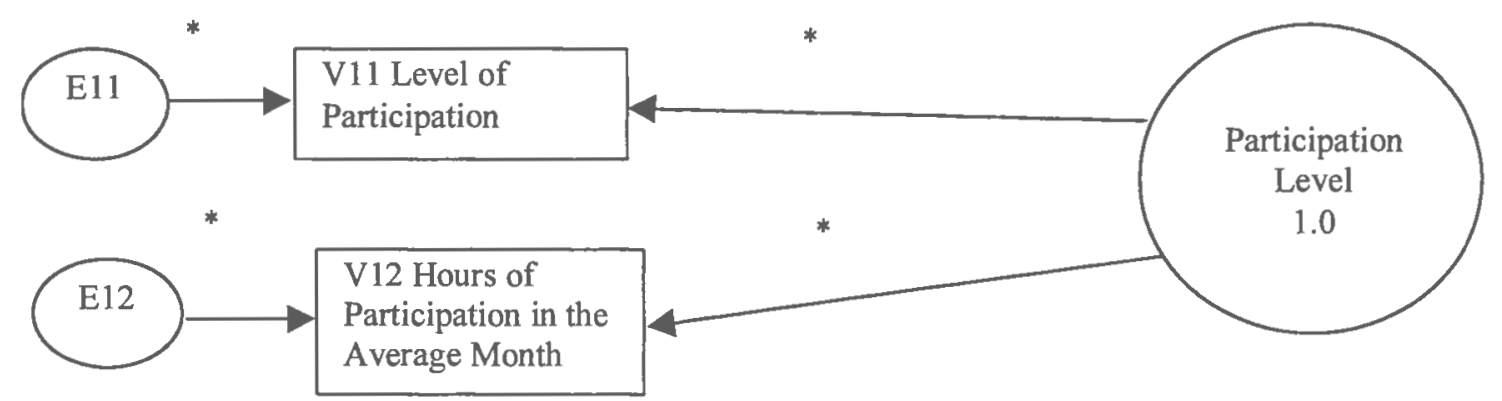




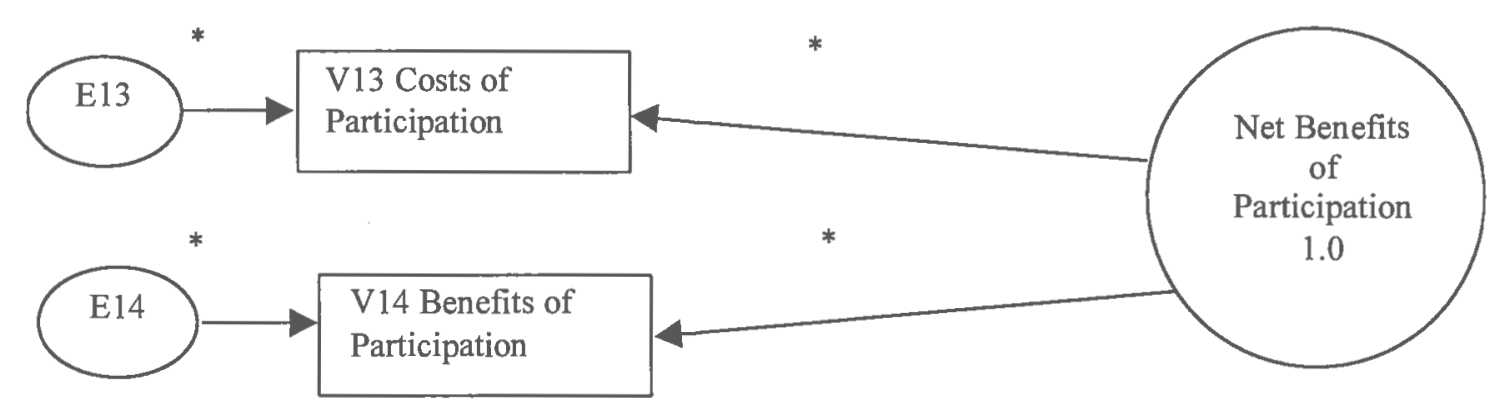

\section{Organizational Characteristics and Empowerment}

Social climate/organizational characteristics involve aspects of the group atmosphere such as group cohesion, ability to focus on tasks, satisfaction with the group, and commitment or identification with the group. Social climate and/or organizational factors have also been theorized (and in a few preliminary studies, empirically found) to have an effect on empowerment. Some factors such as group dynamics, leadership, and political situations have been seen to be facilitators of or barriers to the development of empowerment (Cable, 1992; Clark, 1989; Denmark, 1993; Gruber \& Trickett, 1987; Jenkins, 1994; Kieffer, 1984; Luechauer \& Shulman, 1996; Maton \& Salem, 1995; Riger, 1984; Roberts \& Foti, 1998; Serrano-Garcia, 1984; Spreitzer, 1995; Swift \& Levin, 1987;

Wallerstein, 1992; Yoder, Schleicher, \& McDonald, 1998; Zimmerman, 1990b; Zimmerman, 1995; Zimmerman et al., 1992). The link between organizational perceptions and participation is particularly salient. Several studies have found or theorized that feelings of satisfaction and commitment lead to increased behavioral intentions for future participation, and an organizational social climate that creates 
feelings of involvement can lead to greater development of participatory competence and more identification with the accomplishments of the collective (Florin \& Wandersman, 1984; Gruber \& Trickett, 1987; Hardy \& Leiba-O’Sullivan, 1998; Kieffer, 1984; Riger, 1984; Serrano-Garcia, 1984; Swift \& Levin, 1987; Wallerstein, 1992; Zimmerman, 1990b; Zimmerman et al., 1992; Zimmerman, 1995).

Bond \& Keys (1993) examined the effects of organizational characteristics in their case study analyses of collaboration and empowerment. Bond \& Keys theorized that the synergy necessary for large-scale change (organizational change, political change, community change, etc.) is a result of the combination of empowerment (at individual and organizational levels) and collaboration with other important agencies (other organizations, important individuals, etc.). In contrast to empowerment critics who focus on empowerment initiatives taking resources or power away from others in a "win/lose" fashion, Bond \& Keys talk about and illustrate how organizations don't necessarily take power away from others but instead recognize new resource sources and creatively generate new resource bases. Of note in their study, however, were the potential barriers that they saw to the process of empowerment. Demographic characteristics, like socioeconomic status, were found to be barriers to some of the organizations studied.

Organizational characteristics, such as poor leadership, poor group cohesiveness, lack of commitment and involvement of group participants, were all found to negatively impact upon the development of perceived individual and group level empowerment. In the final analysis, Bond \& Keys pointed to organizational characteristics as the key component of individual and group level empowerment. 
Echoing Bond \& Keys, Foster-Fishman \& Keys (1997) examined the organizational preconditions necessary to foster individual-level empowerment. FosterFishman \& Keys described these organizational preconditions as factors concerning power, control, inclusion, and trust. They hypothesized that organizations desiring to empower their members had to have the following organizational preconditions: a desire for increasing control; an ability to change and expand the power structure; an ability to promote inclusion; and the ability to foster belief and trust in the organization. In their case studies, they found that organizations that had these characteristics also had significantly higher levels of individual sense of community, organizational commitment, decision-making power, group cohesion, and empowerment. When the preconditions did not exist, they found that the most disempowered individuals at the start could not be empowered. As a result, they urged future researchers to take organizational climate under serious consideration.

Other examinations of organizational characteristics in relation to empowerment can be found in the business and educational research literature. Organizational characteristics in these settings have received a great deal of attention (Blanchard \& Randolph, 1996; Brown, 1996; Bushe et al., 1996; Carroll, 1996; Darling, 1996; Dennis, 1991; Hershey, 1996; Loney, 1996; Roberts \& Foti, 1998; Rutledge, 1996; Stone, 1995; Tyree, 1996; Weaver, 1996; Williams, 1996). One example of empowerment in business is the concept of the empowered team. Carroll (1996) examined several empowered work teams in his study of a large North American company. The organizational characteristics he found most empowering as reported by team members were: strong, collaborative 
leadership, an atmosphere where increased roles and responsibilities were encouraged, a more participatory organizational climate, increased team cohesion, opportunities for networking, shared responsibilities and an attention to quality over quantity. Bushe et al., 1996, also examined empowered work teams and found similar results to Carroll.

Researchers interviewed work team members and found increased empowerment when members were satisfied with their work group, when they felt that innovativeness was fostered, when there was a feeling of cohesiveness and commitment to the team, and networking between teams was encouraged. Networking, leadership, sense of community, awareness of organizational barriers, commitment, increasing roles and responsibilities, fostering job ownership, and providing training were found in Brown (1996) to be significant predictors of employee participation and empowerment. Several organizational characteristics have been examined in relationship to empowering outcomes, but-as these studies suggest—commitment, cohesiveness, task focus, and satisfaction with the group appear to be variables that significantly relate to the empowerment process.

A final point about organizational characteristics and empowerment is the salience of leadership. Several of the above-mentioned studies mentioned the importance of strong leadership as part of an empowering group dynamic. Several studies address this issue exclusively, especially in relation to power and women in authority (Brown, 1996; Cable, 1992; Denmark, 1993; Jenkins, 1994; Luechauer \& Shulman, 1996; Maton \& Salem, 1995; Riger, 1984; Roberts \& Foti, 1998; Yoder, Schleicher, \& McDonald, 1998). Riger, 1984, examined empowerment and leadership in grassroots feminist organizations. While 
Riger points out that feminist movement organizations (FMOs) emphasize the necessity of an equal distribution of power in order to achieve internal democracy and achieve their social goals, she also noted a number of factors that led to disintegration of such organizations. Conflicting interests, long-term goals, the desires to provide services versus advocating for social change, and other factors can lead to the breakdown of many groups as they evolve. Riger makes a point of saying that there are several ways to address internal conflicts and even have power differentials amongst members without compromising feminine values. Having strong leadership capable of conflict management, able to unite members and focus them on long-term goals, and able to clarify the focus of the organization (whether it will be emphasizing social change or social service) are three key components of empowering individual members and fostering long-term organizational viability. Yoder, Schleicher, \& McDonald (1998) examined female leadership in male-dominated workgroups. They conducted a controlled study of thirty female undergraduates engaged in leadership roles with all-male task groups on experimental projects. They found that organizational characteristics (whether the woman leaders were appointed, trained with task-relevant information, and legitimated by a male experimenter as credible to the all-male workgroups) were more relevant in determining whether the leaders were effective and empowered than any other characteristics examined. Providing women with power and decision-making was crucial in fostering group cohesion, task focus, and increasing participation. The above studies provide an interesting avenue of research, and although this dissertation does not separate out leadership (leadership skills are embedded within the Organizational Climate 
construct), the importance of strong leadership cannot be understated and should be examined more fully in future studies. The organizational variables examined in this study include Organizational Climate and Commitment. These two variables have good reliability and theoretical support in the literature (Blanchard \& Randolph, 1996; Brown, 1996; Bushe et al., 1996; Carroll, 1996; Darling, 1996; Dennis, 1991; Florin \& Wandersman, 1984; Gruber \& Trickett, 1987; Hardy \& Leiba-O’Sullivan, 1998; Hershey, 1996; Kieffer, 1984; Loney, 1996; Riger, 1984; Roberts \& Foti, 1998; Rutledge, 1996; Serrano-Garcia, 1984; Stone, 1995; Swift \& Levin, 1987; Tyree, 1996; Wallerstein, 1992; Weaver, 1996; Williams, 1996; Zimmerman, 1990b, 1995; Zimmerman et al., 1992). The two scales specifically are drawn from the works of several researchers (Florin \& Wandersman, 1984, 1990; Gruber \& Trickett, 1987; Kieffer, 1984; Zimmerman et al., 1992), were used as part of the Consortium for Community Initiatives project (CRST, 1992), and were tested statistically in a prior study (McMillan et al., 1995). Structural equation modeling representations of the organizational variables examined in this study are provided in Figure 7. 


\section{Figure 7: SEM Representation of Organizational Variables}

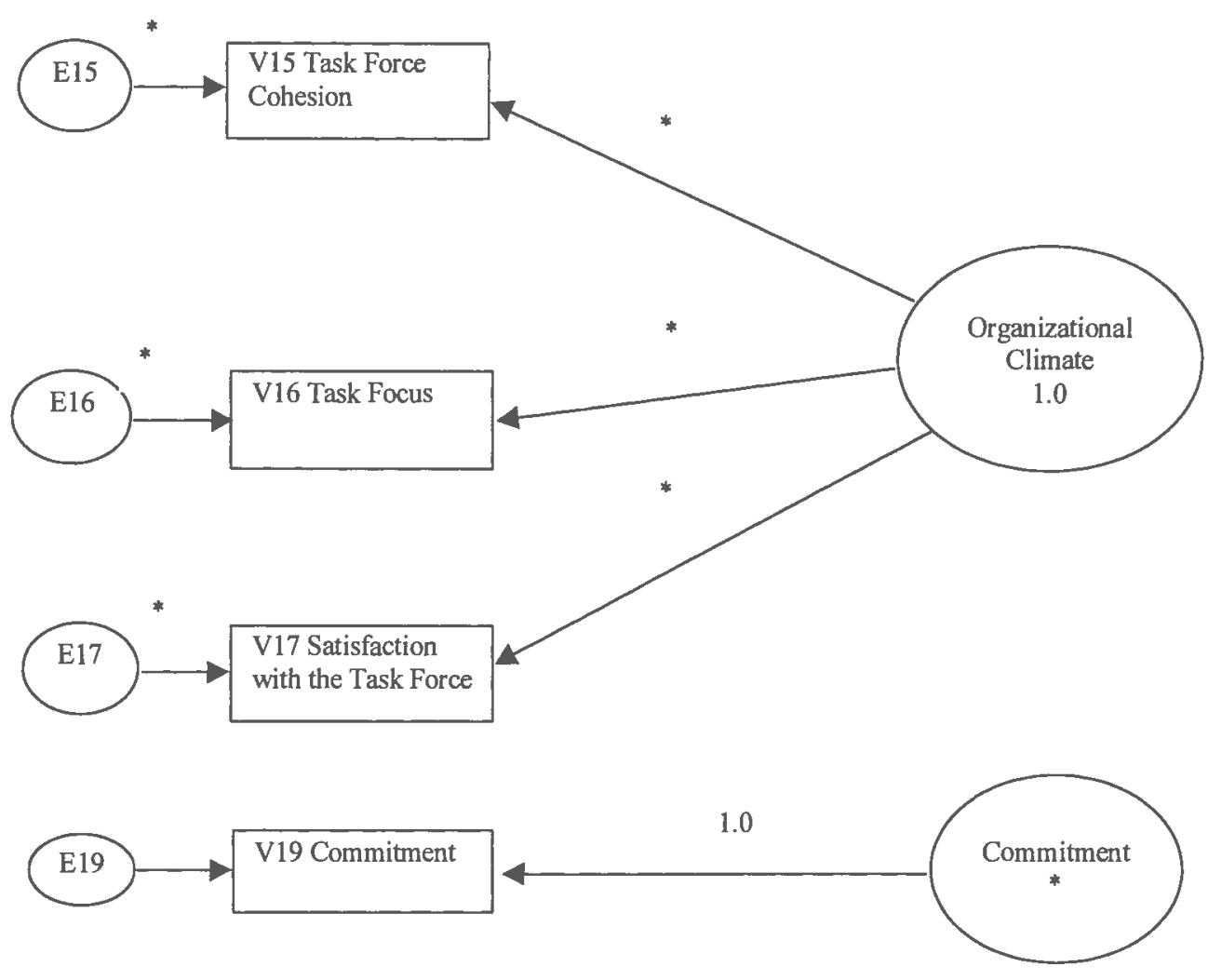

While many studies have examined each of the independent variables mentioned above in relation to empowerment and empowering outcomes, few studies have looked at all of these independent variables together. Some studies have undertaken the task with encouraging results. McMillan et al. (1995) examined the empowerment of members of thirty-five alcohol and other drug abuse prevention organizations within the state of Rhode Island. They found a strong correlation between an individual's level of individual empowerment and participation, organizational climate, knowledge of the severity of community problems, sense of community, commitment to the organization, and benefits of participation. In addition, it was found that organizations that were empowered (as 
defined in that study by the ability of the prevention organizations to gather community resources and influence) had a greater proportion of empowered members.

Saegert and Winkel (1996) examined empowerment, participation, and sense of community in low-income, minority neighborhood housing cooperatives in New York City. Their study examined individual and collective empowerment at different time points using a variety of different measures and statistical analyses. Both participation and sense of community were found to be significantly related to individual empowerment, and participation was found to be significantly related to the collective empowerment of neighborhood co-ops. Other studies mentioned earlier also indicated multiple relationships between independent variables and empowerment (Bond \& Keys, 1993; Brown, 1996; Chavis \& Wandersman, 1990; Florin \& Wandersman, 1990; Merideth, 1994; Robinson \& Wilkinson, 1995; Yeich \& Levine, 1992).

\section{Models}

The four sets of variables mentioned above are conceptualized in this study as influencing the individual's level of empowerment. To this end, self-reported information from members of thirty-five community coalitions on a mailed survey was analyzed using SEM to determine the predictive power of traditional demographics, sense of community, participation and social climate variables on perceived individual-level empowerment.

Structural Equation Modeling (SEM) is a powerful and sophisticated statistical method. Combining the best features of multiple regression analysis, path analysis, and factor analysis, SEM permits comparisons between competing models of the same data 
without the noise introduced by measurement error. In SEM, interest focuses on latent constructs rather than on the manifest variables used to measure these constructs.

Measurement of these latent constructs is recognized as difficult and error-prone. But by explicitly modeling measurement error, SEM derives unbiased estimates for the relations between the latent constructs. To this end, SEM allows multiple measures to be associated with a single latent construct (Bentler, 1993; Bollen \& Long, 1993; Bullock, Harlow, \& Mulaik, 1994; Byrne, 1994; Joreskog, 1993; Tanaka, 1993).

A structural equation model implies a structure of the covariance matrix of the measures (hence, an alternative name for this field is "analysis of covariance structures"). Once the model's parameters have been estimated, the resulting model-implied covariance matrix can then be compared to an empirical or data-based covariance matrix. If the two matrices are consistent with one another, then the structural equation model can be considered a plausible explanation for relations between the measures. Because of the nature of the structural equation modeling approach, however, confirmation of a particular model (i.e., retaining the null hypothesis) only shows that a model provides an acceptable description of the data. Indeed, several possible models of the data in question are theoretically possible. Thus, several researchers have recommended that alternative models of the research data be tested concurrently to rule out equally plausible alternate explanations of the data (Bentler, 1993; Bullock, Harlow, \& Mulaik, 1994; Joreskog, 1993; Tanaka, 1993). Thus, for the purposes of this research, three alternate, nested structural equation models of possible direct and indirect effects of the variables in question have been proposed (see Figures 8-10). 
Finally, it is better in SEM analysis to have models with more variables intercorrelated than parameters that need to be estimated in order for a model to be properly identified. Models that are just identified yield a trivially perfect fit, making the test of fit uninteresting. Models that are overidentified-that have positive degrees of freedom - may not fit well, so the fact that such a model does fit well amounts to meaningful evidence in favor of the proposition that the model is indeed a reasonable representation of the phenomena in question. This differs significantly from other modes of statistical inquiry. Compared to regression and factor analysis, however, SEM is a relatively young field, having its roots in papers that appeared only in the late 1960s (Joreskog, 1967). As such, it is important to remember that the methodology is still developing, and even fundamental concepts are subject to challenge and revision. 


\section{Model 1 (Inclusive Model of Direct Effects)}

As several researchers have indicated (Bentler, 1993; Bullock, Harlow, \& Mulaik, 1994; Joreskog, 1993; Tanaka, 1993), it is highly recommended in structural equation modeling that several different models of effects be examined due to the nature of the statistic. To this effect, Model 1 (see Figure 8) presents the simplest examination of the relationship between the independent variables mentioned above and individual-level empowerment. Model 1 looks at all independent variables intercorrelated with each other and having direct positive effects on individual-level empowerment (as per Figure 3). Based on this, the following hypotheses are proposed:

1) It is predicted that age, gender, and SES will all have a direct positive effect on individual-level empowerment (see Methods section below for how these variables were coded).

2) It is predicted that Sense of Community will have a direct positive effect on individuallevel empowerment.

3) It is predicted that Sense of Community problems will have a direct positive effect on individual-level empowerment.

4) It is predicted that Participation Level will have a direct positive effect on individuallevel empowerment.

5) It is predicted that Net Benefits of Participation will have a direct positive effect on individual-level empowerment.

6) It is predicted that Organizational Climate will have a direct positive effect on individual-level empowerment. 
7) It is predicted that Commitment will have a direct positive effect on individual-level empowerment.

8) It is predicted that all independent variables mentioned in hypotheses 1-7 above will be correlated with each other.

Figure 8: Model \#1

Inclusive Model of Direct Effects

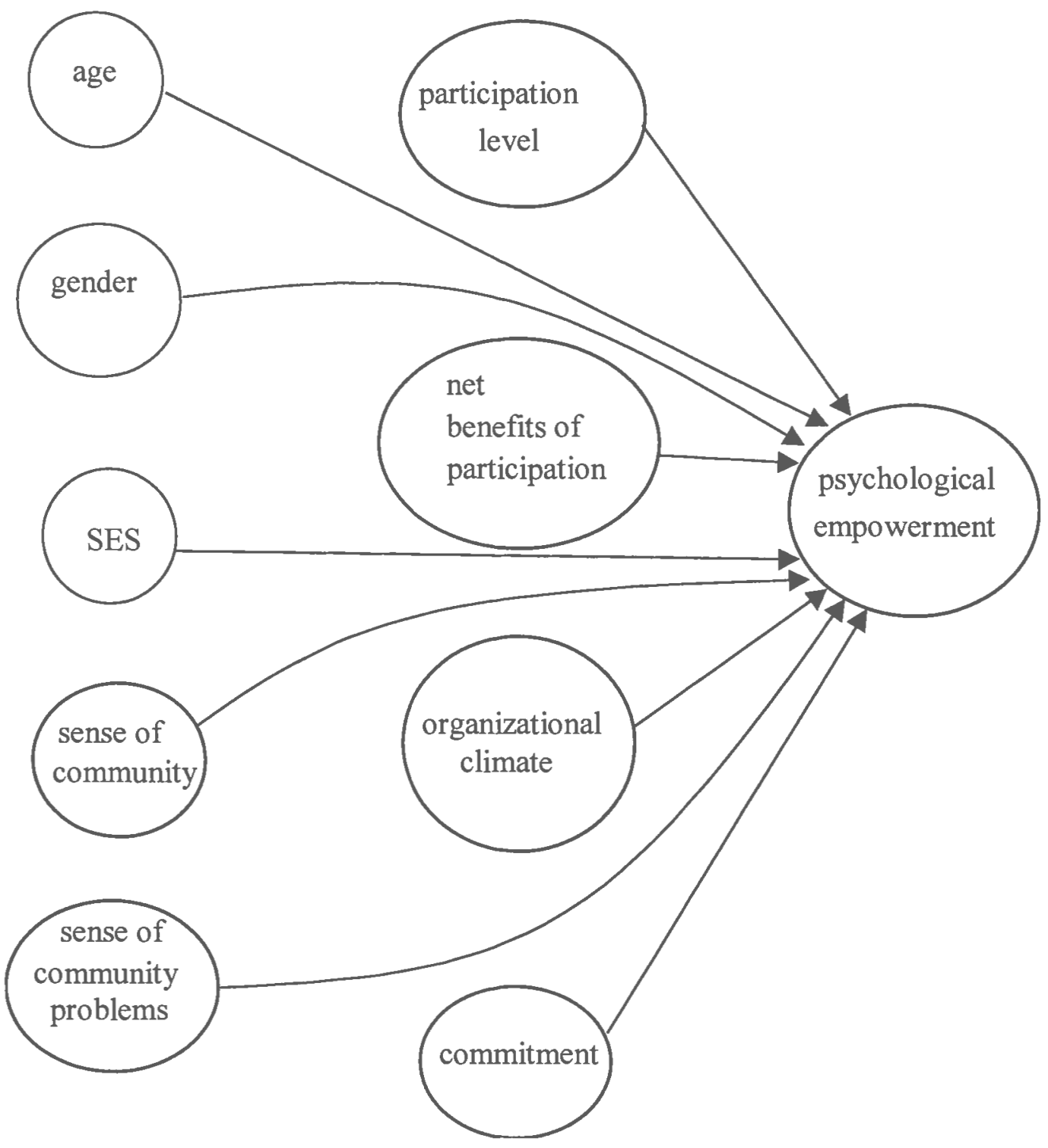




\section{Model 2 (Zimmerman/Rappaport Model of Participation Effects)}

This model is analyzed as a competing view of empowerment, which stems directly from participation effects. It looks at the direct effect of participation and organizational variables on individual-level empowerment with an indirect effect of community perceptions and attitudes as well as demographic variables. This model differs from Model 1 in that demographics and community variables are seen as directly impacting upon participation rather than empowerment. This model is based upon the results of prior studies of participation and empowerment which indicated direct effects of participation variables on empowerment at the individual level (Chavis \& Wandersman, 1990; Florin \& Wandersman, 1984; Florin \& Wandersman, 1990; O'Neill et al., 1988; Zimmerman, 1990a; Zimmerman, 1990b; Zimmerman et al., 1992; Zimmerman \& Rappaport, 1988). In addition, this model examines the indirect effect of demographic variables and community perceptions and attitudes on individual-level empowerment through the mediation of participation variables. Prior studies have shown direct effects of community perceptions or attitudes and demographics on participation, and researchers have theorized indirect effects of these two categories of variables through participation outcomes (Chavis \& Wandersman, 1990; Cowen, 1991; Florin \& Wandersman, 1990; Maton \& Rappaport, 1984; Wallerstein, 1992; Zimmerman, 1991; Zimmerman, 1995). Finally, because of the results of recent studies and theoretical considerations, social climate variables will also be examined to determine if they contribute beyond the variance accounted for by participation (Bandura, 1982; Clark, 1989; Gruber \& Trickett, 1987; Kieffer, 1984; McMillan et. al, 1995; Riger, 1984; 
Serrano-Garcia, 1984; Swift \& Levin, 1987; Wallerstein, 1992; Zimmerman, 1990b; Zimmerman, 1995; Zimmerman et al., 1992). Based upon this, the following hypotheses are proposed for Model 2 (see Figure 9):

1) It is predicted that demographic variables (age, gender, and SES) will be positively correlated with each other as well as with Sense of Community and Sense of Community Problems, will have a direct positive effect on Participation Level and Net Benefits of Participation, and will have a indirect positive effect on empowerment.

2) It is predicted that Sense of Community and Sense of Community Problems will be correlated with each other as well as the demographics mentioned above, will have a direct positive effect on Participation Level and Net Benefits of Participation, and have an indirect positive effect on empowerment.

3) It is predicted that Participation Level and Net Benefits of Participation will be correlated with each other as well as having a direct positive effect on individual-level empowerment.

4) It is predicted that Organizational Climate and Commitment will be correlated with each other as well as having a direct positive effect on individual-level empowerment. 
Figure 9: Model \#2

Zimmerman/Rappaport Model of Participation Effects

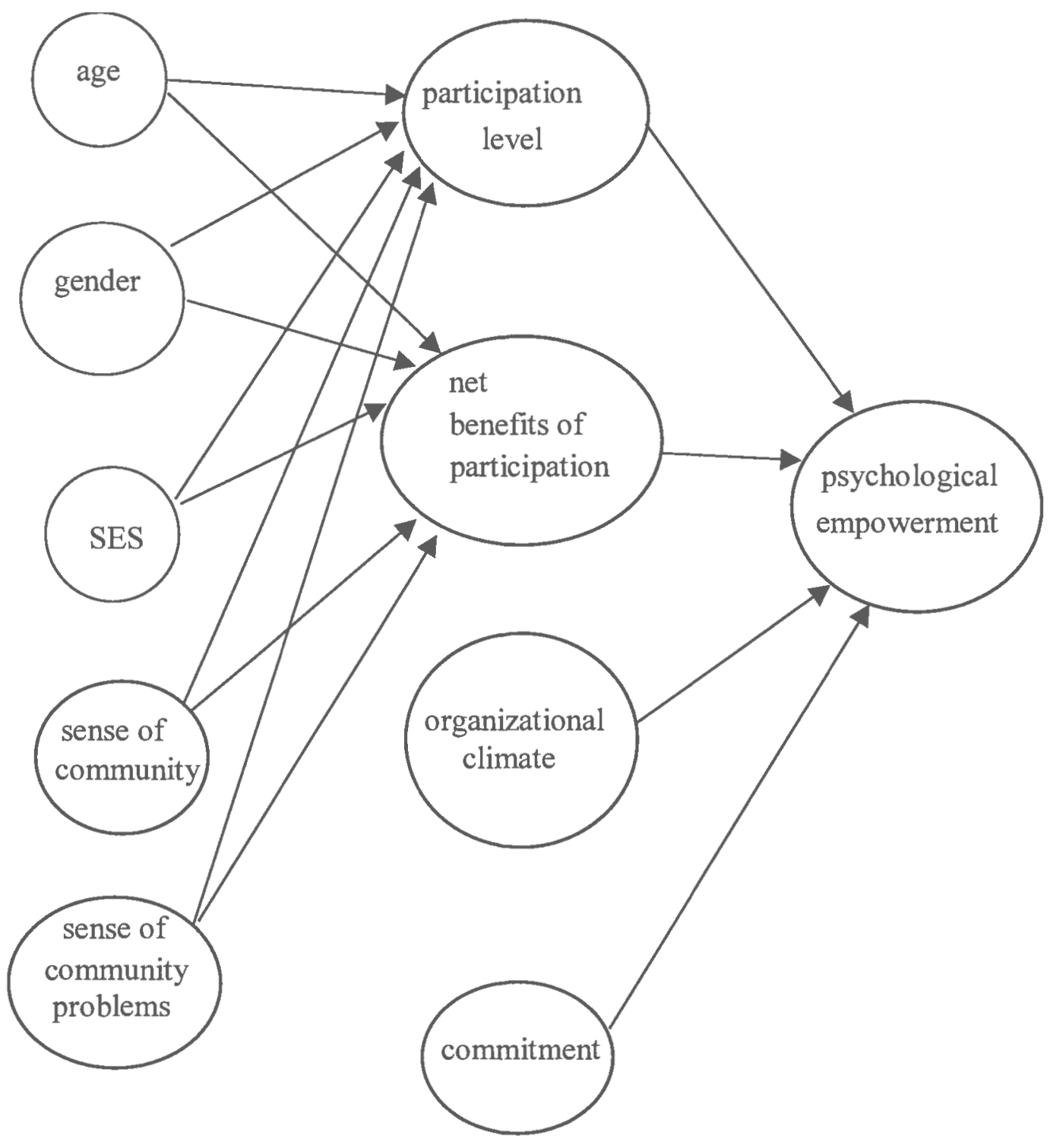


Model 3 (McMillan et al., 1995 Model)

This model is based upon the findings of McMillan et al. (1995) which showed that community perceptions and attitudes, participation, and social climate/organizational variables all had a direct positive effect on individual-level empowerment while having no significant effects of demographic variables. By way of comparison, Model 1-with demographics examined —is actually a test of the initial model examined in McMillan et al., while Model 3 is a test of the final results obtained in that study. This model also differs from Model 2 in that community variables are seen as directly correlated with empowerment rather than indirectly through participation. As such, the following hypotheses are proposed for Model 3 (see Figure 10):

1) It is predicted that community variables (Sense of Community and Sense of Community Problems) will be correlated with each other, participation variables (Participation Level and Net Benefits of Participation), and organizational variables (Organizational Climate and Commitment), as well as having a direct positive effect on individual-level empowerment.

2) It is predicted that Participation Level and Net Benefits of Participation will be correlated with each other, the community variables, and the organizational variables, as well as having a direct positive effect on individual-level empowerment.

3) It is predicted that Organizational Climate and Commitment will be correlated with each other, the community variables, and the participation variables, as well as having a direct positive effect on individual-level empowerment. 
Figure 10: Model \#3

McMillan et al., 1995 Model

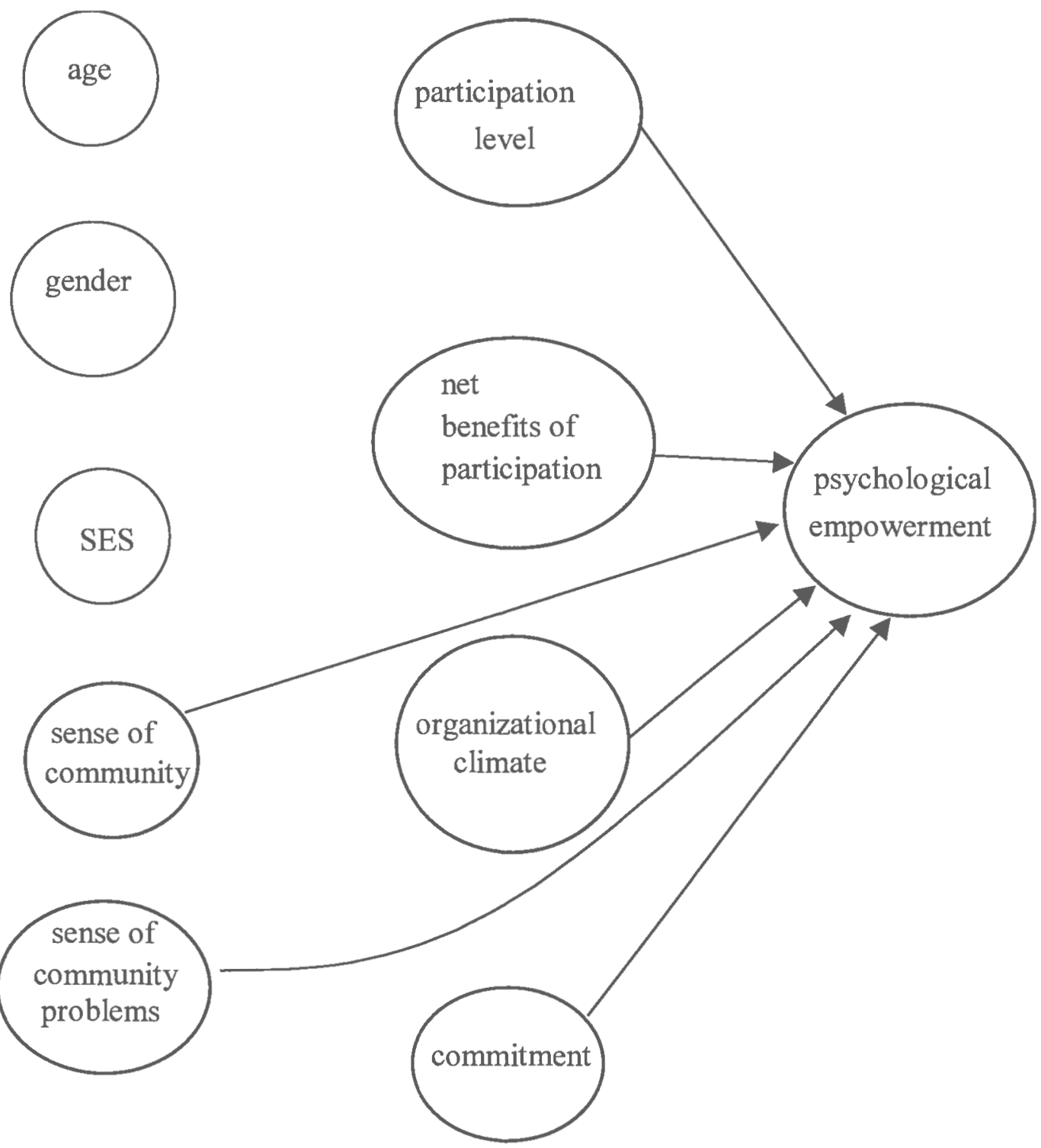




\section{Methods}

\section{$\underline{\text { Setting and Context }}$}

Data utilized in this study were collected as part of an independent evaluation of the Consortium for Community Initiatives (CCI). The CCI grant is a five-year project utilizing thirty-five community coalitions (called task forces in Rhode Island) established under the Rhode Island Substance Abuse Prevention Act (RISAPA) in 1989. RISAPA authorized each community in the state to create a broad-based AOD prevention task force to plan and implement comprehensive prevention programs. Each of these task forces was given the job of tailoring its efforts to the unique, multiple risk factors present in its respective community (identifying and addressing factors contributing to AOD problems using multiple implementation strategies is emphasized rather than any single, uniform intervention model). In order to carry this out, task forces members were drawn from various sectors of the community. In addition to the guidelines established under RISAPA, CCI's specific foci are on expanding the base of citizen involvement, enhancing the leadership pool, expanding the information and resource base by distributing AOD prevention information and establishing legislative monitoring, policy advocacy and focused programming.

The evaluation component of CCI was authorized by the Center for Substance Abuse Prevention (CSAP) and is being carried out by the Community Research and Services Team at the Center for Alcohol and Addiction Studies of Brown University, in collaboration with personnel from the University of Rhode Island. The evaluation uses a multi-method research design. This includes: a mailed survey to all task force members, 
face to face interviews with task force leaders and telephone interviews with key informants in the community. Many of the same instruments used in the earlier RISAPA evaluation were carried over in the CCI project, including the task force member survey, which this study analyzes.

\section{$\underline{\text { Instrument }}$}

The instrument employed for the purposes of this study was the CCI Task Force Member Survey. This survey was initially developed for the process and implementation evaluation of RISAPA and was expanded with additional items in the Consortium for Community Initiatives grant. The survey contains 122 items, which address demographics, participation, social climate in the community and in the task force, outcome expectancies, attitudes, skills, beliefs, networking, and many other issues and constructs. The data utilized in this study were drawn from the 1994 administration of this survey to all the members of the thirty-five community task forces in Rhode Island.

\section{$\underline{\text { Subjects }}$}

The CCI member survey was sent to the 830 current members of the thirty-five community task forces across the state of Rhode Island. 350 current members responded to the survey for an approximate response rate of $41 \%$. Of the subjects who responded to the member survey, $38 \%$ were male and $62 \%$ female. Their ages ranged from fifteen to seventy-six years old, with the majority of respondents $(78 \%)$ falling within the ages of thirty to fifty. Fifty-nine percent of those surveyed had been on their current task force between one and three years. Highest level of education attained ranged from high school 
to some post-doctoral work. Most respondents (84\%), however, had received anywhere from high school diplomas to Master's degrees. Forty-seven percent of those surveyed, however, had achieved a Master's degree or higher. Ninety-three percent of those surveyed described themselves as Caucasian, $05 \%$ as African-American, $01 \%$ as AsianAmerican, 01\% Hispanic/Latino, 01\% American Indian and 01\% were classified as other. Seventy percent were married, $13 \%$ single, $11 \%$ divorced, and $6 \%$ were classified as other (widowed, separated, or living with a romantic partner). Most people surveyed had an annual income between $\$ 30,000$ and $\$ 80,000$. Finally, $72 \%$ worked full-time, $16 \%$ part-time, $01 \%$ were unemployed and $04 \%$ were retired. For a more specific breakdown, please refer to Appendix B.

\section{Choice of Variables}

Individual variables from the CCI member survey that were used in the current study, along with any psychometric information pertaining to these variables, can be found in Appendix C. Specific scale items and response formats for each variable are highlighted in Appendix D.

The dependent variable in this study, individual-level empowerment, is composed of the following five scales drawn from earlier studies as mentioned above, and which also held together in a principal components analysis in a prior study (McMillan et al., 1995):

a) Perceived Participatory Competence: a 6-item scale (alpha coefficient .76 (CRST, 1992)) where respondents rated their level of agreement, on a scale from 1 (strongly disagree) to 5 (strongly agree), with statements about their skills. The statements included both those about generic participation skills (e.g., "I find it hard to speak up at Task Force meetings"; "I can organize people in the Task Force to get things 
done") and skills directly related to Alcohol and Other Drug Prevention (e.g., "I can contribute expertise in the implementation of Alcohol and Other Drug Abuse prevention programs to the group").

b) Perceived Knowledge and Skill Development: a 7-item scale (alpha coefficient .91) that asked participants to rate, on a scale from 1 (no change) to 4 (major increase), the extent to which they felt participating in the Task Force had changed their knowledge (e.g., "Knowledge of risk and protective factors related to Alcohol and Other Drug Abuse"), their beliefs (e.g., "Belief that prevention of Alcohol and Other Drug Problems is possible"), and their skills (e.g., "Skills in conducting a community planning/problemsolving process").

c) Expectancies for Future Group/Organizational Successes: this scale (alpha coefficient .85) asked respondents to rate, on a scale from 1 (very unlikely) to 5 (very likely), the likelihood of five different potential task force accomplishments. Potential Task Force accomplishments included both general (e.g., "The Task Force will continue to expand and strengthen AODA prevention activities in the community") and specific statements (e.g., "The Task Force will increase its resources for prevention programming in this community").

d) Perceived Organizational/Group Influences: a 7-item scale (alpha coefficient .89) where respondents rated, on a scale from 1 (strongly disagree) to 5 (strongly agree), the extent to which they felt their Task Force had produced a variety of effects in their community. Community effects included general ones (e.g., "Increased community-wide awareness of Alcohol and other Drug Abuse"), effects on services (e.g., "Helped organizations working for prevention to increase their joint influence over community decisions"), and long-range impacts (e.g., "Increased the chance that children and youth will avoid developing Alcohol and Other Drug problems").

e) Expectancies for Future Individual Contributions: a 4-item scale (alpha coefficient .79) asked participants to rate, on a scale from 1 (very unlikely) to 5 (very likely), the likelihood that they would engage in each of four different kinds of activities as a member of their community Task Force over the next twelve months. The items included personal participation (e.g., "I will devote time outside of meetings to the Task Force"), as well as intentions to personally produce outcomes in one's own organization (e.g., "I will influence my group or organization to devote resources to increase community Alcohol and other Drug Abuse prevention activities").

The first group of independent variables examined in this study consist of traditional demographic variables which have been linked empirically and theoretically to empowerment and the other predictor variables. As mentioned above, these variables 
have been shown to mimic or confound empowerment effects and level of participation (Chavis \& Wandersman, 1990; Clark, 1989; Florin \& Wandersman, 1984; Gruber \& Trickett, 1987; Serrano-Garcia, 1984; Zimmerman et al., 1992; Zimmerman \& Rappaport, 1988). Variables in this first "set" of independent variables include: age, gender, and SES (education and income, specifically). Other demographic factors (e.g., home ownership, educational level, marital status, and employment) were discarded as possible variables in this study because of the lack of evidence supporting their link to empowerment (McMillan et al., 1995; Zimmerman, 1990b; Zimmerman et al., 1992; Zimmerman \& Rappaport, 1998). The sole demographic variable surveyed in this study that was left out of the proposed structural equation models was ethnicity (which has been examined in previous studies) (Zimmerman, 1990b; Zimmerman et al., 1992;

Zimmerman \& Rappaport, 1998). This demographic characteristic was discarded as a possible variable due to its relatively low variance and inability to discriminate $(93 \%$ of those surveyed were of Caucasian origin). Gender was measured dichotomously (with females coded as 1 and males coded as 2), SES was measured using a set of possible categorical responses (low, medium, and high), and age was tabulated.

The second group of independent variables included community perceptions and attitudes. Based on the results of earlier studies as mentioned above, and the results of the principal components analysis in McMillan et al., 1995, the following scales are proposed:

a) Sense of Community: a 5-item scale (alpha .84) where respondents rated their level of agreement, on a scale from 1 (strongly disagree) to 5 (strongly agree), with statements about their feelings about the community. Items assessed feelings of connectedness (e.g., "A place I 'feel at home' in"), support (e.g., "A place where people 
help each other out"), and collective problem-solving (e.g., "A place where people work together to solve community problems").

b) Sense of Community Problems: an 11-item scale (alpha .89) where participants rated, on a scale from 1 (not a problem) to 5 (very great problem), the extent of severity of different kinds of problems in their community. Problems included AOD problems (e.g., "Drug Abuse", "Drunken Driving"), problems often occurring with AOD problems (e.g., "Family violence/child abuse", "School drop out"), and problematic community conditions (e.g., "Inadequate social services", "Lack of recreational opportunities"). In addition, the use of an "other" category allowed respondents to supply and rate a specific problem not mentioned.

Participation variables will also be examined in the context of this study.

Participation has the most reliable empirical support for its relationship with empowerment in the research literature (Florin \& Wandersman, 1990; McMillan et al., 1995; Zimmerman, 1990a; Zimmerman et al., 1992; Zimmerman \& Rappaport, 1988). Participation variables utilized in this study were drawn from the research literature, and analyzed in McMillan et al., 1995. In that study, hours of participation and kinds of participation roles formed one factor (called Participation Level) in a principal components analysis. In addition, costs and benefits of participation formed another factor (called Net Benefits of Participation). For the purposes of this study, these scales are based upon the results of the principal components analysis:

a) Level of Participation: respondents were asked what kinds of roles they play in the Task Force. They responded "yes" or "no" to nine different roles which included general participatory roles (e.g., "serve as a member of a committee") to structural leadership roles (e.g., "chair a committee", "chair the entire task force"). The variable was created by summing the number of "yes" responses across the nine different roles.

b) Benefits of Participation: a 6-item scale (alpha .84) where respondents rated, on a scale from 1 (very much a benefit) to 4 (not at all a benefit), the extent to which their participation produced personal (e.g., "Gain personal recognition and respect from others") and social (e.g., "Fulfills a sense of responsibility to contribute to the community") benefits. Scale scores were reversed for the purposes of analysis. 
c) Costs of Participation: a 7-item scale (alpha .71) that asked respondents to indicate, on a scale from 1 (very much a difficulty) to 4 (not at all a difficulty), how much their participation produced either personal difficulties (e.g., "Demands too much of my personal time") or difficulties directly related to Task Force functioning (e.g., "Feeling that the Task Force never gets anything done").

d) Hours of Participation in the Average Month: respondents were asked to estimate the number of hours they devoted "in an average month" to each of four different kinds of participation activities. A measure of participation in an average month was created by summing across respondents' reports of the number of hours devoted to hours of subcommittee work, hours spent on activities, and hours devoted to other areas.

The final set of independent variables to be examined consists of social climate/organizational variables. Like the participation variables mentioned above, variables in this set were also drawn from earlier studies and combined based upon the results of a prior principal components analysis (McMillan et al., 1995). Task focus, cohesion, and satisfaction held together on one factor (called Organizational Climate), while Commitment stood on its own. This study will examine these variables in this same manner for all analyses:

a) Task Force Cohesion: a 5-item scale (alpha coefficient .85) where participants rated their level of agreement, on a scale from 1 (strongly disagree) to 5 (strongly agree), with statements about member involvement (e.g., "Everyone is involved in discussions, not just a few") and inclusion (e.g., "The Task Force uses the abilities of all, not just a few") in Task Force operations.

b) Task Focus: a 5-item scale (alpha .84) where respondents rated their level of agreement, on a scale from 1 (strongly disagree) to 5 (strongly agree), with statements about order (e.g., "The Task Force was disorganized and inefficient") and organization (e.g., "The group needs more formalization and structure") in the Task Force.

c) Satisfaction With the Task Force: Respondents rated their level of satisfaction, on a scale from 1 (very dissatisfied) to 5 (very satisfied), on four different aspects of the Task Force (e.g., "The programs proposed to meet objectives"). The four items formed a highly cohesive scale (alpha .90).

d) Commitment to the Task Force: a 4-item scale (alpha .86) which asked participants to rate their level of agreement, from 1 (strongly disagree) to 5 (strongly 
agree), with statements of pride in (e.g., "I feel a strong sense of pride in Task Force accomplishments") and commitment to the organization (e.g., "I really care about the future of this Task Force").

\section{$\underline{\text { Analysis }}$}

This study analyzed data in two stages. Descriptive statistics were calculated for all final measures, including: means, standard deviations, ranges, and internal consistencies where appropriate. The data set examined in this study was previously cleaned up for use in a prior study (McMillan et al., 1995). Part of that process included discarding individual variables if more than one individual item of any given variable were missing. In addition, if more than two variables in any given "set" were missing, then that individual's score was discarded. The variable mean was substituted in those cases were there were less than two variables missing. Out of the 830 current task force members available at the start of this study, 350 returned surveys and 284 were retained for analysis. After discarding missing cases, all variables were transformed to Z-scores in order to minimize skewness and kurtosis. Principal Components Analyses of all independent variables and the empowerment variable used in this study were also performed in McMillan et al., 1995-the results of the PCAs are provided in Appendix E.

In the next stage of data analysis, an inclusive, full-scale structural equation model of all factors examined in McMillan et al., 1995, was performed (see Figure 8). Further analysis of structural equation models with competing, nested path diagrams were then conducted as presented in Figures 9-10. Guidelines for running and evaluating structural equation models are provided briefly below. 
In structural equation modeling, covariances among variables-according to the theoretically guided underlying constructs—are compared with the observed matrix of covariance among the measured variables. When a predicted matrix approximates the covariance matrix of the observed data, the model is said to "fit." Models demonstrate two main types of fit: overall fit and the local fit of individual parameters. Overall fit is evaluated by how well it explained all of the data in the entire analysis. Local fit is determined by examining how parameters that are free for estimation (i.e., not constrained at zero) may have achieved statistical significance within the model. The measurement model presents standardized factor loadings of the measured variables on the latent factors. These loadings may be interpreted as the degree to which the observed variables adequately measure the underlying construct. Error terms associated with each measured variable represent the proportion of unique variance in the measure that is not explained by the underlying latent construct (Bentler, 1993; Bollen \& Long, 1993; Byrne, 1994).

Overall model fit requires consideration of several indicators. Bollen and Long (1992) argue that the first guide to measuring the adequacy of particular models is strong substantive theory. Empirically, model fit is evaluated with several criteria, including: chi-square (which should be low relative to degrees of freedom), comparative fit index (CFI: Bentler, 1993; which should be close to 1.0), and average absolute standardized residuals (AASR: Bentler, 1993; which should be close to zero). Of all of these indicators, however, the chi-square benchmark has been questioned by some researchers as it will almost always achieve statistical significance as sample size and degrees of 
freedom increase. Therefore, it has been suggested that the ratio of chi-square to degrees of freedom be examined as a alternative realistic indicator of fit when sample sizes and/or degrees of freedom are large (with a ratio of 5:1 to 2:1 considered to be within the acceptable range) (Tanaka, 1993). Local model fit focuses on parameter significance, direction, and magnitude. The main test of parameter significance is a z-test for individual paths (which should be $>1.96$ at the .05 level of significance). Additional support regarding local fit is indicated when significant paths are found to be in the hypothesized direction, and the magnitude of the item loadings is greater than .45. All of the above guidelines were followed, and the SEM analyses were conducted using the EQS computer package (Bentler, 1995).

\section{Results}

\section{Inclusive Model of Direct Effects Analysis}

The analysis of the Inclusive Model of Direct Effects yielded results that did not support an initial adequate fit of the model to the data. While the average absolute standardized residuals were below .06 which is within the acceptable range for goodfitting structural equation models (AASR=.042), the overall Chi-square was high relative to degrees of freedom $\left(\chi^{2}=217.677, \mathrm{df}=67 ; \mathrm{p}<.05\right)$. In addition, other specific fit indicators were substandard. The model's comparative fit index $(\mathrm{CFI}=.88)$ did not achieve the recommended level to offset the chi-square results (CFI should be greater than .90 in order to make a strong argument for disregarding the chi-square result). The normed fit and nonnormed fit indices were also only marginal indicators of good overall fit $(\mathrm{NFI}=.84 ; \mathrm{NNFI}=.81)$. As per exploratory data analysis in $\mathrm{SEM}$, some parameter 
estimates were adjusted or dropped post-hoc according to the results of the LaGrange Multiplier Test and the Wald Test which are both designed to test model restrictions and parameter estimations (Bentler, 1995; Bollen and Long, 1993; Byrne, 1994). An overview of these adjustments can be found in Appendix F. In the final analysis, Commitment was dropped from the Inclusive Model of Direct Effects due to its poor model fit (see the McMillan et al., 1995 Model below for further explanation of this change). Final parameter estimates showed no significant pathways for the Demographic variables and the Net Benefits of Participation. Sense of Community, Participation Level, Sense of Community Problems, and Organizational Climate, however, did show significant correlations with the Empowerment variable. The results of the final post-hoc individual parameter adjustments are presented in Tables 1 and 2. While these results were encouraging, some alterations were made to the initial structural equation model (see Figures 11 and 12). Limitations of this sort of post-hoc adjustment are discussed in the discussion section below. 
TABLE 1: Measurement Equations, Standard Errors, $Z$ statistics and Significance Levels: Model of Direct Effects $(\mathbf{N}=\mathbf{2 8 4})$

\begin{tabular}{lllll}
\hline Variable Name & Loading & $\begin{array}{l}\text { Standardized } \\
\text { Error }\end{array}$ & $\mathbf{Z}$ \\
\hline
\end{tabular}

Factor 1: Empowerment

Participatory Competence .581

.075

7.773

.075

7.498

Knowledge and Skill Dev. .562

1.000

Future Org Successes

.070

13.121

.073

10.267

Future Ind. Contributions

.745

07

\section{Factor 2: Participation}

Level

Level of Participation $\quad 1.000$

Hrs Worked in Avg

.329

4.244

Month

Factor 3: Net Benefits of Participation

Benefits of Participation

Costs of Participation

1.000

Factor 4: Organizational

\section{Climate}

Task Force Cohesion

1.000

Task Focus

.875

.052

16.974

Satisfaction with TF

.916

.051

18.066

${ }^{*} \mathrm{p}<.05$ Chi-Square $=217.677(\mathrm{df}=67)$ 


\begin{tabular}{lllll} 
Variable Name & $\begin{array}{l}\text { Standardized } \\
\text { Loading }\end{array}$ & $\begin{array}{l}\text { Measurement } \\
\text { Error (E) }\end{array}$ & $\mathbf{E}^{2}$ & $\mathbf{P}$ \\
\hline
\end{tabular}

\section{Factor 1: Empowerment \\ Participatory Competence $\quad .473$}

.881

.78

Knowledge and Skill Dev. $\quad .458$

.889

.79

Future Org Successes

.815

.580

.34

Perceived Org Influences $\quad .747$

.664

.44

Future Ind. Contributions $\quad .607$

.795

Factor 2: Participation

Level

Level of Participation

.427

.904

.82

Hrs Worked in Avg

.597

.802

.64

Month

Factor 3: Net Benefits of

Participation

Benefits of Participation $\quad .785$

.620

.38

Costs of Participation

.495

.869

.76

Factor 4: Organizational

Climate

Task Force Cohesion

.908

.418

Task Focus

.795

.606

Satisfaction with TF

.832

.554

.31

${ }^{*} \mathrm{p}<.05$ Chi-Square $=217.677(\mathrm{df}=67)$ 


\section{Figure 11: Standard Solution for Inclusive Model of Direct Effects Latent Constructs}
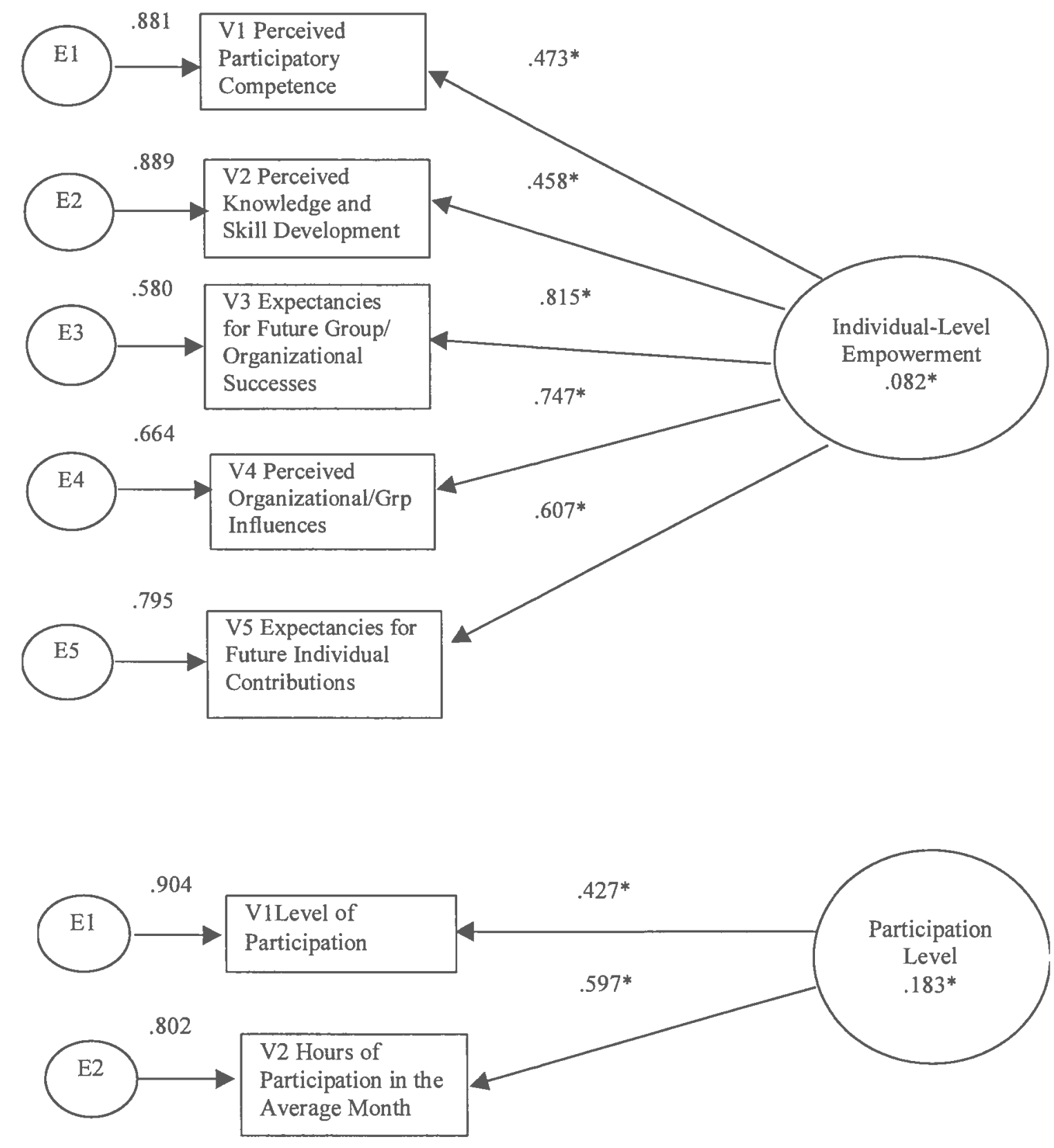

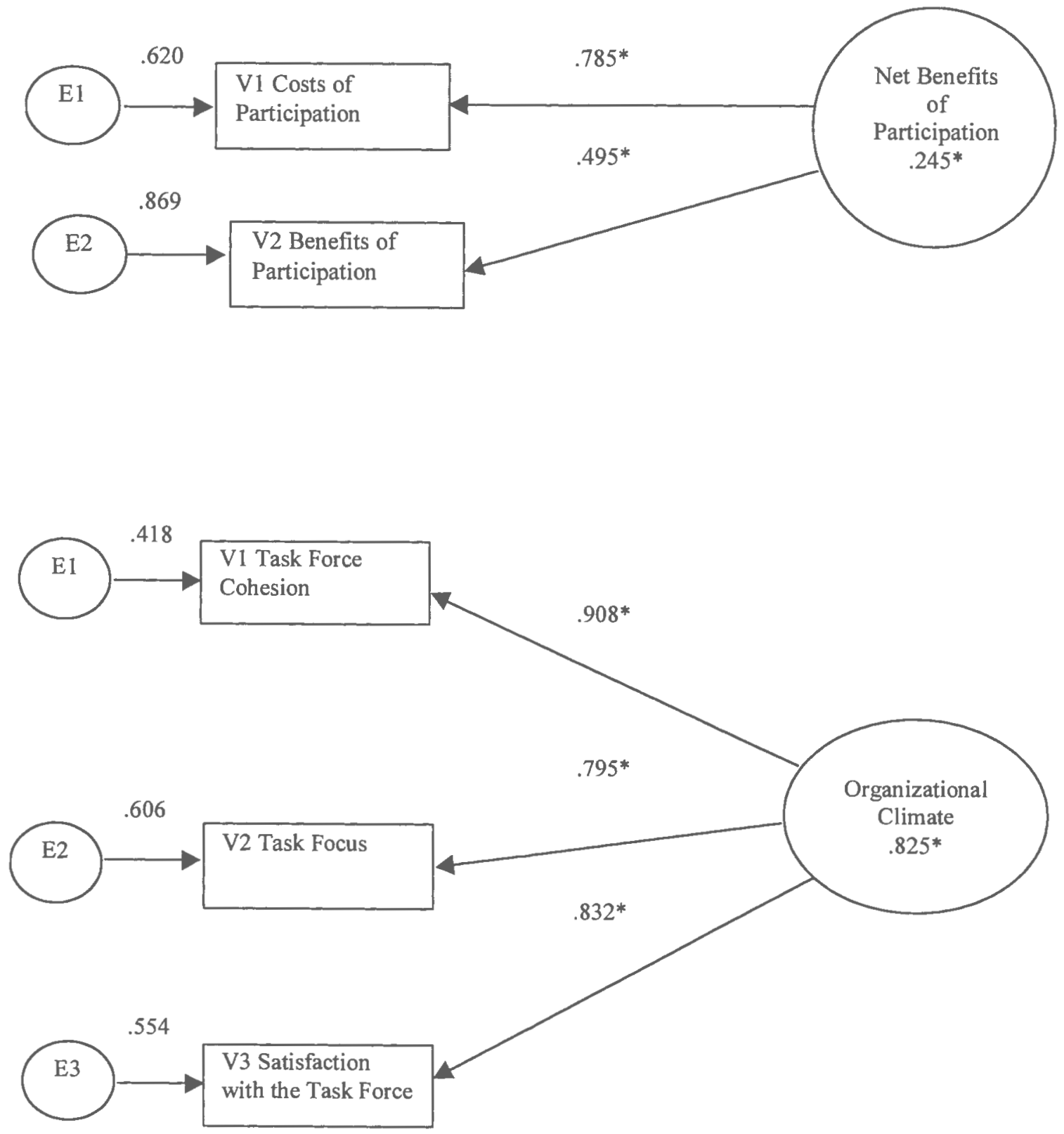

${ }^{*} \mathrm{p}<.05$ 


\section{Figure 12: Inclusive Model of Direct Effects SEM ${ }^{\mathrm{a}}$}

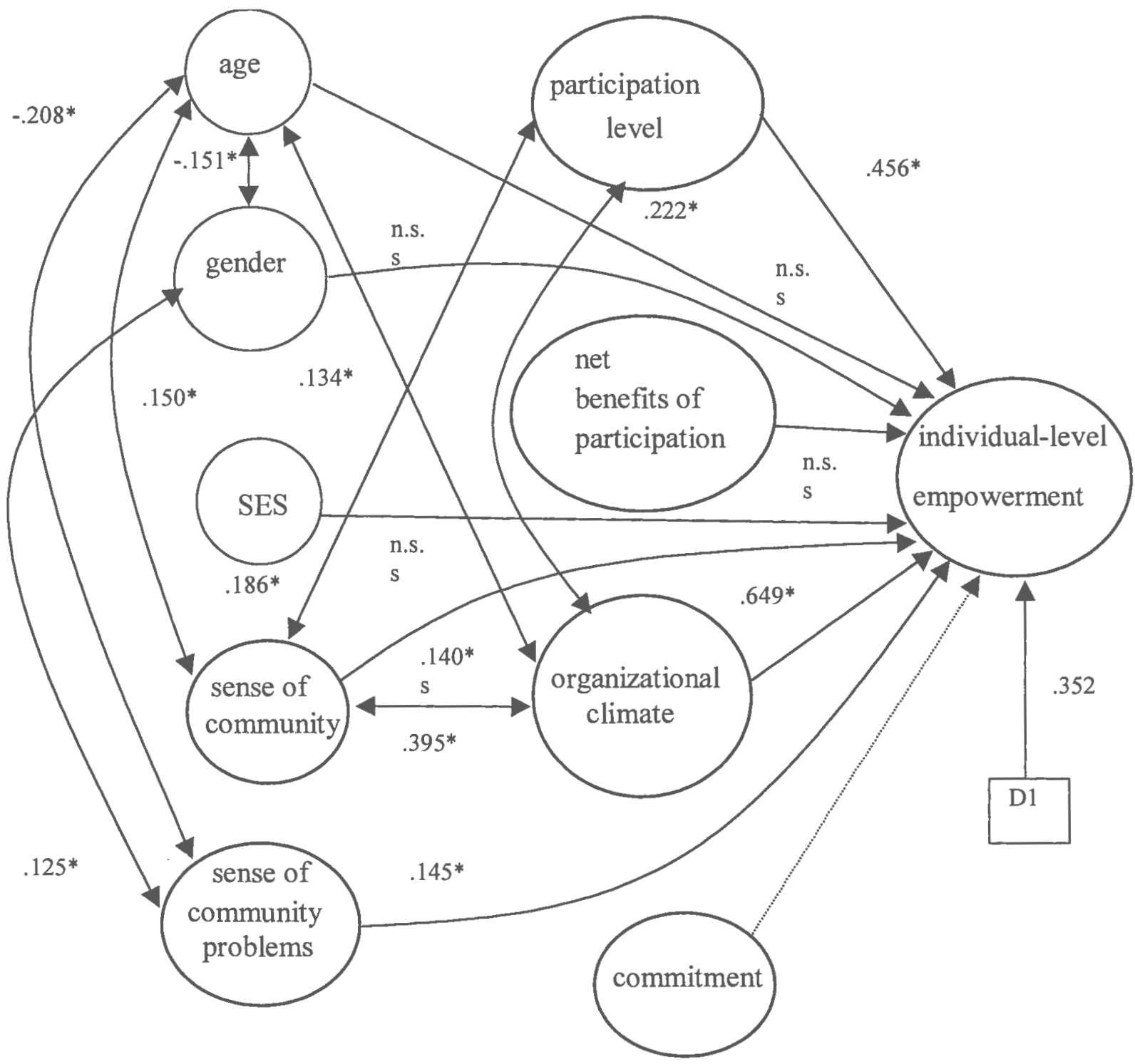

${ }^{a}$ All independent variables are covaried with each other, but only significant covariance pathways are noted in this figure. Dashed lines indicate dropped paths of the SEM.

${ }^{*} \mathbf{p}<.05$ 


\section{Zimmerman/Rappaport Model of Participation Effects}

The analysis of the alternative Model of Participation effects yielded results that were less satisfactory than the Inclusive Model of Direct Effects mentioned above. While the Inclusive Model of Direct Effects provided at least a marginal fit to the data, the Zimmerman/Rappaport Model of Participation Effects did not prove to be acceptable. The average absolute standardized residuals were above .06 which is outside the acceptable range for good-fitting structural equation models (AASR=.097), and the overall Chi-square was high relative to degrees of freedom $\left(\chi^{2}=328.133, \mathrm{df}=72 ; \mathrm{p}<.05\right)$. Other specific fit indicators also showed a lack of adequate model fit. The model's comparative fit index $(\mathrm{CFI}=.80)$ did not achieve the recommended level to offset the chisquare results, and the additional normed fit and nonnormed fit indices were equally as poor $(\mathrm{NFI}=.76 ; \mathrm{NNFI}=.71)$. While exploratory data analysis was conducted, adjustment of parameters in this model did not significantly alter the final SEM results (see Appendix F). The only significant alteration that helped the analysis was the removal of Commitment as an independent variable due to its collinearity with other independent variables. Since Commitment did not stand up in the SEM model, it was dropped from this analysis and the other competing structural equation models were also tested without Commitment as an independent variable. Final parameter estimates showed no significant pathways for the Demographic variables in relation to Participation Level, Net Benefits of Participation, or Empowerment. Sense of Community was significantly related to Net Benefits of Participation, but not Participation Level. Sense of Community Problems was the exact opposite-relating significantly to Participation Level but not to Net Benefits of 
Participation. Both participation factors as well as Organizational Climate were significantly related to Empowerment. The results of the individual parameter analyses are presented in Table 3 . While these results present some interesting possibilities, the overall model did not fit this particular data set and should not be interpreted. As mentioned above, further manipulations of the data set (i.e., the parameter adjustments mentioned above and in the next section) did not significantly alter the model fit, and-in some cases-made the overall fit worse. 
TABLE 3: Measurement Equations, Standard Errors, $Z$ statistics and Significance Levels: Participation Model ( $\mathbf{N}=\mathbf{2 8 4})$

\begin{tabular}{lllll} 
Variable Name & Loading & $\begin{array}{l}\text { Standardized } \\
\text { Error }\end{array}$ & $\mathrm{Z}$ & $\mathbf{P}$ \\
\hline
\end{tabular}

Factor 1: Empowerment

Participatory Competence $\quad .563$

.095

5.909

.091

$6.627 \quad *$

Knowledge and Skill Dev. .606

1.000

Future Org Successes

1.002

.093

10.829

Perceived Org Influences$$
10.829
$$

Factor 2: Participation

Level

Level of Participation $\quad 1.000$

Hrs Worked in Avg $\quad .659$

.225

2.922

Month

Factor 3: Net Benefits of

Participation

Benefits of Participation

1.127

.180

6.267

Costs of Participation

1.000

\section{Factor 4: Organizational}

\section{Climate}

Task Force Cohesion

Task Focus

.866

.054

16.158

Satisfaction with TF

.926

.052

17.805

${ }^{*} \mathrm{p}<.05$ Chi-Square $=328.133(\mathrm{df}=72)$

AASR: 097 CFI: .80 


\section{McMillan et al., 1995 Model}

The analysis of the McMillan et al., 1995 Model provided the best overall model fit of all three proposed models. While some parameter adjustments were made as part of the exploratory data analysis (see Appendix F), the initial run of this model was still noticeably better than the two mentioned above. Three parameter adjustments were made to the final measurement model in order to eliminate some error and improve overall model fit. Commitment did not stand up in the SEM model and was dropped from the analysis. The "Expectancies for Future Individual Contributions" variable was dropped from the analysis due to its high correlation with Participation Level, Empowerment, and Organizational Climate. Finally, the Net Benefits of Participation factor ended up not holding up internally (poor individual parameter fit with its contributing variables) and also correlated significantly with Organizational Climate. This finding was also noted in the two models outlined above, but adjustments did not significantly alter the results of the above-mentioned models. Due to this result, this factor was folded into the Organizational Climate factor in this model (Benefits of Participation was discarded due to its correlation with several factors, and Costs of Participation was incorporated into the Organizational Climate factor). These changes were made on the basis of underlying theoretical issues related to individual-level empowerment and the current state of the literature regarding this construct and its relationship to these independent variables (see Discussion below). These changes increased the model's overall fit (CFI improved, AASR went down, Perceived Knowledge and Skill Development achieved significance on the Empowerment factor, and Sense of Community Problems achieved significance). 
It should be noted, however, that these were exploratory investigations with multiple runs through the data set with no correction for the error rate and no validation on an independent sample. Thus, conclusions drawn from these analyses must be interpreted with caution. In the final analysis, the average absolute standardized residuals were below .06 which is within the acceptable range for good-fitting structural equation models (AASR=.041). The overall Chi-square was high relative to degrees of freedom $\left(\chi^{2}=113.976, d f=47 ; \mathfrak{p}<.05\right)$, but this was lower than the previous two models and other specific fit indicators also showed a very good model fit. The model's comparative fit index $(\mathrm{CFI}=.94)$ exceeded the recommended level to offset the chi-square results, and the additional normed fit and nonnormed fit indices were also high (NFI=.91; NNFI=.92). Finally, the ratio of the chi-square statistic to the degrees of freedom was just slightly under 2.5:1 which is well within the range indicating adequate model fit (Tanaka, 1993). Final individual parameter estimates showed significant pathways for the Sense of Community, Sense of Community Problems, Participation Level, and Organizational Climate factors in relation to the Empowerment factor. All variables hypothesized to be significantly related to each factor were found to be significant and in the proposed directions. Taken together, the independent latent constructs accounted for $90 \%$ of the variance of the empowerment latent construct-this is slightly higher than the variance accounted for by any of the other two models (the Inclusive Model of Direct Effects accounted for $88 \%$ ). The results of the individual parameter analyses are presented in Tables 4 and 5 and the full structural equation model is presented in Figures 13 and 14 . 
As above, the steps taken during the post-hoc exploratory analyses are presented in Appendix F. 
TABLE 4: Measurement Equations, Standard Errors, $Z$ statistics and Significance Levels: McMillan Model $(\mathrm{N}=\mathbf{2 8 4})$

\begin{tabular}{llll} 
Variable Name & Loading & $\begin{array}{l}\text { Standardized } \\
\text { Error }\end{array}$ & Z \\
\hline
\end{tabular}

Factor 1: Empowerment

Participatory Competence

Knowledge and Skill Dev. $\quad .586$

.078

$7.196 *$

Future Org Successes $\quad 1.000$

Perceived Org Influences $\quad .979$

.075

$13.118 *$

Factor 2: Participation

Level

Level of Participation $\quad 1.000$

Hrs Worked in Avg $\quad .969$

.255

3.802

Month

Factor 4: Organizational

Climate

Task Force Cohesion $\quad 1.000$

Tas

Task Focus

.876

.051

$17.046 \quad *$

Satisfaction with TF

.921

.050

18.593

Costs of Participation

.733

.057

12.874

${ }^{*} \mathrm{p}<.05$ Chi-Square $=113.976(\mathrm{df}=42)$

AASR: .041

CFI: .94 


\begin{tabular}{lllll} 
Variable Name & $\begin{array}{l}\text { Standardized } \\
\text { Loading }\end{array}$ & $\begin{array}{l}\text { Measurement } \\
\text { Error (E) }\end{array}$ & $\mathbf{E}^{2}$ & $\mathbf{P}$ \\
\hline
\end{tabular}

\section{Factor 1: Empowerment}

Participatory Competence $\quad .45$

.896

.80

Knowledge and Skill Dev. .46

.887

.79

Future Org Successes

.79

.618

.38

Perceived Org Influences

.77

.638

.41

Factor 2: Participation

Level

Level of Participation

.858

.74

Hrs Worked in Avg

.50

.867

.75

Month

Factor 4: Organizational

Climate

Task Force Cohesion

.91

.425

.18

Task Focus

.79

.609

.37

.552

.30

Satisfaction with TF

.83

748

.56

Costs of Participation

.66

.748

*

${ }^{*} \mathrm{p}<.05$ Chi-Square $=113.976(\mathrm{df}=42) \quad$ AASR: $.041 \quad$ CFI: .94 


\section{Figure 13: Standard Solution for McMillan et al., 1995 Latent Constructs}
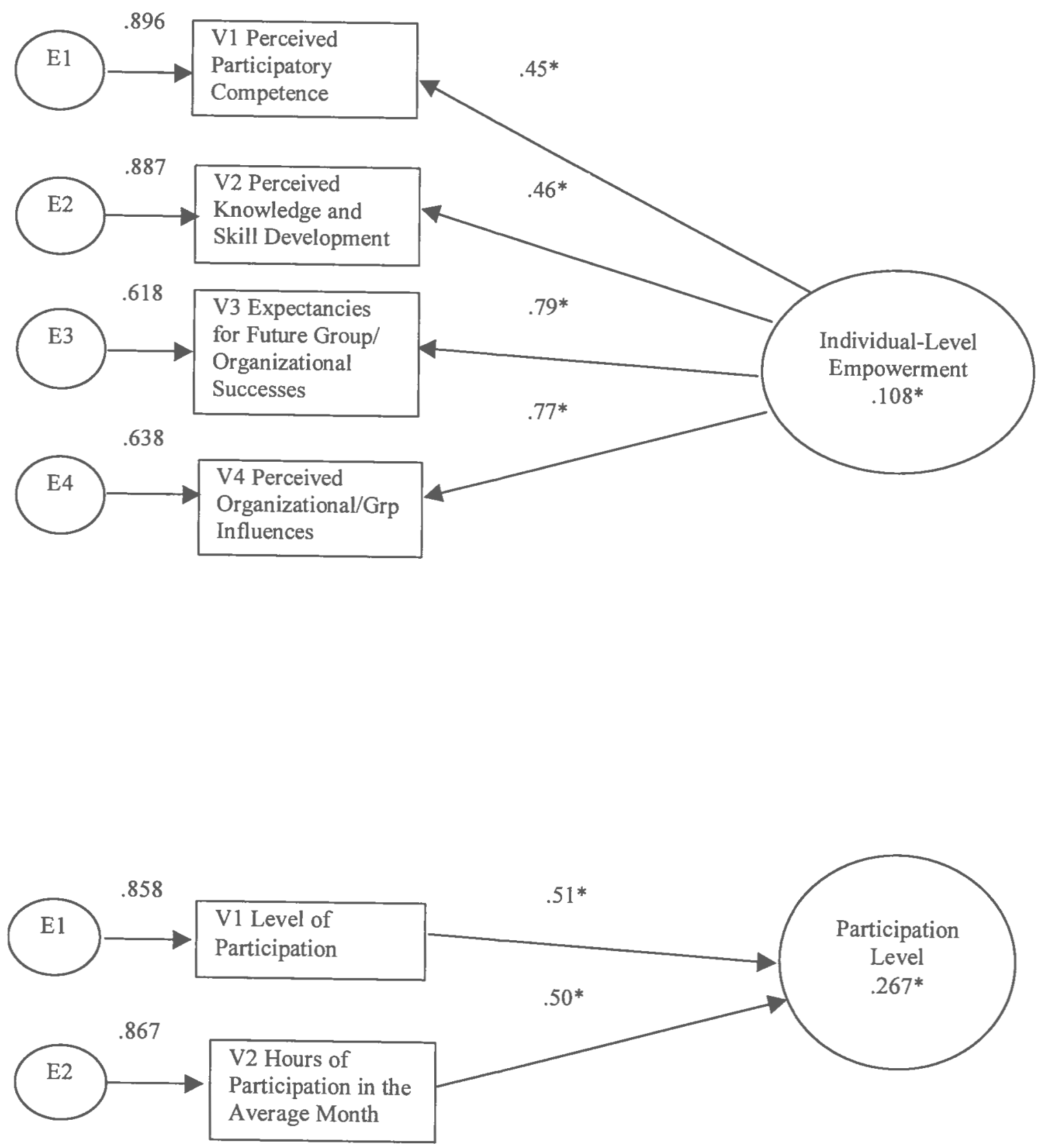


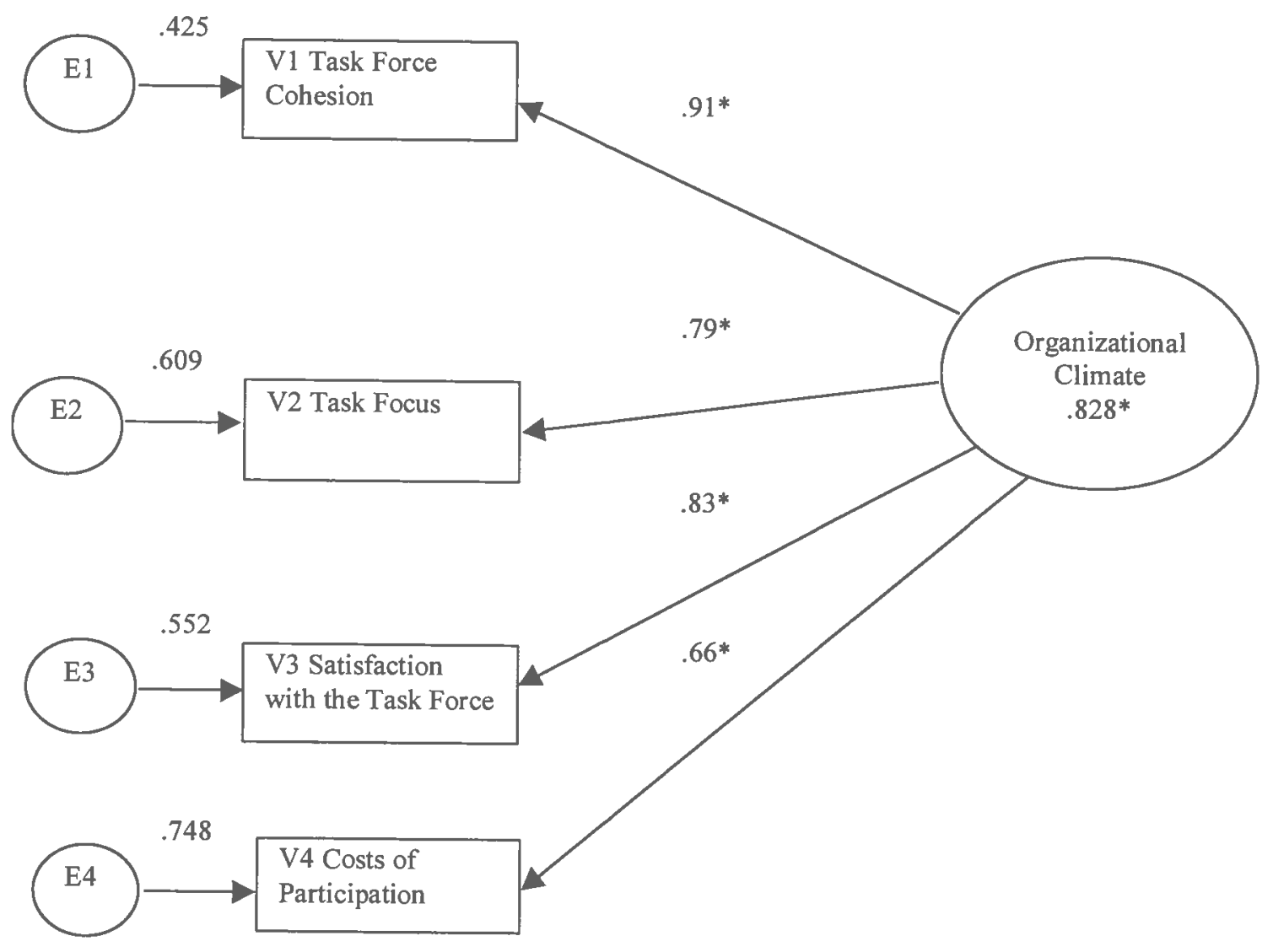

${ }^{*} \mathrm{p}<05$ 
Figure 14: McMillan et al., 1995 Final Structural Model

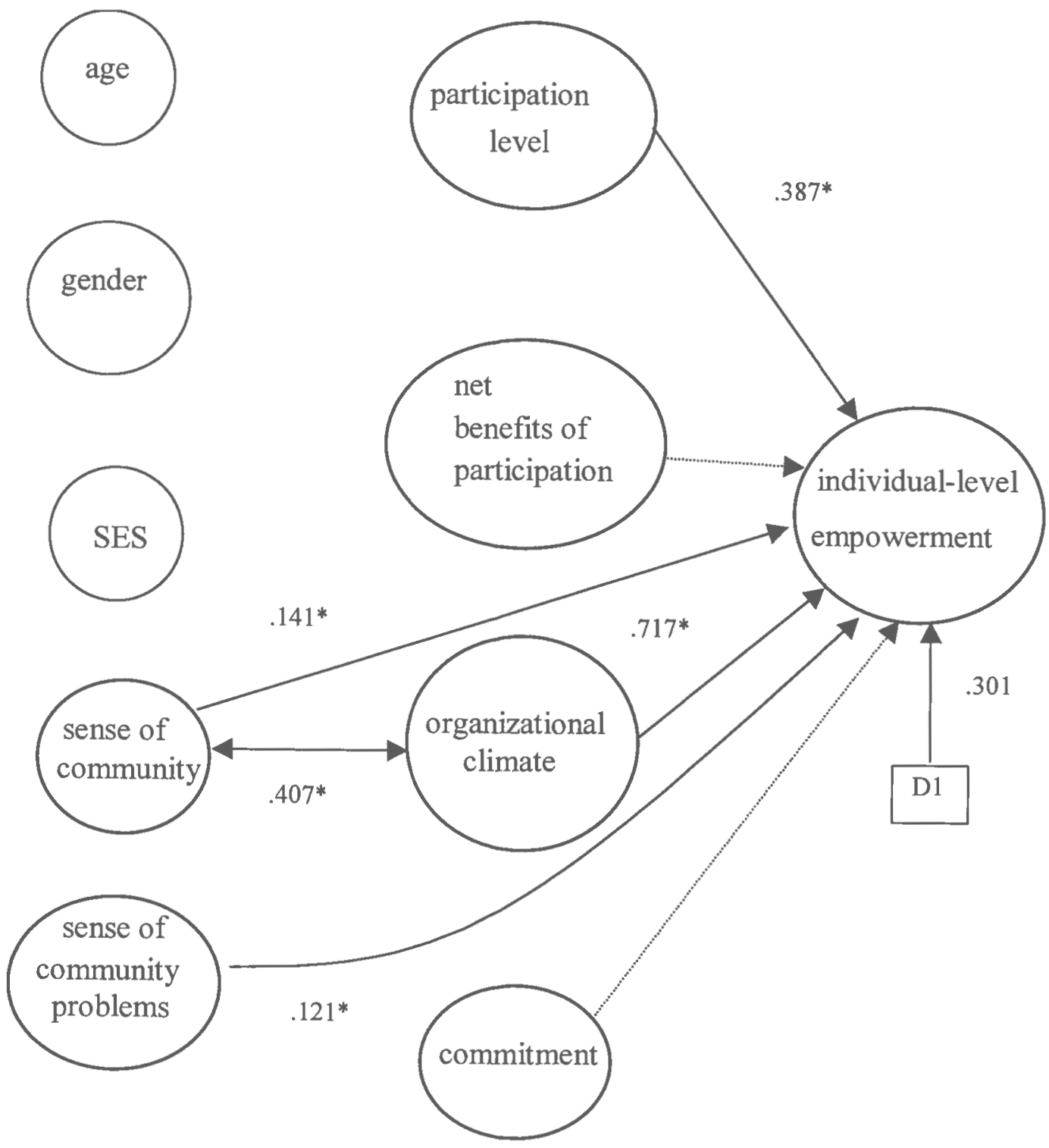

${ }^{*} \mathrm{p}<.05$ 


\section{Discussion}

\section{General Contributions and Implications}

The primary purpose of this investigation was to increase understanding of empowerment processes and to provide a further foundation to empowerment theory upon which to build empirical examinations of empowerment in practice. By providing alternate methodology and conceptualization of empowerment, this study hoped to help enable researchers to design alternate studies to measure the empowerment process, to evaluate how conditions in the community and in organizations foster or hinder empowerment, and to be able to provide technical assistance to foster individual and group empowerment (Florin, Mitchell \& Stevenson, 1993; Florin \& Wandersman, 1990; Kieffer, 1984; Rappaport, 1981; Wallerstein, 1992; Zimmerman, 1990a; Zimmerman, 1990b; Zimmerman \& Rappaport, 1988).

The results presented above support the hypothesis presented in McMillan et al., 1995, that individual-level empowerment is a higher-order construct influenced positively by sense of community, sense of community problems, participation, and organizational climate. Since many possible models may fit any particular data set in SEM, three competing models of empowerment effects were examined in this study to test the relationships of these variables to individual-level empowerment. All three models gave some evidence of supporting the effects of all of these independent variables, but the revised McMillan et al., 1995 Model of empowerment was a better fit for the data examined in this study. Given that the Inclusive Model and the revised McMillan et al. Model examine the same data set utilized in McMillan et al. (1995), it is not surprising 
that these two models prove to be good fits in this study. What is important, however, is that the basic model presented in McMillan et al. (1995) continues to prove viable even under scrutiny by a different (and somewhat more conservative) methodology.

For the Inclusive Model of Direct Effects, $85 \%$ of the hypotheses presented in relation to this model were found to be statistically accurate. For the Zimmerman \& Rappaport Participation Model, $0 \%$ of the hypotheses proved to be statistically significant since the overall model was not a proper fit to the data. The revised McMillan et al. Model mimicked the Inclusive Model in terms of hypothesis testing, but the McMillan et al. Model best fit the data examined. In all three models, Commitment did not prove to be significantly related to empowerment as an independent construct and its inclusion in the model inhibited the overall model fit (e.g., collinearity with other independent constructs). Since this factor was relatively weak in McMillan et al. (1995), and the construct's intercorrelations with the other independent variables in this study were fairly high, it may have caused this factor to fall below the threshold of significance. Dropping the construct from the analysis in follow-up exploratory analyses proved helpful. Future studies of commitment should look at strengthening the internal structure of the variable and doing what is possible to distinguish it from other related constructs (such as participation, sense of community, and organizational climate).

No demographic variables had a direct positive effect on individual-level empowerment in either the Inclusive Model of Direct Effects or the Zimmerman/Rappaport Model. This is consistent with several of the studies mentioned above where—although theoretically linked to empowerment—only a few studies have 
actually shown demographics to affect empowering outcomes (Chavis \& Wandersman, 1990; Clark, 1989; Florin \& Wandersman, 1984; Gruber \& Trickett, 1987; SerranoGarcia, 1984; Zimmerman, 1990b; Zimmerman et al., 1992; Zimmerman \& Rappaport, 1988). Thus, the results presented in this study are not necessarily disappointing, since prior studies had simply attempted to control demographic variables because of their direct relationship to empowerment outcomes (e.g., higher levels of SES being positively related to empowerment at the individual level of analysis) (Chavis \& Wandersman, 1990; Florin \& Wandersman, 1984; Gruber \& Trickett, 1987; Serrano-Garcia, 1984; Zimmerman et al., 1992; Zimmerman \& Rappaport, 1988). There are at least two potential explanations for the results found in this study. One possibility is that specific demographic characteristics themselves are neither necessary nor limiting conditions for the empowerment process. This is encouraging because it implies that empowerment is not severely restricted by demographic factors. A second, and more likely explanation, however, is that the demographic characteristics represented in this sample were fairly homogenous and it may have been the lack of diversity that led to the lack of any statistical significance (see limitations below).

In this study both sense of community and sense of community problems were found to be significantly related to empowerment, replicating results found in McMillan et al (1995). Higher levels of sense of community and sense of community problems were positively related to higher levels of individual-level empowerment. This is consistent with earlier studies of sense of community that show higher levels of this construct being related to positive feelings of empowerment (Chavis \& Wandersman, 1984; Florin \& 
Wandersman, 1990; Maton \& Rappaport, 1984). In addition to sense of community, perceptions of community problems was also positively related to empowerment (although this is a much weaker correlation). While this may seem counterintuitive, there is some evidence that a moderate level of perception of the severity of community problems is a motivator for action (Chavis \& Wandersman, 1990; Florin \& Wandersman, 1984). Some explanations for this relationship may be that an increase in perceptions of community problems is related to increased levels of certain aspects of individual-level empowerment (i.e., increased skills may make recognizing and rating problems more efficient, and perceptions of future participation may be influenced by how problematic the community is perceived to be, among other things). While several researchers have proposed an indirect link of community variables to empowerment through the effects of participation (Chavis \& Wandersman, 1990; Fawcett et al., 1995; Flynn, Ray, \& Rider, 1994; Merideth, 1994; Robinson \& Wilkinson, 1995; Sagy, Stern, \& Krakover, 1996; Stewart \& Weinstein, 1997), this study makes more of a case for the examination of a direct relationship between community variables and empowerment. This study provides support for the findings of other studies that make the argument that community variables are important in their own right (Cowen, 1991; Florin \& Wandersman, 1990; Heller, 1990; Maton \& Rappaport, 1984; Saegert \& Winkel, 1996; Wallerstein, 1992; Zimmerman, 1990a; Zimmerman, 1995).

Consistent with the findings of prior empowerment studies (Florin \& Wandersman, 1990; Zimmerman, 1990a; Zimmerman et al., 1992; Zimmerman \& Rappaport, 1988), Participation Level was found to be a positively correlated with 
Individual-Level Empowerment. In point of fact, participation variables in this study were very strongly correlated (.39), and accounted for $15 \%$ of empowerment's variance. This study thus gives further empirical support to prior studies that indicate a link between participation and empowerment. Even examined in a different context and with a different population of study than in prior studies, this relationship remains one of the strongest in the analyses of this study. Net Benefits of Participation, however, did not stand up well in the McMillan et al. Model, although this relationship was found in Inclusive Model of Direct Effects analysis. Research on the costs and benefits of participation is still a relatively new area (Chavis \& Wandersman, 1990; Lord et al., 1998; Prestby et al., 1990; Shefner-Rogers et al., 1998), so these conflicting results may indicate some poor specificity of the Net Benefits of Participation construct used in this study. Close examination of individual scale items used to make up the Net Benefits of Participation latent variable included items of both an individual and organizational nature. By separating out organizational and individual costs/benefits of participation in future studies, it may be possible to get a clearer understanding of how these variables relate to empowerment and the other independent variables examined in this study.

Organizational Climate was found to be the most highly correlated variable with individual-level empowerment. Organizational Climate (with the additional variables added from Net Benefits of Participation) was very strongly correlated (.72), and accounted for $51 \%$ of empowerment's variance. These findings confirm the relationship suggested by some researchers and outlined by others that organizational factors are related to empowerment levels (Clark, 1989; Florin \& Wandersman, 1984; Gruber \& 
Trickett, 1987; Kieffer, 1984; Riger, 1984; Serrano-Garcia, 1984; Swift \& Levin, 1987; Wallerstein, 1992; Zimmerman, 1990b; Zimmerman, in press; Zimmerman et al., 1992). In fact, the findings in this study appear to strongly suggest that certain group characteristics (such as satisfaction with the group, feelings of group cohesion and feeling that the group is task focused) are not only linked with empowerment but that organizational climate may indeed be a more salient factor associated with empowerment than participation. The costs of participation variable loaded highly on this factor in all three models (although it held together enough in the Inclusive Model of Direct Effects to justify keeping it in the Net Benefits of Participation latent construct) -this finding was unexpected, but it does make some logical sense since many of the items that make up this variable have the organization as the referent. Prior studies have shown a relationship between organizational costs and barriers (measured in the Costs of Participation variable used in this study) and empowerment (Blanchard \& Randolph, 1996; Brown, 1996; Bushe et al., 1996; Carroll, 1996; Darling, 1996; Dennis, 1991; Hershey, 1996; Loney, 1996; Roberts \& Foti, 1998; Rutledge, 1996; Stone, 1995; Tyree, 1996; Weaver, 1996; Williams, 1996). These research studies support the inclusion of this variable with the Organizational Climate variable. It may be helpful in future examinations of participation costs if variables are specific enough to delineate organizational costs from individual costs.

The following major conclusions can be drawn from this study: Despite the limitations outlined below, the SEM results presented in this study do appear to support prior theoretical explanations of empowerment theory and also replicate earlier studies of 
the underlying structure of individual-level empowerment (Clark, 1989; Florin \& Wandersman, 1990; Kieffer, 1984; McMillan et al., 1995; Prestby, Wandersman, Florin, Rich, \& Chavis, 1990; Rappaport, 1981; Swift \& Levin, 1987; Wallerstein, 1992; Yeich \& Levine, 1992; Yeich \& Levine, 1994; Zimmerman, 1990a; Zimmerman, 1995; Zimmerman \& Zahniser, 1991). This finding makes it easier for researchers to assess some aspects of the empowerment process by providing them with a relatively simple and straightforward measure. In addition, behavioral and interpersonal aspects of individuallevel empowerment should also be explored in relation to this factor. Individual-level empowerment is —after all—contextual and constantly changing, so exploration of different ways of applying and redefining this measure could be most helpful. As stated above, the development of a universal and global measure of empowerment may not be appropriate since it may not mean the same thing for every person, organization, or community everywhere (Zimmerman, 1995). Thus, future studies should attempt to establish the stability and external validity of this measure across other samples and contexts.

Second, the significant independent latent constructs examined in this study (Participation Level, Sense of Community, Sense of Community Problems, and Organizational Climate) accounted for almost $90 \%$ of the variance of the individual-level empowerment latent construct. It is reasonable to assume that these results did not occur by chance and that these constructs are important in the development of empowerment. While the variance accounted for in this study suggests the possibility of collinearity between independent and dependent constructs, the individual items making up these 
constructs have less overlap than might be expected (see Appendix D for a breakdown of individual items). Principal components analyses conducted in McMillan et al. (1995) examined the relationship of individual items to each other as one step during creation of variable sets. Variable sets (e.g., the independent and dependent variables used in this study) loaded on their respective factors and were not significantly intercorrelated in most instances (McMillan et al., 1995). Still, future studies should attempt to further delineate the independent and dependent variables utilized in this study to reduce the possibility of collinearity (i.e., costs of participation loading with Organizational Climate variables and the others mentioned above).

Finally, the importance of organizational characteristics is highlighted in this study. While participation has been shown to be strongly associated with empowerment effects (Florin \& Wandersman, 1990; Zimmerman \& Rappaport, 1988; Zimmerman et al., 1992), this study makes a case for equal if not increased examination of the organizational context. As theorized by other researchers (Florin \& Wandersman, 1984; Kieffer, 1984; Gruber \& Trickett, 1987; Riger, 1984; Serrano-Garcia, 1984; Swift \& Levin, 1987; Wallerstein, 1992; Zimmerman, 1990, 1995; Zimmerman et al., 1992) and indicated in this study, the perceived climate of a group can have just as important impact upon the individual as their participation. Thus, it would be helpful in future studies to focus on how organizational characteristics impact on the empowerment process at multiple levels. In addition, an exploration of the interaction between organizational characteristics, participation, and sense of community (which was significantly correlated with organizational climate in this study) could help identify more of the mechanisms that 
make up the empowerment process. Further research into what organizational characteristics lead to creating "empowered" and/or "empowering" organizations as first touched upon in McMillan et al. (1995) would also be beneficial.

\section{Limitations and Directions for Future Research}

As this study is exploratory in nature, there are several limitations that deserve to be mentioned before too many conclusions are drawn. As mentioned above, although demographic information in this study proved once again to be nonsignificant, other studies have found at least some influence of demographics on the other variables measured in this study (Chavis \& Wandersman, 1990; Florin \& Wandersman, 1984; Gruber \& Trickett, 1987; Serrano-Garcia, 1984; Zimmerman et al., 1992; Zimmerman \& Rappaport, 1988). In point of fact, Zimmerman et al. (1992) found that a higher income and educational background were positively related to a subject's participation, and also that African-Americans were less likely to participate than other ethnic groups. One very salient reason for the lack of positive results in this study may be the relatively low variance of the demographic information used in this study, particularly in regards to ethnicity (see Appendix B). Thus, it is possible that results may be unable to detect relationships due to these variance problems. In future studies, it would be helpful to sample a more diverse population to see how that affects the results presented here.

Another significant limitation of this study is that it only examines mostly intrapsychic components of empowerment and also examines them only at the individual level of analysis. Interpersonal and environmental components of individual empowerment have not been explored in the context of this study. In addition, 
organizational empowerment and more general community influences are not considered in any great detail either. Finding out what characteristics make a group empowered and/or empowering to its members are important areas of research which have yet to be fully explored (Cowen, 1991; Fawcett et al., 1984; Florin, Mitchell \& Stevenson, 1993; Florin \& Wandersman, 1990; Heller, 1989; Minkler, 1992; Riger, 1984; Rosenfield, 1992; Schlaff, 1991; Wallerstein, 1992; Zimmerman, in press). It would also be helpfulin future studies - to explore individual empowerment qualitatively and at more levels than just an intrapsychic one.

Another significant limitation revolves around the design of the present study. Results found in this study may have been distorted by the self-report nature of the data, and important information may have been overlooked by the cross-sectional nature of data collection and analysis. This makes inferences about causality extremely limited. While the results presented here support the findings of McMillan et al., 1995—in that relationships between empowerment and the independent variables examined exist-the directionality of these findings is still unclear due to the inherent nature of cross-sectional analyses. It may be that perceived empowerment may be the catalyst for increased participation, more favorable impressions of organizational climate, and a strong sense of community. Using longitudinal data, integrating data that are not self-report (e.g., social indicators, management information system data), and utilizing more research methods (e.g., additional statistical methods, qualitative designs) are recommended. In addition, one must be cognizant of the possibility of a social desirability response set. A number of prior studies have been concerned with this issue, and some have even gone so far as to 
control for it as a possible covariates (Zimmerman, 1990b; Zimmerman et al., 1992;

Zimmerman \& Rappaport, 1988). Empowerment effects described here could well have been exaggerated due to participants' perceptions of what the "correct response" should be to any given section in the CCI Task Force Member Survey. In the future, it will be important to continue to test these findings with different methods, different samples, and in different contexts. Obtaining some sort of social desirability scale as well as obtaining longitudinal data would also be advisable.

Finally, the nature of structural equation modeling presents its own limitations. Since multiple parameters are being estimated simultaneously, maintenance of one hypothesis may be subject to the simultaneous maintenance of another. Also, chi-square analyses are influenced by sample size. The literature presents several reports of observed biases, noting overall fit parameter and local parameter instability tied to the complexity of the structural equation model and sample size. While several authors have suggested minimum sample sizes of $100-200$ subjects and a sample ratio to parameter estimate of at least 5 to 10 subjects per parameter with normal data (and as many as 20 to 40 for poorly distributed data) to protect against instability, there is still a lack of clear consensus in the research literature. Given the fact that SEM is still a fairly recent statistical procedure, there is still much debate upon the exact guidelines to utilize when running SEM analyses (Bentler, 1993; Bollen \& Long, 1993; Bullock, Harlow, \& Mulaik, 1994; Joreskog, 1993; Tanaka, 1993). Finally, given that this was an exploratory SEM study with some post-hoc adjustment of parameters, the initial models outlined above have all been subjected to theoretical tinkering. It is possible-since a potentially infinite number of structural 
equation models exist-that another structural equation model of the present data set would more accurately capture the patterns in the data than the models presented above. Also, despite the theoretical decisions that drove the post-hoc adjustments, this type of activity can increase the likelihood of finding chance occurrences or increasing errors. Thus, further examination of the Inclusive and McMillan Models with different data sets (and under more rigorous conditions) is recommended.

\section{Practice Implications}

In practice, those seeking to foster empowerment can concentrate on finding ways to increase group participation; increase the number of benefits of participating; and work on establishing a well-focused, satisfactory group climate. Participatory competencies may be achieved through trainings, organizational progress, and achievements celebrated or expectations raised through sharing "success" stories from elsewhere. In addition, since empowerment was so strongly related to participation variables, practitioners in organizations such as community task forces would do well to first provide a variety of participation options for members. A greater variety of participation options provides more opportunities to engage members' energies and interests. A member can choose from an array of levels of involvement (e.g., officer, committee chair, committee member, and general member) as well as particular content areas of involvement (e.g., what particular subcommittee to which to devote time). Practitioners should also make well-delineated participation demands on new members to reduce fears of open-ended, free-wheeling commitments, and allow the reinforcements from participation to work. Practitioners should always be attempting to increase the benefits and reduce the costs of 
participation for their members (e.g., using a form of incentive management, such as providing daycare services or transportation). Voluntary organizations that practice incentive management have been shown to promote more participation among members and to be more organizationally viable over time (Prestby et al., 1990).

Finally, practitioners should pay a good deal of attention to creating an inclusive and task-focused organization. Organizational Climate was very strongly related to empowerment in this study, and several studies have found that participatory decisionmaking (involvement/inclusion) and structure/formalization (task focus) within voluntary organizations promote involvement and commitment to these organizations (Milburn \& Barbarin, 1987; Prestby \& Wandersman, 1985). To the degree that more structure relates to more organizational empowerment in accomplishing tasks and achieving goals, individual empowerment also appears to be reinforced and amplified. Continued study of the factors outlined in this research should be attempted with the goal of replicating these results in future studies. 


\section{Appendix A}

\section{CONCEPTUALIZING EMPOWERMENT}

\section{Zimmerman (Zimmerman \& Rappaport, 1988)}

empowerment is/is characterized by:

--a developmental process

--made up of 11 integrated components (e.g., mastery, self-efficacy, perceived competence, desire for control, civic duty, etc.)

--multi-level construct

--situation-specific

\section{$\underline{\text { Kieffer (Kieffer, 1984) }}$}

empowerment is/ is characterized by:

--a developmental process

--a critical awareness of environment

--political efficacy

--self-efficacy

--perceived control

--participatory competence (set of insights \& skills)

\section{$\underline{\text { Swift \& Levin (Swift \& Levin, 1987) }}$}

empowerment is/ is characterized by:

--both a process and a goal

--a re-allocation of resources

--tied to the environment

--a social motivation to take action

\section{Wallerstein (Wallerstein, 1992)}

empowerment is/ is characterized by:

--self-efficacy

--perceived control

--skill development

--embedded in participation

--improved quality of life/ social justice

--a developmental process

--individual level of analysis

\section{Clark (Clark, 1989)}

empowerment is/ is characterized by:

--political activism (political efficacy)

--re-allocation of resources

--self-efficacy (skill-building \& increased knowledge)

--increased decision-making power

--multi-faceted social process

--increased perceived control 


\section{Appendix B}

\section{DEMOGRAPHICS OF THE TASK FORCE MEMBERS \\ Age}

$15-30$ yrs. old.........13\%

$31-45$ yrs. old.........46\%

$46-60$ yrs. old.........32\%

$61-76$ yrs. old.........09\%

\section{Gender}

Female..............62\%

Male...................38\%

Highest Level of Educational Achievement

Some High School.......03\%

High School Diploma...11\%

Some College..............16\%

Bachelor's Degree........23\%

Master's Degree...........34\%

Master's +................13\%

\section{$\underline{\text { Marital Status }}$}

Never Married.........13\%

Married..................70\%

Divorced................11\%

Other....................06\%

\section{Home Ownership}

Homeowner.............84\%

Renter...................16\%

\section{Employment Status}

Full-time...............72\%

Part-time...............16\%

Unemployed.............01\%

Retired..................04\%

Ethnicity

African-American......05\% American Indian.......01\% * Asian-American....... $01 \%$ * Hispanic/Latino........01\% * White......................93\%

Other.....................01\% *

* less than $1 \%$ of sample 


\section{Appendix C}

\section{Variables from 1992 CCI Member Survey}

Dependent Variable

Empowerment

1. Self-perceived skills

2. Self-perceived changes in skills

3. Personal expectations for participation

4. Personal expectations for task force's future impact

5. Perceptions of the task force's current impact

$\underline{\text { Independent Variables }}$

Set A: Demographics

1. Age

2. Gender

3. Education (SES)

4. Income (SES)

Set B: Community Variables

1. Sense of Community

2. Sense of Community Problems

Set C: Participation

1. Sum of hours participating (level of partic.)

2. Roles played in task force (level of partic.)

3. Benefits of participation (net ben. of partic.)

4. Costs of participation (net ben. of partic.)

Set D: Social Climate

1. Task force cohesion (org. climate)

2. Task force focus (org. climate)

3. Task force commitment

4. Satisfaction with the task force (org. climate) $\underline{\text { Item \# }}$

Alpha

06

08

.76

.87

04

N/A

05

.85

07

.89

01

N/A

01

N/A

N/A

N/A

06

.84

12

.89

04

N/A

09 N/A

$06 \quad .84$
07

$\begin{array}{ll}07 & .80\end{array}$

$05 \quad .84$

$05 \quad .84$

$04 \quad .86$

$04 \quad .90$ 


\section{Appendix D}

\section{EMPOWERMENT VARIABLES}

\section{Self-Perceived Skills:}

(5-point Likert-type scale from Strongly Agree to Strongly Disagree)

1. I find it hard to speak up at Task Force meetings

2. I can work well as part of the Task Force group

3. I can help the group with the planning process

4. I can organize people in the Task Force to get things done

5. I can contribute knowledge about the content of alcohol and other drug abuse (AODA) prevention programs to the group

6. I can contribute expertise in the implementation of AODA prevention programs to the group

\section{Self-Perceived Changes in Skills:}

(Perceived changes in skills as a result of participation using a 4-point Likert-type scale: no change, minor increase, moderate increase, major increase)

1. Understanding of prevention concepts

2. Knowledge of risk and protective factors for AODA

3. Belief that prevention of AOD problems is possible

4. Awareness of resources for prevention programming in your community

5. Skills in presenting my views on community needs before a group

6. Skills in conducting a community planning/problem solving process

7. Skills in designing and implementing prevention programs

8. Other

\section{Personal Expectations for Participation:}

(measured using a 5-point Likert scale from Very Likely to Very Unlikely)

1. I will attend Task Force meetings regularly

2. I will devote time outside of meetings to the Task Force

3. I will influence my group or organization to devote resources to increase community AODA prevention activities

4. I will increase linkages between my organization and other organizations to promote AODA prevention activities 
Personal Expectations for Task Force's Future Impact:

(measured using a 5-point scale from Very Likely to Very Unlikely)

1. The Task Force will continue to expand and strengthen AODA prevention activities in the community

2. The Task Force will increase coordinated AODA prevention planning among community organizations

3. The Task Force will increase its resources for prevention programming in this community

4. The Task Force activities will result in a decrease of AOD problems within the community

5. The Task Force will increase its influence over community decisions

\section{Perception of Task Force's Impact:}

(measured with a 5-point Likert-type scale from Strongly Agree to Strongly Disagree)

1. Increased community-wide awareness of AODA

2. Improved communication among organizations that can help prevent AODA

3. Improved services and programs for AODA prevention in this community

4. Helped organizations working for prevention to increase their share of community resources

5. Helped organizations working for prevention to increase their joint influence over community decisions

6. Increased the chance that children and youth will receive treatment for AOD problems in this community

7. Increased the chance that children and youth will avoid developing AOD problems 


\section{COMMUNITY VARIABLES}

\section{Sense of Community:}

(measured using a 5-point Likert-type scale from Strongly Agree to Strongly Disagree)

1. A place I "feel at home" in

2. A place where people help each other out

3. A place where I'm accepted for who I am

4. A place where people really feel a "sense of community togetherness"

5. A place where people work together to solve community problems

\section{Perceptions of Community Problems:}

(Perceived community problems rated using a 5-point Likert scale:

Not a problem, small problem, moderate problem, big problem, very great problem)

1. Violent crime

2. Family violence/child abuse

3. Alcoholism

4. Drug abuse

5. Drunken driving

6. AIDS

7. Truancy (skipping school)

8. School drop-out

9. Teen pregnancy

10. Inadequate social services

11. Lack of recreational opportunities

12. Unemployment 


\section{PARTICIPATION VARIABLES}

\section{Sum of Hours Spent Participating:}

(measured as a sum of reported hours engaged in the following activities)

1. Hours for regular Task Force meetings

2. Hours for subcommittee work outside of meetings

3. Hours for Task Force sponsored activities outside of meetings

4. Hours for preparation for meetings or activities

5. Hours for administration, paperwork

\section{Roles Played in the Task Force:}

(measured as a summation of YES responses)

1. Talk at meetings (make comments, express ideas, etc...)

2. Serve as a member of a committee

3. Do work for the Task Force outside of meetings

4. Help organize activities (other than meetings)

5. Chair a committee

6. Chair the entire Task Force

7. Serve as a Task Force officer other than chair (e.g. treasurer, secretary)

8. Direct a particular program's implementation

9. Serve in a paid capacity as Task Force coordinator

\section{Benefits of Participation:}

(measured using a 4-point scale: Very much a benefit, Somewhat of a benefit, Not very much of a benefit, Not at all a benefit)

1. Gain support by working with other members of the community

2. Gain personal recognition and respect from others

3. Learn new skills (public speaking, program planning)

4. Receive information about community services, events, etc.

5 . Provides a "sense of community"

6. Fulfills a sense of responsibility to contribute to the community 


\section{Costs of Participation:}

(measured using a 4-point scale: Very much a difficulty, Somewhat of a difficulty, Not very much of a difficulty, Not at all a difficulty)

1. Finding caregivers during meetings for family members (children, elderly)

2. Demands too much of my personal time

3. Feeling that the Task Force never gets anything done

4. Feeling that the Task Force cannot really do much to prevent AOD problems

5. Feeling that the Task Force is not fully using my skills

6. Disagreeing personally with particular activities of the Task

Force

7. Feeling that too few people actually implement activities 


\section{SOCIAL CLIMATE VARIABLES}

\section{Task Force Cohesion:}

(measured using a 5-point Likert-type scale from Strongly Agree to Strongly Disagree)

1. The group has a feeling of cohesiveness and team spirit

2. Everyone is involved in discussions, not just a few

3. The general membership has real decision-making control over the policies and actions of the task force

4. The group is tolerant of differences or disagreements

5. The Task Force uses the abilities of all, not just a few

\section{Task Focus:}

(measured using a 5-point Likert-type scale from Strongly Agree to Strongly Disagree)

1. The purpose of agenda items is defined and kept in mind

2. The Task Force is disorganized and inefficient

3. The group needs more formalization and structure

4. The leader is too "laissez faire" and not in control

5. There is too much talking and not enough doing

\section{Task Force Commitment:}

(measured as above)

1. I really care about the future of this Task Force

2. I am proud to tell others I am on this Task Force

3. I feel strongly committed to this Task Force

4. I feel a strong sense of pride in Task Force accomplishments

\section{Satisfaction with the Task Force:}

(Satisfaction with the above statements measured using a 5-point scale from Very Satisfied to Very Dissatisfied)

1. The planning process used by the Task Force

2 . The programs proposed to meet objectives

3. The degree of Task Force involvement with program implementation

4. Overall Task Force functioning 


\section{Appendix E}

\section{Principal Components Analysis of Dependent and Independent Constructs}

\begin{tabular}{|c|c|c|}
\hline CONSTRUCT & FACTO & \\
\hline I. Empowerment & F1 & F2 \\
\hline $\begin{array}{l}\text { V3 Expectancies for Future Group/ } \\
\text { Organizational Successes }\end{array}$ & .844 & \\
\hline $\begin{array}{l}\text { V4 Perceived Group/ } \\
\text { Organizational Influences }\end{array}$ & .769 & \\
\hline $\begin{array}{l}\text { V5 Behavioral Intentions to } \\
\text { Participate }\end{array}$ & .751 & \\
\hline $\begin{array}{l}\text { V1 Perceived Knowledge and Skill } \\
\text { Development }\end{array}$ & .619 & \\
\hline $\begin{array}{l}\text { V2 Perceived Participatory } \\
\text { Competence }\end{array}$ & .520 & \\
\hline$\%$ of Variance Accounted For & $50.4 \%$ & \\
\hline II. Participation & & \\
\hline V3 Costs of Participation (Net Benefits of Participation) & .844 & -.036 \\
\hline V2 Benefits of Participation (Net Benefits of Participation) & .811 & .285 \\
\hline V4 Roles Played in the Task Force (Participation Level) & .240 & .762 \\
\hline V1 Sum of Hours Participating (Participation Level) & -.016 & .804 \\
\hline$\%$ of Variance Accounted For & $38.8 \%$ & $28.4 \%$ \\
\hline
\end{tabular}




\begin{tabular}{||l|l|l||}
\hline \hline III. Climate Variables & & \\
\hline V1 Satisfaction (Organizational Climate) & .902 & \\
\hline V4 Task Focus (Organizational Climate) & .874 & \\
\hline V3 Task Force Cohesion (Organizational Climate) & .861 & \\
\hline V2 Commitment* & .677 & \\
\hline \% of Variance Accounted For & $69.4 \%$ & \\
\hline \hline
\end{tabular}

*Commitment entered as a separate variable in the stepwise hierarchical multiple regression conducted in McMillan et al., 1995 study due to its unique variance standing alone. Sense of Community, Sense of Community Problems, and Demographic variables were also entered separately. 


\section{Appendix F}

\begin{tabular}{|c|c|c|c|c|c|}
\hline Model & $\begin{array}{l}\text { Chi- } \\
\text { Square }\end{array}$ & AASR & CFI & NFI & NNFI \\
\hline $\begin{array}{l}\text { Step } 1 \text { Inclusive Model: } \\
\text { V5 "Expectancies for } \\
\text { Future Individual } \\
\text { Contributions" dropped }\end{array}$ & 313.209 & .05 & .86 & .83 & .79 \\
\hline $\begin{array}{l}\text { Step } 2 \text { Inclusive Model: } \\
\text { Commitment dropped } \\
\text { from analysis }\end{array}$ & 234.013 & .05 & .88 & .85 & .82 \\
\hline $\begin{array}{c}\text { Step } 3 \text { Inclusive Model: } \\
\text { Net Benefits of } \\
\text { Participation Factor } \\
\text { dropped }\end{array}$ & $110.469^{*}$ & .04 & .93 & .90 & .86 \\
\hline $\begin{array}{l}\text { Step } 4 \text { Inclusive Model: } \\
\text { Costs of Participation } \\
\text { added to Organizational } \\
\text { Climate Factor }\end{array}$ & $182.541^{*}$ & .05 & .88 & .86 & .77 \\
\hline $\begin{array}{l}\text { Step } 5 \text { Inclusive Model: } \\
\text { V5 "Expectancies for } \\
\text { Future Individual } \\
\text { Contributions" and Net } \\
\text { Benefits of Participation } \\
\text { put back in the model }\end{array}$ & \multicolumn{5}{|c|}{ Final results as presented in Table 2} \\
\hline $\begin{array}{l}\text { Step 1 Participation } \\
\text { Model: Demographics } \\
\text { dropped from analysis }\end{array}$ & $418.102^{*}$ & .14 & .77 & .74 & .69 \\
\hline $\begin{array}{c}\text { Step } 2 \text { Participation } \\
\text { Model: V5 } \\
\text { "Expectancies for Future } \\
\text { Individual Contributions" } \\
\text { dropped }\end{array}$ & $372.771^{*}$ & .11 & .79 & .75 & .71 \\
\hline $\begin{array}{l}\text { Step } 3 \text { Participation } \\
\text { Model: Commitment } \\
\text { dropped }\end{array}$ & $489.226^{*}$ & .11 & .75 & .72 & .65 \\
\hline $\begin{array}{l}\text { Step } 4 \text { Participation } \\
\text { Model: Net Benefits of } \\
\text { Participation Factor } \\
\text { dropped }\end{array}$ & $237.876^{*}$ & .09 & .85 & .82 & .78 \\
\hline $\begin{array}{l}\text { Step } 5 \text { Participation } \\
\text { Model: Costs of } \\
\text { Participation added to } \\
\text { Organizational Climate } \\
\text { Factor }\end{array}$ & $206.697^{*}$ & .07 & .89 & .85 & .85 \\
\hline
\end{tabular}




\begin{tabular}{|c|c|c|c|c|c|}
\hline \hline $\begin{array}{c}\text { Step 1 McMillan } \\
\text { Model: V5 } \\
\text { "Expectancies for Future } \\
\text { Individual Contributions" } \\
\text { dropped }\end{array}$ & 283.467 & .07 & .84 & .81 & .76 \\
\hline $\begin{array}{c}\text { Step 2 McMillan } \\
\text { Model: Commitment } \\
\text { dropped }\end{array}$ & 209.409 & .07 & .87 & .84 & .81 \\
\hline $\begin{array}{c}\text { Step 3 McMillan } \\
\text { Model: Net Benefits of } \\
\text { Participation Factor } \\
\text { dropped }\end{array}$ & 110.797 & .05 & .93 & .90 & .90 \\
\hline $\begin{array}{c}\text { Step 4 McMillan } \\
\text { Model: Costs of } \\
\text { Participation added to } \\
\text { Organizational Climate } \\
\text { Factor }\end{array}$ & \multicolumn{2}{|c|}{ Final results as presented in Table 5 } \\
\hline
\end{tabular}

*condition codes made the model's interpretation invalid 


\section{Bibliography}

Airhihenbuwa, C. (1994). Health promotion and the discourseon culture: Implications for empowerment. Health Education Quarterly, 21(3), 345-353.

Altman, D. G., Feighery, E., Robinson, T. N., Haydel, K. F., Strausberg, L., Lorig, K., \& Killen, J. D. (1998). Psychological factors associated with youth involvement in community activities promoting heart health. Health Education and Behavior, 25(4), 489-500.

Bandura, A. (1982). Self-efficacy mechanisms in human agency. American Psychologist, 37, 122-147.

Bentler, P. (1995). EQS: Structural equations program manual. Los Angeles, CA: BMDP Statistical Software, Inc.

Bernstein, E., Wallerstein, N., Braithwaite, R., Gutierrez, L., Labonte, R., \& Zimmerman, M. (1994). Empowerment forum: A dialogue between guest editorial board members. Health Education Quarterly, 21(3), 281-294.

Bickman, L., Heflinger, C. A., Northrup, D., Sonnichsen, S., \& Schilling, S. (1998). Long term outcomes to family caregiver empowerment. Journal of Child and Family Studies, 7(3), 269-282.

Blanchard, K., \& Randolph, A. (1996). Empowerment is key to growth. Executive Excellence, 5, 10.

Bollen, K. A., \& Long, J. S. (Eds.). (1993). Testing structural equation models. Newbury Park, CA: Sage Publications, Inc.

Bolton, B., \& Brookings, J. (1998). Development of a measure of intrapersonal empowerment. Rehabilitation Psychology, 43(2), 131-142.

Bond, M. A., \& Keys, C. B. (1993). Empowerment, diversity, and collaboration: Promoting synergy on community boards. American Journal of Community Psychology, 21(1), 37-57.

Braithwaite, R., Bianchi, C., \& Taylor, S. (1994). Ethnographic approach to community organization and health empowerment. Health Education Quarterly, 21(3), 407-416. 
Brown, M. J. (1996). What can community organizers teach us? Journal for Quality and Participation, 9, 78-84.

Bullock, H., Harlow, L., \& Mulaik, S. (1994). Causation issues in structural equation modeling research. Structural Equation Modeling, 1(3), 253-267.

Bushe, G. R., Havlovic, S. J., \& Coetzer, G. (1996). Exploring empowerment from the inside-out. Journal for Quality and Participation, 3, 36-45.

Butchart, A., \& Seedat, M. (1990). Within and without: Images of community and implications for South African psychology. Social Science \& Medicine, 31(10), 1093-1102.

Byrne, B. (1994). Structural equation modeling with EQS and EQS/Windows: Basic concepts, applications, and programming. CA: Sage Publications, Inc.

Cable, S. (1992). Women's social movement involvement: The role of structural availability in recruitment and participation processes. The Sociological Quarterly, 33(1), 35-50.

Campbell, C. R., \& Martinko, M. J. (1998). An integrative attributional perspective of empowerment and learned helplessness: A multimethod field study. Journal of Management, 24(2), 173-200.

Carroll, B. (1996). The power of empowered teams. National Productivity Review, 3, 85-92.

Chavis, D., \& Wandersman, A. (1990). Sense of community in the urban environment: a catalyst for participation and community development. American Journal of Community Psychology, 18(1), 55-81.

Chinman, M. J., \& Linney, J. A. (1998). Toward a model of adolescent empowerment: Theoretical and empirical evidence. Journal of Primary Prevention, 18(4), 393-413.

Clark, P. (1989). The philosophical foundation of empowerment. Journal of Aging and Health, 1(3), 267-285. 
Clark, P. (1994, October). Communication between provider and patient: Values, biography, and empowerment in clinical practice. Paper presented at the $23^{\text {rd }}$ Annual Scientific and Educational Meeting of the Canadian Association on Gerontology, Winnipeg, Manitoba.

Clarke, H. F., \& Mass, H. (1998). Comox valley nursing centre: From collaboration to empowerment. Public Health Nursing, 15(3), 216-224.

Cohen, M. B. (1998). Perceptions of power in client/worker relationships. Families in Society, 79(4), 433-442.

Community Research \& Services Team (CRST) (1992). CCI Task Force Member Survey Report (CCI Report No. 92-2). Rhode Island: Brown University, Center for Alcohol and Addiction Studies.

Cowen, E. (1991). In pursuit of wellness. American Psychologist, 46(4), 404-408.

Crabtree, R. D. (1998). Mutual empowerment in cross-cultural participatory development and service learning: Lessons in communication and social justice from projects in El Salvador and Nicaragua. Journal of Applied Communication Research, 26(2), 182-209.

Cummins, J. (1986). Empowering minority students: A framework for intervention. Harvard Educational Review, 56(1), 18-36. 2, 23-28.

Darling, M. (1996). Empowerment: Myth or reality? Executive Speeches,

Denmark, F. L. (1993). Women, leadership, and empowerment. Psychology of Women Quarterly, 17, 343-356.

Dennis, B. J. (1991). The Tao of empowerment. Performance Improvement Quarterly, 4(4), 71-80.

Edwards, P., Collinson, M., \& Rees, C. (1998). The determinants of employee responses to total quality management: Six case studies. Organizational Studies, 19(3), 449-475.

Eisen, A. (1994). Survey of neighborhood-based, comprehensive community empowerment initiatives. Health Education Quarterly, 21(2), 235-252. 
Eng, E., \& Parker, E. (1994). Measuring community competence in the Mississippi delta: The interface between program evaluation and empowerment. Health Education Quarterly, 21(2), 199-220.

Eng, E., Salmon, M., \& Mullan, F. (1992). Community empowerment: The critical base for primary health care. Family \& Community Health, 15(1), $1-12$.

Erzinger, S. (1994). Empowerment in spanish: Words can get in the way. Health Education Quarterly, 21(3), 417-419.

Fawcett, S., Paine-Andrews, A., Francisco, V. T., Schulz, J. A., Richter, K. P., Lewis, R. K., Williams, E. L., Harris, K. J., Berkley, J. Y., Fisher, J. L., \& Lopez, C. M. (1995). Using empowerment theory in collaborative partnership for community health and development. American Journal of Community Psychology, 23(5), 677-697.

Fawcett, S., Seekins, T., Whang, P., Muiu, C. \& Suarez de Balcazar, Y. (1984). Creating and using social technologies for community empowerment. Studies in Empowerment: Steps toward Understanding and Action. Prevention in Human Services, 3(2/3), 145-171.

Fawcett, S., White, G. W., Balcazar, F. E., Suarez-Balcazar, Y., Mathews, R. M., Paine-Andrews, A., Seekins, T., \& Smith, J. (1994). A contextual-behavioral model of empowerment: Case studies involving people with physical disabilities. American Journal of Community Psychology, 22(4), 471-496.

Flick, L. H., Reese, C. G., Rogers, G., Fletcher, P. \& Sonn, J. (1994). Building community for health: Lessons from a seven-year-old neighborhood/university partnership. Health Education Quarterly, 21(3), 369-380.

Florin, P., Mitchell, R., \& Stevenson, J. (1993). Identifying training and technical assistance needs in community coalitions: a developmental approach. Journal of Health Education Research: Theory and Practice, 8(3), 417-432.

Florin, P., \& Wandersman, A. (1984). Cognitive social learning and participation in community development. American Journal of Community Psychology, 12(6), 689-708. 
Florin, P., \& Wandersman, A. (1990). An introduction to citizen participation, voluntary organizations, and community development: insights for empowerment through research. American Journal of Community Psychology, $18(1), 41-54$.

Flynn, B. C., Ray, D. W., \& Rider, M. S. (1994). Empowering communities: Action research through healthy cities. Health Education Quarterly, 21(3), 395-405.

Foster-Fishman, P. G., \& Keys, C. B. (1997). The person/environment dynamics of employee empowerment: An organizational culture analysis. American Journal of Community Psychology, 25(3), 345-369.

Foster-Fishman, P. G., Salem, D. A., Chibnell, S., Legler, R., \& Yapchai, C. (1998). Empirical support for the critical assumptions of empowerment theory. American Journal of Community Psychology, 26(4), 507-536.

Gruber, J., \& Trickett, E. (1987). Can we empower others? The paradox of empowerment in the governing of an alternative public school. American Journal of Community Psychology, 15(3), 353-371.

Hardy, C., Leiba-O'Sullivan, S. (1998). The power behind empowerment: Implications for research and practice. Human Relations, 51(4), 451-483.

Heller, K. (1989). The return to community. American Journal of Community Psychology, 17(1), 1-15.

Heller, K. (1990). Social and community intervention. Annual Review of Psychology, 41, 141-168.

Hershey, P. (1996). The toll road to empowerment. Executive Excellence, 4, 14-15.

Israel, B., Checkoway, B., Schulz, A., \& Zimmerman, M. (1994). Health education and community empowerment: Conceptualizing and measuring perceptions of individual, organizational, and community control. Health Education Quarterly, 21(2), 149-170.

Jenkins, S. R. (1994). Structural power and experienced job satisfactions: The empowerment paradox for women. Sex Roles, 30(516), 347-369. 
Johnson, J. J., \& McIntye, C. L. (1998). Organizational culture and climate correlates of job satisfaction. Psychological Reports, 82(3, Pt. 1), 843-850.

Joreskog, K. G. (1967). Some contributions to maximum likelihood factor analysis. Psychometrika, 32, 443-482.

Joreskog, K. G. (1993). Testing structural equation models. In K. A. Bollen \& J. S. Long (Eds.), Testing Structural Equation Models (pp. 294-316). CA:

Sage Publications, Inc.

Kieffer, C. (1984). Citizen empowerment: a developmental perspective. Studies in Empowerment: Steps Toward Understanding and Action. Prevention in Human Services, 3(2/3), 9-36.

Kroeker, C. J. (1995). Individual, organizational, and societal empowerment: A study of the processes in a Nicaraguan agricultural cooperative. American Journal of Community Psychology, 23(5), 749-764.

Kumpfer, K. L., Turner, C., Hopkins, R., \& Librett, J. (1993). Leadership and team effectiveness in community coalitions for the prevention of alcohol and other drug abuse. Health Education Research: Theory \& Practice, 8(3), 359-374.

Labonte, R. (1994). Health promotion and empowerment: Reflections of professional practice. Health Education Quarterly, 21(2), 253-268.

Levine, M. (1988). An analysis of mutual assistance. American Journal of Community Psychology, 16(2), 167-183.

Loney, T. J. (1996). TQM and labor-management cooperation—a noble experiment for the public sector. International Journal of Public Administration, 19(10), 1845-1863.

Lord, J., \& Hutchison, P. (1993). The process of empowerment: Implications for theory and practice. Canadian Journal of Community Mental Health, 12(1), 5-22.

Lord, J., Ochocka, J., Czarny, W., \& MacGillivary, H. (1998). Analysis of change within a mental health organization: A participatory process. Psychiatric Rehabilitation Journal, 21(4), 327-339. 
Luechauer, D. L., \& Shulman, G. M. (1996). Training transformational leaders: A call for practicing empowerment in the classroom. International Journal of Public Administration, 19(6), 827-848.

Maton, K. I., \& Rappaport, J. (1984). Empowerment in a religious setting: A multivariate investigation. In J. Rappaport \& R. Hess (Eds.), Studies in Empowerment: Steps Toward Understanding Action (pp.37-72). New York: Haworth Press, Inc.

Maton, K. I., \& Salem, D. A. (1995). Organizational characteristics of empowering community settings: A multiple case study approach. American Journal of Community Psychology, 23(5), 631-656.

Maxwell, J. P. (1998). Conflict management and mediation training: A vehicle for community empowerment? Mediation Quarterly, 15(2), 83-96.

McFarlane, J., \& Fehir, J. (1994). De Madres a Madres: A community, primary health care program based on empowerment. Health Education Quarterly, 21(3), 381-394.

McMillan, B., Florin, P., Stevenson, J., Kerman, B., \& Mitchell, R. (1995). Empowerment praxis in community coalitions. American Journal of Community Psychology, 23(5), 699-727.

McMillan, D., \& Chavis, D. (1986). Sense of community: A definition and theory. Journal of Community Psychology, 14, 6-23.

Merideth, E. (1994). Critical pedagogy and its application to health education: A critical appraisal of the Casa en Casa model. Health Education Quarterly, 21(3), 355-367.

Milburn, N. G., \& Barbarin, O. A. (1987). Functional and structural aspects of neighborhood associations: Their effects on citizen participation. Unpublished manuscript.

Minkler, M. (1992). Community organizing among the elderly poor in the United States: A case study. International Journal of Health Services, 22(2), 303-316.

Mischel, W. (1973). Toward a cognitive social learning reconceptualization of personality. Psychological Review, 80, 52-283. 
Mowbray, C. (1990). Community treatment for the seriously mentally ill: Is this community psychology? American Journal of Community Psychology, $18(6), 893-902$.

Neath, J., \& Shriner, K. (1998). Power to people with disabilities: Empowerment issues in employment programming. Disability and Society, 13(2), 217-228.

O'Neill, P., Duffy, C., Enman, M., Blackmer, E., Goodwin, J., \& Campbell, E. (1988). Cognition and citizen participation in social action. Journal of Applied Social Psychology, 18(12), 1067-1083.

Pecukonis, E. V., \& Wenocur, S. (1994). Perceptions of self and collective efficacy in community organization theory and practice. Journal of Community Practice, 1(2), 5-21.

Perkins, D. (1995). Speaking truth to power: Empowerment ideology as social intervention and policy. American Journal of Community Psychology, 23(5), 765-794.

Perkins, D., Florin, P., Rich, R., Wandersman, A., \& Chavis D. (1990). Participation and the social and physical environment of residential blocks: Crime and community context. American Journal of Community Psychology, 18, 83-117.

Perkins, D., \& Zimmerman, M. (1995). Empowerment theory, research, and application. American Journal of Community Psychology, 23(5), 569-579.

Petoskey, E. L., Van Stelle, K. R., \& De Jong, J. A. (1998). Prevention through empowerment in a Native American community. Drugs and Society, 12(1-2), 147-162.

Plough, A., \& Olafson, F. (1994). Implementing the Boston healthy start initiative: A case study of community empowerment and public health. Health Education Quarterly, 21(2), 221-234.

Prestby, J. E., \& Wandersman, A. (1985). An empirical exploration of framework of organizational viability: Maintaining block organizations. The Journal of Applied Behavioral Science, 21, 287-305.

Prestby, J., Wandersman, A., Florin, P., Rich, R., \& Chavis, D. (1990). Benefits, costs, incentive management and participation in voluntary organizations: A means to understanding and promoting empowerment. American Journal of Community Psychology, 18, 117-151. 
Purdey, A. F., Adhikari, G. B., Robinson, S. A., \& Cox, P. W. (1994). Participatory health development in rural Nepal: Clarifying the process of community empowerment. Health Education Quarterly, 21(3), 329-343.

Rappaport, J. (1977). Community psychology: Values, research and action. New York: Holt, Rinehart, \& Winston.

Rappaport, J. (1981). In praise of paradox: a social policy of empowerment over prevention. American Journal of Community Psychology, 9, 1-25.

Rappaport, J. (1984). Studies in empowerment: Introduction to the issue. Prevention in Human Services, 3, 1-7.

Rappaport, J. (1987). Terms of empowerment/exemplars of prevention: Toward a theory of community psychology. American Journal of Community Psychology, 15(2), 121-144.

Rappaport, J. (1995). Empowerment meets narrative: Listening to stories and creating settings. American Journal of Community Psychology, 23(5), $795-807$.

Rich, R. C., Edelstein, M., Hallman, W. K., \& Wandersman, A. H. (1995). Citizen Participation and empowerment: The case of local environmental hazards. American Journal of Community Psychology, 23(5), 657-676.

Riger, S. (1984). Vehicles for empowerment: the case of feminist movement organizations. Studies in Empowerment: Steps Toward Understanding and Action. Prevention in Human Services, 3(2/3), 99-117.

Riger, S. (1993). What's wrong with empowerment? American Journal of Community Psychology, 21(3), 279-292.

Rissel, C. (1994). Empowerment: The holy grail of health promotion? Health Promotion International, 9(1), 39-47.

Roberts, H. E., \& Foti, R. J. (1998). Evaluating the interaction between self-leadership and work structure in predicting job satisfaction. Journal of Business and Psychology, 12(3), 257-267.

Robertson, A., \& Minkler, M. (1994). New health promotion movement: A critical examination. Health Education Quarterly, 21(3), 295-312. 
Robinson, D., \& Wilkinson, D. (1995). Sense of community in a remote mining town: Validating a neighborhood cohesion scale. American Journal of Community Psychology, 23(1), 137-148.

Rosenfield, S. (1992). Factors contributing to the subjective quality of life of the chronic mentally ill. Journal of Health and Social Behavior, 33(12), 299-315.

Rudd, R., \& Comings, J. (1994). Learner developed materials: An empowering product. Health Education Quarterly, 21(3), 313-327.

Rutledge, H. (1996). Empowerment, education and citizenship: A local study. Adults Learning, 3, 172-174.

Saegert, S., \& Winkel, G. (1996). Paths to community empowerment: Organizing at home. American Journal of Community Psychology, 24(4), $517-550$.

Sagy, S., Stern, E., \& Krakover, S. (1996). Macro- and microlevel factors related to sense of community: The case of temporary neighborhoods in Israel. American Journal of Community Psychology, 24(5), 657-676.

Schlaff, A. (1991). Boston's Codman Square Community Partnership for Health Promotion. Public Health Reports, 106(2), 186-191.

Serrano-Garcia, I. (1984). The illusion of empowerment: community development within a colonial context. Studies in Empowerment: Steps Toward Understanding and Action. Prevention in Human Services, 3(2/3), 173-199.

Shefner-Rogers, C. L., Rao, N., Rogers, E. M., Wayangankar, A. (1998). The empowerment of women dairy farmers in India. Journal of Applied Communication Research, 26(3), 319-337.

Shinn, M. (1987). Expanding community psychology's domain. American Journal of Community Psychology, 15(5), 555-574.

Snell, R., \& Chak, A. M. K. (1998). The learning organization: Learning and empowerment for whom? Management Learning, 29(3), 337-364.

Speer, P. W., \& Hughey, J. (1995). Community organizing: An ecological route to empowerment and power. American Journal of Community Psychology 23(5), 729-748. 
Spreitzer, G. (1995). An empirical test of a comprehensive model of intrapersonal empowerment in the workplace. American Journal of Community Psychology, 23(5), 601-629.

Stewart, E., \& Weinstein, R. S. (1997). Volunteer participation in context: Motivations and political efficacy within three AIDS organizations. American Journal of Community Psychology, 25(6), 809-837.

Stone, S. (1995). Empowering teachers, empowering children. Childhood Education, 294-295.

Swift, C., \& Levin, G. (1987). Empowerment: an emerging mental health technology. Journal of Primary Prevention, 8(1/2), 71-94.

Tanaka, J. S. (1993). Multifaceted conceptions of fit in structural equation models. In K. A. Bollen \& J. S. Long (Eds.), Testing structural equation models (pp. 10-39). Newbury Park, CA: Sage Publications, Inc.

Trickett, E. (1994). Human diversity and community psychology: Where ecology and empowerment meet. American Journal of Community Psychology, 22(4), 583-592.

Tyree, C. L. (1996). Collaboration and empowerment: A prescription for rural school education. Rural Educator, 17(2), 14-17.

Unger, D. G., \& Nelson, P. (1990). Evaluating community-based parenting support programs: Successes and lessons learned from empowering parents of adolescents. The Journal of Applied Social Sciences, 15(1), 125-152.

Wallerstein, N. (1992). Powerlessness, empowerment, and health: Implications for health promotion programs. American Journal of Health Promotion, 6(3), 197-205.

Wallerstein, N., \& Bernstein, E. (1994). Introduction to community empowerment, participatory education, and health. Health Education Quarterly, 21(2), 141-148.

Wang, C., \& Burris, M. A. (1994). Empowerment through photo novella: Portraits of participation. Health Education Quarterly, 21(2), 171-186.

Weaver, R. L. (1996). Motivating the motivators: Eight characteristics for empowering those who empower others. Executive Speeches, 3, 35-37. 
Wickizer, T. M., Von Korff, M., Cheadle, A., Maeser, J., Wagner, E. H., Pearson, D., Beery, W., \& Psaty, B. M. (1993). Activating communities for health promotion: A process evaluation method. American Journal of Public Health, $83(4), 561-567$.

Williams, B. R. (1996). The realities of empowering teams: A case study. Hospital Material Management Quarterly, 17(3), 60-66.

Wilson, M. M. (1998). Self-determination, empowerment and community: A prespective from Ireland. Journal of Vocational Rehabilitation, 9(1), 47-56.

Yeich, S., \& Levine, R. (1992). Participatory research's contribution to a conceptualization of empowerment. Journal of Applied Social Psychology, 22(24), 1894-1908.

Yeich, S., \& Levine, R. (1994). Political efficacy: Enhancing the construct and its relationship to mobilization of people. Journal of Community Psychology, $22,259-271$.

Yoder, J. D., Schleicher, T. L., \& McDonald, T. W. (1998). Empowering token women leaders: The importance of organizationally legitimated credibility. Psychology of Women Quarterly, 22(2), 209-222.

Yuval-Davis, N. (1994). Women, ethnicity and empowerment. Feminism \& Psychology, 4(1), 179-197.

Zimmerman, M. (1990a). Taking aim on empowerment research: On the distinction between individual and psychological conceptions. American Journal of Community Psychology, 18(1), 169-177.

Zimmerman, M. (1990b). Toward a theory of learned hopefulness: A structural model analysis of participation and empowerment. Journal of Research in Personality, 24, 71-86.

Zimmerman, M. (1995). Psychological empowerment: Issues and illustrations. American Journal of Community Psychology, 23(5), 581-599.

Zimmerman, M., Israel, B., Schulz, A., \& Checkoway, B. (1992). Further explorations in empowerment theory: An empirical analysis of psychological empowerment. American Journal of Community Psychology, 20(6), 707-727. 
Zimmerman, M., \& Rappaport, J. (1988). Citizen participation, perceived control, and psychological empowerment. American Journal of Community Psychology, 16(5), 725-750.

Zimmerman, M., \& Zahniser, J. (1991). Refinements of sphere-specific measures of perceived control: Development of a sociopolitical control scale. Journal of Community Psychology, 19, 189-204. 